Check for updates

Cite this: Nanoscale Adv., 2019, 1, 2059

\title{
Zinc oxide ultraviolet photodetectors: rapid progress from conventional to self-powered photodetectors
}

\begin{abstract}
Buddha Deka Boruah (iD *
Currently, the development of ultraviolet (UV) photodetectors (PDs) has attracted the attention of the research community because of the vast range of applications of photodetectors in modern society. A variety of wide-band gap nanomaterials have been utilized for UV detection to achieve higher photosensitivity. Specifically, zinc oxide $(\mathrm{ZnO})$ nanomaterials have attracted significant attention primarily due to their additional properties such as piezo-phototronic and pyro-phototronic effects, which allow the fabrication of high-performance and low power consumption-based UV PDs. This article primarily focuses on the recent development of ZnO nanostructure-based UV PDs ranging from nanomaterials to architectural device design. A brief overview of the photoresponse characteristics of UV PDs and potential ZnO nanostructures is presented. Moreover, the recent development in self-powered PDs and implementation of the piezo-phototronic effect, plasmonic effect and pyro-phototronic effect for performance enhancement is highlighted. Finally, the research perspectives and future research direction related to ZnO nanostructures for next-generation UV PDs are summarized.
\end{abstract}

Received 28th February 2019

Accepted 28th March 2019

DOI: 10.1039/c9na00130a

rsc.li/nanoscale-advances

presently, ultraviolet (UV) photodetectors (PDs) have drawn potential applications in society, the scientific community and military defense. ${ }^{\mathbf{1 - 4}}$ Moreover, the human body is sensitive to UV radiation that may cause different types of diseases including cataracts and skin cancer. ${ }^{8-11}$ Thus, the development of modern efficient UV PDs is necessary. Fig. 1a shows the total solar radiation spectrum, where UV radiation falls in the higher energy region. ${ }^{12}$ The UV spectrum can be classified into three bands (according to the International Commission on Illumination), which include the UVA wavelength range from 320 to $400 \mathrm{~nm}$, UVB from 280 to $300 \mathrm{~nm}$ and UVC from 10 to $280 \mathrm{~nm},,^{9,13}$ where the content of UVA is the greatest in the solar spectrum. The working mechanism of UV PDs is mainly based on the photoconductivity effect, where under UV illumination on a wide band gap semiconductor, the absorption of UV light occurs, generating electron-hole $\left(\mathrm{e}^{-}-\mathrm{h}^{+}\right)$pairs when the photon energy $(h \nu)$ is larger or equal to the bandgap $\left(E_{\mathrm{g}}\right)$. The photogenerated electrons and holes are then collected in the external circuit in the form of a photocurrent. There are three main steps in the photoconduction process: (i) absorption of UV energy and generation of $\mathrm{e}^{-}-\mathrm{h}^{+}$pairs, (ii) separation of photogenerated $\mathrm{e}^{-}-$ $\mathrm{h}^{+}$pairs through a transportation process and (iii) collection of photogenerated electrons and holes in the form of a photocurrent. Photogenerated electrons and holes can be separated for photocurrent generation by applying an external bias voltage or current (i.e. conventional) or generating an internal built-in electric field (i.e. self-powered).

Over the last decades, UV PDs have been mainly based on thin-film technology, and thus the photosensitivity of PDs is 

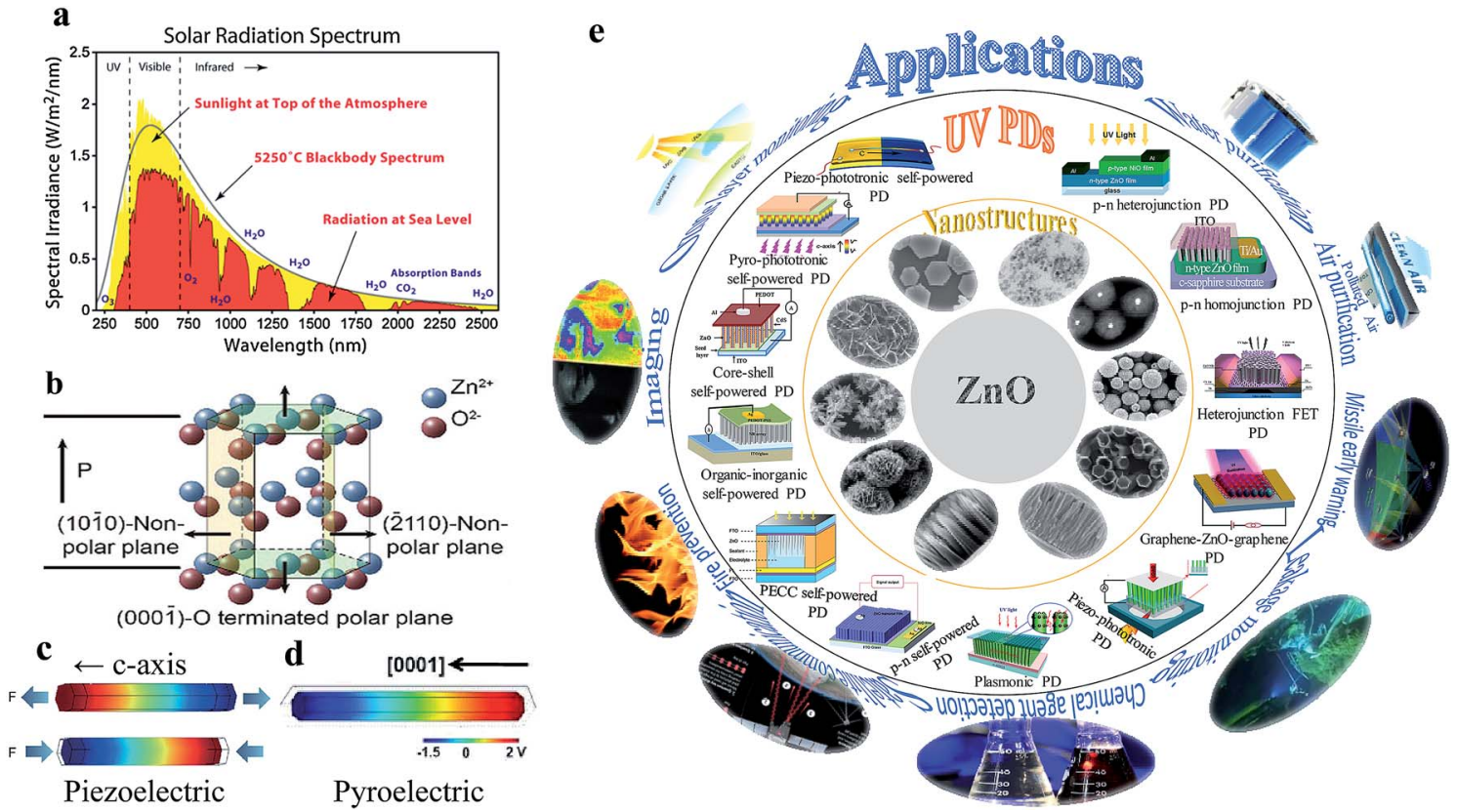

Fig. 1 (a) Total solar radiation spectrum..$^{12}$ (b) Atomic model of the $\mathrm{ZnO}$ wurtzite structure. Reproduced with permission from ref. 38 Copyright 2012, Wiley-VCH. (c) Simulated piezopotential distribution along a ZnO NW in the presence of strain along the c-axis. Colour gradient indicates the piezopotential generation, where red represents the positive piezopotential and blue the negative piezopotential. Reproduced with permission from ref. 39 Copyright 2009, American Institute of Physics. (d) Electric potential distribution along a ZnO NW when the temperature is decreased from RT 295 to 289 K. Reproduced with permission from ref. 40 Copyright 2012, American Chemical Society. (e) Schematic summarizing the $\mathrm{ZnO}$ nanostructures, currently developed UV PDs from conventional to self-powered and their possible future applications.

restricted by a limited UV exposure surface area. However, the field of nanotechnology has allowed the direct realization of highperformance UV PDs by introducing high surface-to-volume ratio nanomaterials for multiple photon interactions. Nanomaterials offer tunable and unique optical, electrical, mechanical, and chemical properties over their bulk and thin film counterparts. ${ }^{14-16}$ Numerous wide bandgap nanomaterials including $\mathrm{GaN},{ }^{17} \mathrm{ZnS},{ }^{18,19} \mathrm{SiC},{ }^{20} \mathrm{ZnSe},{ }^{21} \mathrm{ZnTe},{ }^{22} \mathrm{In}_{2} \mathrm{Te}_{3},{ }^{23} \mathrm{MoS}_{2},{ }^{24} \mathrm{Nb}_{2} \mathrm{O}_{5},{ }^{25,26}$ $\mathrm{Ga}_{2} \mathrm{O}_{3},{ }^{27} \mathrm{Zn}_{2} \mathrm{GeO}_{4},{ }^{28} \mathrm{Zn}_{2} \mathrm{SnO}_{4},{ }^{29} \mathrm{TiO}_{2},{ }^{30} \mathrm{ZnO},{ }^{31} \mathrm{NiO},{ }^{32} \mathrm{SnO}_{2},{ }^{33}$ and $\mathrm{K}_{2} \mathrm{Nb}_{8} \mathrm{O}_{21}{ }^{34}$ have been explored for UV PD applications. Among them, $\mathrm{ZnO}$ is preferable for use in UV PDs because it possesses unique properties, such as a wide direct bandgap $(\sim 3.37 \mathrm{eV}), \mathrm{n}$ type semiconducting behavior, and large exciton binding energy of $60 \mathrm{meV}$ at room temperature, which are attractive features for UV PDs. ${ }^{35,36}$ Basically, ZnO has three types of crystal structures, including wurtzite, zinc blende, and rock salt, where the thermodynamically most stable phase is wurtzite at ambient pressure and temperature. Wurtzite $\mathrm{ZnO}$ has a hexagonal structure belonging to the $\mathrm{P6}_{3} \mathrm{mc}$ space group with the lattice parameters of $a=0.3296$ and $c=0.52065 \mathrm{~nm} \cdot{ }^{37}$ In the $\mathrm{ZnO}$ wurtzite structure, the $\mathrm{Zn}$ and $\mathrm{O}$ atoms are arranged in an hep pattern and are stacked alternately along the $c$-axis, where each $\mathrm{Zn}$ atom is surrounded by four $\mathrm{O}$ atoms and vice versa, forming a tetrahedral non-centrosymmetric structure (Fig. 1b, wurtzite-structured $\mathrm{ZnO}$ atomic model)..$^{38}$ Thereby, wurtzite $\mathrm{ZnO}$ shows piezoelectric (Fig. 1c) and pyroelectric (Fig. 1d) properties, which are additional features that improve the photoconductivity of ZnO-based UV PDs. ${ }^{39,40}$ Besides, ZnO is a biocompatible material, which can be applied directly for biomedical applications. Moreover, different dimensional $\mathrm{ZnO}$ nanomaterials ranging from 0 to $3 \mathrm{D}$ can be obtained for promising nanoscale applications. Fig. 1e shows a schematic summarizing the novel ZnO nanostructures, recently developed ZnO UV PDs and their future applications.

This review article focuses on the recent development of UV PDs based on energy-efficient ZnO nanomaterials. The characteristic photodetection parameters, photoconduction mechanism and novel ZnO nanostructures are briefly discussed. The progress and current status of device fabrication approaches ranging from conventional to self-powered are highlighted. Also, recently coupled novel mechanisms such as piezoelectric, pyroelectric and plasmonic effects for performance assistance in ZnO self-powered UV PDs are discussed in detail. Finally, it is summarized by scientifically analyzing the reported literature and concluded with possible future outlooks for nextgeneration high-performance UV PDs.

\section{Characteristic parameters of UV photodetectors}

For the detection of a light signal, the bandgap of a photosensitive material should be smaller or equal to the illuminated photon energy. Spectral photoresponse analysis of a UV PD primarily provides information about its UV signal detection limit. For photocurrent generation, the photogenerated electrons and holes need to be separated before recombination upon exposure to UV light on a PD. The response current of a PD is defined as the current generated by a PD under UV 
Table 1 Characteristic parameters and mathematical relationships of UV PDs

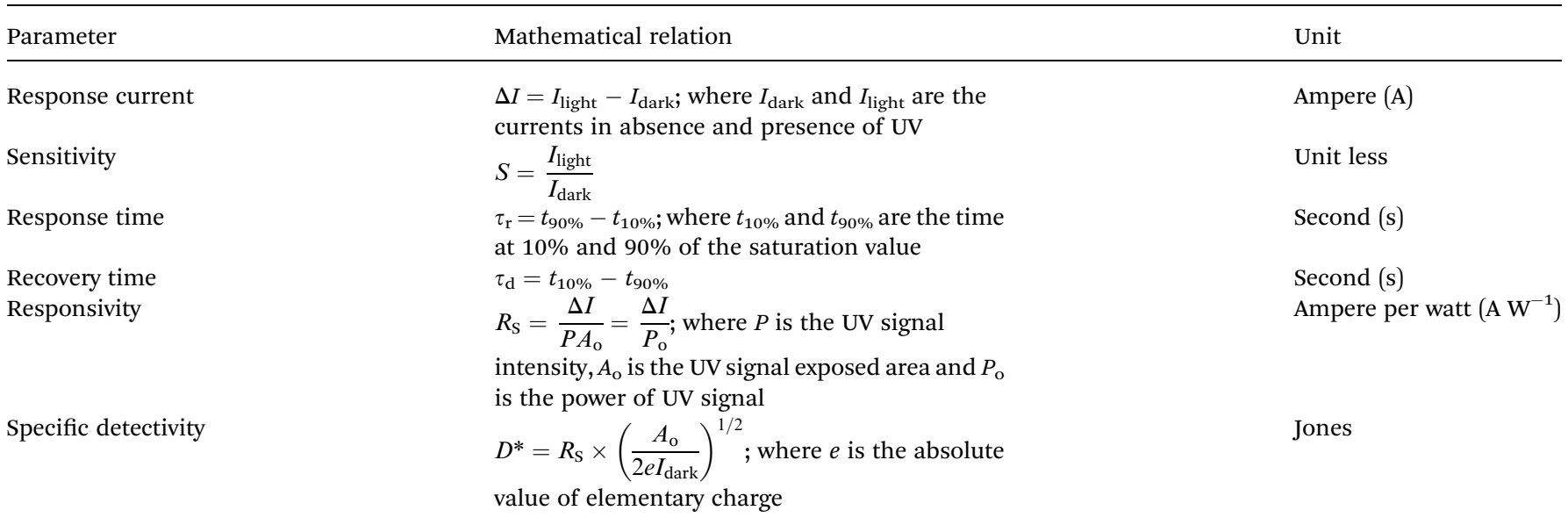

illumination, where the current generated only due to UV light can be distinguished. The term sensitivity of a PD provides information related to the signal-to-noise level upon exposure to UV light at a given intensity, and hence, both response current and sensitivity need to be larger for a given high-performance UV PD. The photodetection speed of a PD is another important parameter, which defines how a PD can detect a UV signal or how quickly it goes to its original state after being switched off UV. Primarily, two parameters, response time and recovery time, define the photodetection speed of a $\mathrm{PD}$; hence, a rapid response (smaller values of response time and recovery time) UV PD is extremely important.

Furthermore, the additional photoresponse parameter, responsivity, of a $\mathrm{PD}$ provides information related to the generation of a response current per unit incident UV illumination power on a PD. In addition to study the noise-related signal of a $\mathrm{PD}$, specific detectivity defines the information associated with the ability to detect a weak UV signal by a PD. In general, the specific detectivity of a PD is related to its noise, which arises from its thermal fluctuations and dark current. Mainly, there are three types of noise present in a PD, including shot noise, Johnson noise and flicker noise, where both Johnson and flicker noise originate from thermal fluctuation, and hence, play an important role in high frequency- and very low frequency-based PD. Table 1 summarizes the typical UV PD parameters and mathematical relations used to evaluate the overall photodetection performance.

\section{Zinc oxide-based UV photodetectors}

For photoconduction in a ZnO UV PD, the photogenerated electrons and holes under exposure to UV illumination are separated by an external (conventional PD) or internal (self-powered PD) driving force. The strength of the driving force plays an important role in the $\mathrm{e}^{-}-\mathrm{h}^{+}$pair separation and recombination process, which determines the overall photoresponse behavior of a PD. The photoresponse mechanism of ZnO-based UV PDs is typically different from that using conventional semiconducting materials, where oxygen molecule adsorption and desorption play a crucial role in photoconduction. In the dark, oxygen molecules adsorb on the $\mathrm{ZnO}$ surface from ambient atmosphere according to the equation: $\mathrm{O}_{2}$ (gas) $+\mathrm{e}^{-}$(surface) $\rightarrow \mathrm{O}_{2}{ }^{-}$ (adsorption), and then form a low conductivity depletion region. Under exposure to UV illumination, $\mathrm{e}^{-}-\mathrm{h}^{+}$pairs are photogenerated, where some of the photogenerated holes desorb the adsorbed oxygen molecules from the $\mathrm{ZnO}$ surface to decrease the low conductivity depletion width as follows, $\mathrm{h}^{+}+\mathrm{O}_{2}{ }^{-}$(adsorption) $\rightarrow \mathrm{O}_{2}$ (gas). Finally, the unpaired photogenerated free electrons together with available holes contribute to photoconduction in the presence of an external driving force. ${ }^{\mathbf{4 1 , 4 2}} \mathrm{Fig} .2$ demonstrates the photoconduction mechanism of a ZnO NW-based UV PD (Fig. 2a) with exposure to UV illumination. ${ }^{32}$ As shown in Fig. 2b (bottom schematic), due to the adsorption of oxygen molecules on the surface of $\mathrm{ZnO} \mathrm{NW}$, upward energy band bending takes place due to the formation of a low conductivity depletion layer in the dark (top schematic). Upon exposure to UV illumination, the photogenerated holes migrate to the surface of the NW along the potential slope originating from energy band bending for the desorption of adsorbed oxygen molecules, resulting in a reduction in the low conductivity depletion width. Fig. 2c shows the migration of the photogenerated holes (bottom schematic) for oxygen desorption and decrease in upward energy band bending (top schematic) upon exposure to UV illumination. Again, the oxygen molecules are re-adsorbed when the UV light is turned off and vice versa.

Various $\mathrm{ZnO}$ nanomaterials including $\mathrm{NWs},{ }^{43}$ nanorods (NRs), ${ }^{44}$ nanotubes (NTs), ${ }^{45}$ nanobelts (NBs), ${ }^{46}$ nanoflakes (NFs), ${ }^{47}$ nanoparticles (NPs), ${ }^{48}$ and quantum dots (QDs) ${ }^{49}$ have been utilized to improve the performance of UV PDs. Nanomaterials basically show efficient photoconduction behavior compared to their bulk and thin film counterparts due to their large surface-to-volume ratios. Hence, many physical and chemical synthetic approaches have been used for the synthesis of $\mathrm{ZnO}$ nanostructures, such as pulsed laser ablation, ${ }^{50}$ molecular beam epitaxy, ${ }^{51}$ vapor phase transport, ${ }^{52}$ electrochemical deposition, ${ }^{53}$ metal organic chemical vapor deposition, ${ }^{54}$ physical vapor deposition, ${ }^{55}$ chemical vapor deposition, ${ }^{56}$ wet- 


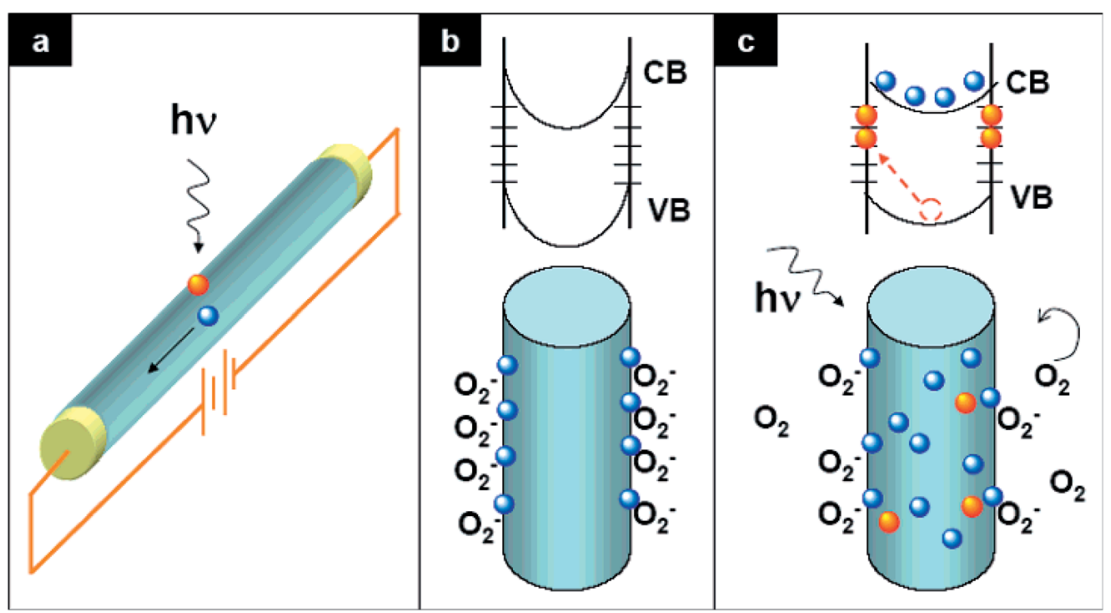

Fig. 2 Photoconduction mechanism of ZnO UV PD. (a) Schematic illustration of ZnO NW-based UV PD. (b) Adsorption of oxygen molecules on the surface of $\mathrm{ZnO} N W$ in the dark and top schematic depicts the upward energy band banding (valence band (VB) and conduction band (CB)) together with the presence of surface trap states. Bottom schematic shows the capturing of oxygen molecules on the ZnO NW surface. (c) Upon exposure to UV illumination, with photon energy greater or equal to the bandgap of $\mathrm{ZnO}$, electron-hole pairs are photogenerated, where some of the photogenerated holes migrate to the $\mathrm{ZnO} N W$ surface for the desorption of adsorbed oxygen molecules (bottom schematic). This effectively decreases the low conductivity depletion width of NW. The unpaired electrons together with the free photogenerated holes contribute to the photocurrent under an external driving force. Reproduced with permission from ref. 42 Copyright 2007 American Chemical Society.

chemical-based methods such as sol-gel ${ }^{57}$ and hydrothermal/ solvothermal growth. ${ }^{58,59}$ Among them, recently, the wetchemical-based approach has been widely applied due to its advantages such as relatively low temperature synthesis (mostly below $150{ }^{\circ} \mathrm{C}$ ), cost-effective and simple synthetic processes, and controllable nanostructure morphology, surface and dimensions. ${ }^{60-65}$ Additionally, it allows the direct growth of nanostructures on conductive or flexible plastic substrates. ${ }^{66,67}$ As shown in Fig. 3, different dimensional ZnO nanostructures such as 3D (microflowers, ${ }^{68}$ hierarchical superstructures, ${ }^{69}$ superstructures ${ }^{70}$ hierarchical structures ${ }^{71}$ etc.), 2D (nanosheets, ${ }^{72}$ nanoflakes, ${ }^{73}$ nanodisks, ${ }^{74}$ mesoporous single-crystal sheets, ${ }^{75}$ etc.), 1D (NWs, ${ }^{76} \mathrm{NRs}^{77} \mathrm{NTs}^{78}{ }^{78} \mathrm{NBs},{ }^{79}$ etc.) and 0D (QDs ${ }^{80} \mathrm{NPs}^{81}{ }^{81}$ core-shell structures, ${ }^{82}$ hollow spheres, ${ }^{83}$ etc.) structures can be synthesized vie the wet-chemical process.

\subsection{Conventional UV photodetectors}

Conventional ZnO UV PDs are mostly operated by an external driving force in terms of voltage or current source. Upon exposure to UV illumination, photogenerated electrons and hole are driven by the externally applied driving force for the generation of a photocurrent. Therefore, the external driving force plays an important role in photogenerated electron and hole recombination, separation and transportation processes, which determine the overall photoresponse behavior of a conventional PD. Based on the device design and working mechanisms, conventional ZnO UV PDs can be classified into different categories.

3.1.1 Conventional metal-semiconductor-metal-based UV photodetectors. In the past decade, pristine $\mathrm{ZnO}$ oxide nanomaterials in conventional metal-semiconductor-metal (MSM) PDs have been widely applied for the detection of UV light due to their simple fabrication. Basically, conventional MSM PDs can be obtained using symmetric back-to-back ohmic contacts (non-rectifying type), symmetric back-to-back Schottky contacts (non-rectifying type) or asymmetric electrodes depending on the work function of the metal electrode and electron affinity of ZnO. An applied external voltage across the metal electrodes drives the photogeneration of electrons and holes to contribute to the photocurrent. Conventionally, due to their low charge carrier mobility, high resistivity and inherent defects, pristine ZnO nanostructure-based PDs suffer from a slow photoresponse speed in the range of a few seconds to minutes. ${ }^{66,84,85}$ Hence, tremendous research efforts have been devoted to improving their UV photoresponse. ZnO nanostructures have been doped with the other elements such as hydrogen $(\mathrm{H}),{ }^{86}$ titanium $(\mathrm{Ti}),{ }^{87}$ fluorine $(\mathrm{F}),{ }^{88}$ chlorine $(\mathrm{Cl}),{ }^{89}$ aluminium $(\mathrm{Al}),{ }^{90}$ gallium $(\mathrm{Ga}),{ }^{91}$ indium (In), ${ }^{92}$ and europium (Eu), ${ }^{93}$ to increase their carrier mobility. For instance, Kouklin reported Cu-doped ZnO NWs for efficient photodetection application, where doping of $\mathrm{Cu}$ in $\mathrm{ZnO}$ NWs not only enhanced their photosensitivity but also resulted in photosensitivity towards visible light. ${ }^{94}$ Chiu et al. fabricated Ga-doped ZnO for PD and a higher photoresponse was observed in the Ga-doped ZnO PD compared to the pristine ZnO PD. ${ }^{95}$ Hsu et al. reported La-doped ZnO NWs for photodetection applications. ${ }^{96}$ Kao and co-authors developed Sb-doped ZnO NWs for UV detection. ${ }^{97}$ More detailed photoresponses of doped-ZnO nanostructure-based MSM-based UV PDs can be found in the review article. ${ }^{98}$ In addition, doping of other elements such as nitrogen $(\mathrm{N}),{ }^{99}$ phosphorus (P), ${ }^{100}$ arsenic $(\mathrm{As}),{ }^{101}$ antimony $(\mathrm{Sb}),{ }^{102}$ copper $(\mathrm{Cu}),{ }^{103}$ silver $(\mathrm{Ag}),{ }^{104}$ gold $(\mathrm{Au}),{ }^{105}$ lithium $(\mathrm{Li}),{ }^{106}$ sodium $(\mathrm{Na}),{ }^{107}$ and potassium $(\mathrm{K})^{108}$ changed the ZnO property to p-type. Most importantly, ZnO nanomaterials (pristine or doped) in conventional MSM PDs display higher recombination rates of photogenerated charge carriers, and hence need the application of a large bias voltage 

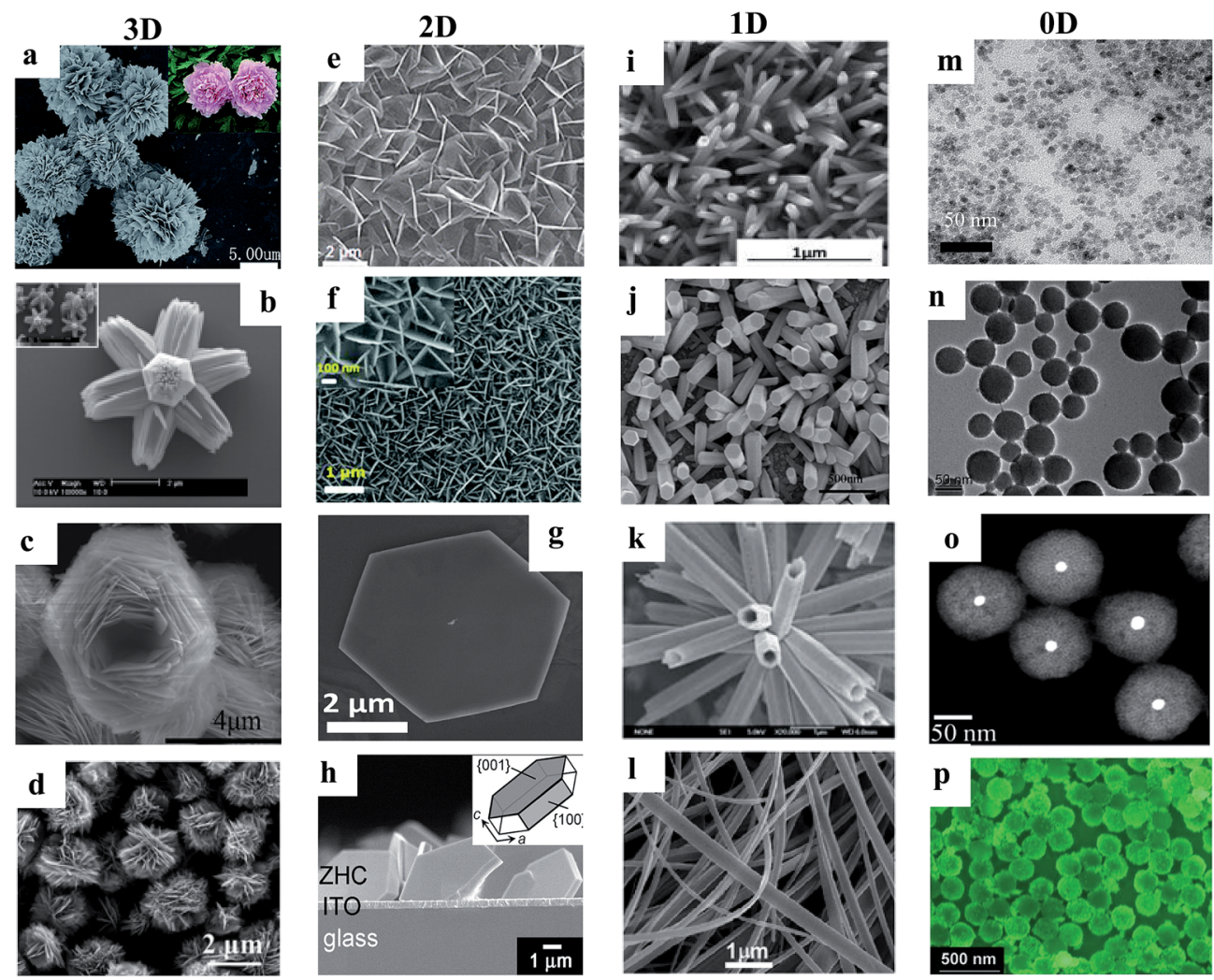

Fig. 3 Various dimensional ZnO nanostructures synthesized via the hydrothermal process. 3D: (a-d) microflowers, ${ }^{68}$ hierarchical superstructures, $^{69}$ superstructures ${ }^{70}$ and hierarchical structures. ${ }^{71} 2 \mathrm{D}$ : (e-h) nanosheets, ${ }^{72} \mathrm{NFs}^{73}$ nanodisks ${ }^{74}$ and mesoporous single-crystal sheets. ${ }^{75} 1 \mathrm{D}$ : (i1) $\mathrm{NWs}^{76}{ }^{7 R s},{ }^{77} \mathrm{NTs}^{78}$ and $\mathrm{NBs}{ }^{79}$ and $\mathrm{OD}:(\mathrm{m}-\mathrm{p}) \mathrm{QDs},{ }^{80} \mathrm{NPs},{ }^{81}$ core-shell structures ${ }^{82}$ and hollow spheres ${ }^{83}$ Reproduced with permission from ref. 68-83 Copyright 2015 Royal Society of Chemistry. Copyright 2006 American Chemical Society. Copyright 2012 American Chemical Society. Copyright 2013 American Chemical Society. Copyright 2013 American Chemical Society. Copyright 2016 Royal Society of Chemistry. Copyright 2014 Royal Society of Chemistry. Copyright 2017 American Chemical Society. Copyright 2013 IOP. Copyright 2013 WILEY-VCH. Copyright 2013 Royal Society of Chemistry. Copyright 2006 Royal Society of Chemistry. Copyright 2015 Royal Society of Chemistry. Copyright 2010 WILEY-VCH. Copyright 2015 American Chemical Society. Copyright 2011 WILEY-VCH.

for the detection of UV light. Various MSM device configurations via alteration, ranging from non-rectifying to rectifying electrodes, have been applied predominantly for optimum photoconductivity at a low external bias voltage, where rectifying junction-based PDs commonly show a low dark current, fast switching behavior and controllable photoresponse performance under an external driving force compared to that of ohmic junctions. ${ }^{109,110}$

Recently, atomically-thin 2D graphene was used with ZnO for the efficient collection of photogenerated charges in UV PDs due to its inherent intrinsic properties, such as outstanding mobility, transparency, mechanical stability, and flexibility. A generated built-in electric field at the interface of graphene and $\mathrm{ZnO}$ offers efficient charge separation and transportation for rapid photoconduction under an external driving force. ${ }^{111-113}$ We fabricated a $\mathrm{ZnO} \mathrm{NW} / \mathrm{graphene}$ foam heterostructure for UV PD application, where highly dense ZnO NWs were direct grown on 3D graphene foam for efficient charge conduction and separation. ${ }^{114}$ As shown in Fig. 4a, first graphene foam was grown on 3D nickel foam followed by CVD, and then the nickel template was etched to directly grow ZnO NWs on graphene foam via the thermal evaporation technique. Fig. $4 \mathrm{~b}$ shows a schematic diagram of the $\mathrm{PD}$, and its respective $I-V$ responses in both the absence and presence of UV are shown in Fig. 4c. Under UV illumination ( $365 \mathrm{~nm}, 1.3 \mathrm{~mW} \mathrm{~cm}^{-2}$ ), the current of the PD increased due to the increase in conductivity, where the cyclic photoresponse of the PD is depicted in Fig. 4d. At a bias voltage of $5 \mathrm{~V}$, the PD showed a current response of $700 \mu \mathrm{A}$ and response time/recovery time of $9.5 \mathrm{~s} / 38 \mathrm{~s}$ (Fig. 4e). With an increase in the bias voltage of the PD, the response current increased due to the increase in the drift velocity of charge carriers, where an $\sim 868 \%$ enhancement in response current was observed at a bias voltage of $8 \mathrm{~V}$ compared to that at a bias voltage of $1 \mathrm{~V}$ (Fig. 4f). Moreover, we reported a $\mathrm{ZnO} \mathrm{NW} /$ graphene heterostructure UV PD (Fig. 4g), ${ }^{84}$ graphene/ZnO NW/graphene UV PD (Fig. 4h), ${ }^{115}$ and graphene-ZnO QDsgraphene UV PD (Fig. 4i), ${ }^{80}$ where faster and higher photoresponses were measured under UV illumination, and their overall photoresponse performances are listed in Table 2 .

Moreover, $\mathrm{ZnO}$ nanostructures were directly grown on carbon nanotubes (CNTs) for direct charge conduction, where CNTs provide rapid charge carrier transportation, for instance, Hart's group fabricated ZnO NWs-coated aligned CNTs, ${ }^{116}$ where a faster photodetection performance of $0.25 \mathrm{~s}$ response time and $0.35 \mathrm{~s}$ 

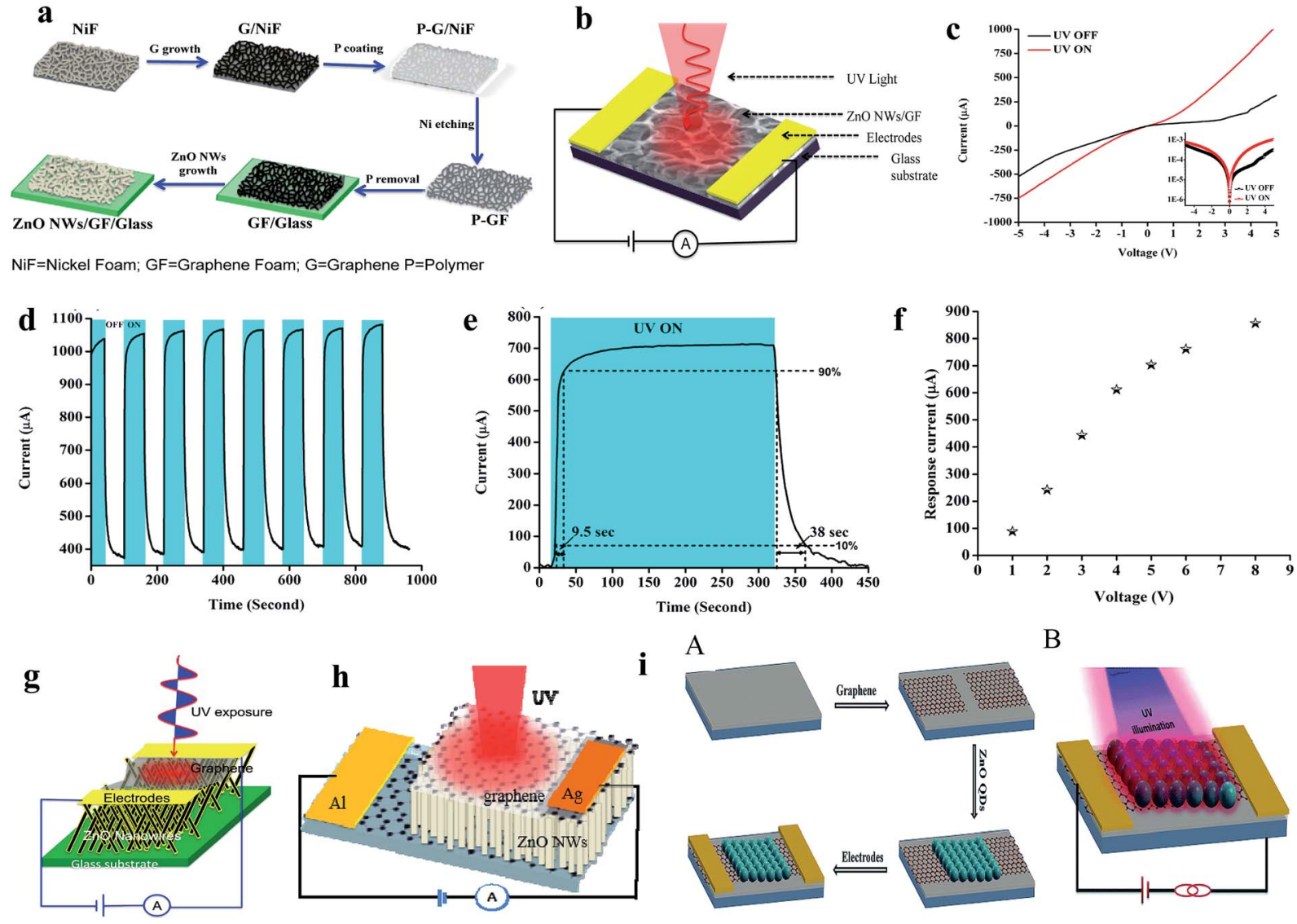

A

B

Fig. 4 ( $a$ and b) Schematic representation of the steps involved in the fabrication of a UV PD and schematic diagram the as-fabricated PD, respectively. ( $c$ and d) $I-V$ responses in both the absence and presence of UV (365 nm, $1.3 \mathrm{~mW} \mathrm{~cm}^{-2}$ ) and cyclic photoresponse of the PD at a bias voltage of $5 \mathrm{~V}$, respectively. (e) Estimation of response time and recovery time of the PD. (f) Response current as a function of bias voltage plot. Reproduced with permission from ref. 114 Copyright 2015 American Chemical Society. (g) ZnO NWs/graphene heterostructure PD. Reproduced with permission from ref. 84 Copyright 2015 IOP. (h) Graphene/ZnO NWs/graphene PD. Reproduced with permission from ref. 115 Copyright 2016 IOP. (i) Graphene-ZnO QDs-graphene PD: (A and B) schematic diagram of the fabrication processes in the PD and schematic diagram of the PD, respectively. Reproduced with permission from ref. 80 Copyright 2015 Royal Society of Chemistry.

recovery time was measured due to the direct transportation of photogenerated charges through aligned CNTs, which effectively reduced the recombination rate of the photogenerated electrons and holes under UV illumination. In addition, we fabricated $\mathrm{ZnO}$ QD-decorated CNTs for UV PD application, ${ }^{117}$ and nearly $275 \%$ enhancement in response current was measured at $1 \mathrm{~V}$ bias voltage compared to the pristine ZnO QD PD.

The localized surface plasmon resonance (LSPR) effect of nanomaterials results in unique light absorption capacity, which photoexcites electrons in contact with $\mathrm{ZnO}$ upon exposure to UV light, thereby modifying the photoconduction. Fundamentally, nanomaterials (preferably NPs) based on noble metals such as $\mathrm{Au},{ }^{118,119} \mathrm{Ag},{ }^{120,121} \mathrm{Al},{ }^{122}$ and $\mathrm{Pt},{ }^{123}$ have attracted special attraction due to their efficient LSPR effects and widely coupled with $\mathrm{ZnO}$ nanomaterials for photoconduction enhancement. Liu et al. reported Ag NPs-decorated ZnO NWs for application in UV PDs, as shown in Fig. 5a (device schematic). ${ }^{120}$ It can be seen from the $I-V$ characteristics (Fig. $5 \mathrm{~b}$ ) that upon exposure to UV light, the Ag NP-decorated ZnO NWs showed a higher photoresponse compared to their bare counterpart due to the enhancement in light absorption, which is related to the LSPR effect of Ag NPs. Fig. $5 \mathrm{c}$ shows the energy band of the $\mathrm{Ag}$ and $\mathrm{ZnO}$ heterojunction (top schematic), where under exposure to UV light, electrons and holes are photogenerated and hot electrons transferred from the Ag NPs to the CB of ZnO (bottom schematic), thereby enhancing the photoconduction. Similar results were also reported by Wang and coauthors, where Ag NPs were decorated on top of a ZnO film for application in a UV PD, as shown in Fig. 5d (device schematic). ${ }^{121}$ As shown in Fig. 5e, the Ag NP-decorated ZnO PD displayed a higher photoresponse performance compared to the pristine ZnO PD due to the LSPR effect of the Ag NPs. Lu and co-authors demonstrated an Al NP-decorated ZnO NR UV PD, where a superior enhancement in responsivity from 0.12 to 1.59 A $\mathrm{W}^{-1}$ and nearly 6-fold enhancement in sensitivity were measured in the Al NP-decorated ZnO NR PD compared to the pristine ZnO NR PD due to the localized surface plasmons (LSPs) of the Al NPs. ${ }^{122}$ The authors also reported that the Al NPdecorated ZnO NR PD showed a faster photodetection speed of $0.030 \mathrm{~s}$ (response time) and $0.035 \mathrm{~s}$ (recovery time) compared to that of the bare PD of $0.80 \mathrm{~s}$ and $0.85 \mathrm{~s}$, respectively, mainly due to the rapid resonant couplings between the LSPs of the Al NPs 
Table 2 Summary the photoresponses of conventional UV PDs based on ZnO nanostructure materials

\begin{tabular}{|c|c|c|c|c|c|c|c|}
\hline PD & Bias & UV light & $\begin{array}{l}\text { Response } \\
\text { current }\end{array}$ & $\begin{array}{l}\text { Response time \& } \\
\text { recovery time }\end{array}$ & Sensitivity & Responsivity & $\begin{array}{l}\text { Specific } \\
\text { detectivity }\end{array}$ \\
\hline ZnO NWs ${ }^{165}$ & $1 \mathrm{~V}$ & $360 \mathrm{~nm}$ & $34 \mathrm{nA}$ & $2 \mathrm{~s} \& 100 \mathrm{~s}$ & 12.26 & $0.39 \mathrm{~A} \mathrm{~W}^{-1}$ & $1.9 \times 10^{8}$ Jones \\
\hline ZnO NWs ${ }^{146}$ & $3 \mathrm{~V}$ & $310 \mathrm{~nm}$ & $5.13 \mu \mathrm{A}$ & $229 \mathrm{~s} \& 547 \mathrm{~s}$ & - & - & - \\
\hline $\mathrm{ZnO} \mathrm{NRs}^{167}$ & & $325 \mathrm{~nm}$ & - & $3.7 \mathrm{~s} \& 63.6 \mathrm{~s}$ & - & - & - \\
\hline ZnO NW/graphene foam ${ }^{114}$ & $5 \mathrm{~V}$ & $365 \mathrm{~nm}$ & $\sim 700 \mu \mathrm{A}$ & $9.5 \mathrm{~s} \& 38 \mathrm{~s}$ & & $6 \mathrm{~A} \mathrm{~W}^{-1}$ & \\
\hline${\mathrm{ZnO}-\mathrm{SnO}_{2}}_{2}$ nanofiber film ${ }^{151}$ & $10 \mathrm{~V}$ & $300 \mathrm{~nm}$ & $\sim 7.9 \mathrm{nA}$ & $32.2 \mathrm{~s} \& 7.8 \mathrm{~s}$ & $\sim 5000$ & & \\
\hline ZnO NP-graphene core-shell ${ }^{149}$ & $20 \mathrm{~V}$ & $375 \mathrm{~nm}$ & & $9 \mathrm{~ms} \& 11 \mathrm{~ms}$ & 600 & $640 \mathrm{~A} \mathrm{~W}^{-1}$ & \\
\hline Graphene/ZnO NWs ${ }^{84}$ & $5 \mathrm{~V}$ & $365 \mathrm{~nm}$ & $3.02 \mathrm{~mA}$ & $11.9 \mathrm{~s} \& 240 \mathrm{~s}$ & & $32000 \mathrm{~A} \mathrm{~W}^{-1}$ & $3.9 \times 10^{13}$ Jones \\
\hline Graphene/ZnO NW/graphene ${ }^{115}$ & $-5 \mathrm{~V}$ & $365 \mathrm{~nm}$ & $\sim 300 \mu \mathrm{A}$ & $3 \mathrm{~s} \& 0.47 \mathrm{~s}$ & & $23 \mathrm{~A} \mathrm{~W}^{-1}$ & \\
\hline Co-ZnO NRs ${ }^{168}$ & $5 \mathrm{~V}$ & $365 \mathrm{~nm}$ & $80 \mu \mathrm{A}$ & $1.2 \mathrm{~s} \& 7.4 \mathrm{~s}$ & & $760 \mathrm{~A} \mathrm{~W}^{-1}$ & \\
\hline Monolayer graphene/ZnO NRs ${ }^{124}$ & $-1 \mathrm{~V}$ & $365 \mathrm{~nm}$ & & $0.7 \mathrm{~ms} \& 3.6 \mathrm{~ms}$ & & $113 \mathrm{~A} \mathrm{~W}^{-1}$ & \\
\hline ZnO NW array $^{171}$ & $5 \mathrm{~V}$ & $370 \mathrm{~nm}$ & & $0.1 \mathrm{~ms} \& 0.4 \mathrm{~ms}$ & 1.4 & & \\
\hline ZnO spatial tetrapod network ${ }^{172}$ & $1 \mathrm{~V}$ & $365 \mathrm{~nm}$ & & $0.4 \mathrm{~s} \& 0.3 \mathrm{~s}$ & $10^{6}$ & & \\
\hline ZnO nanotetrapod network ${ }^{173}$ & $2.4 \mathrm{~V}$ & $365 \mathrm{~nm}$ & & $67 \mathrm{~ms} \& 30 \mathrm{~ms}$ & $4.5 \times 10^{3}$ & & \\
\hline $\mathrm{NiO} / \mathrm{ZnO}^{141}$ & $-5 \mathrm{~V}$ & $310 \mathrm{~nm}$ & & & 100 & $21.8 \mathrm{~A} \mathrm{~W}^{-1}$ & $1.6 \times 10^{12}$ Jones \\
\hline $\mathrm{ZnO} / \mathrm{Si}^{138}$ & $-2 \mathrm{~V}$ & $365 \mathrm{~nm}$ & - & - & - & $0.34 \mathrm{~A} \mathrm{~W}^{-1}$ & $2.11 \times 10^{10}$ Jones \\
\hline ZnS-coated $\mathrm{ZnO}$ array $^{146}$ & $3 \mathrm{~V}$ & $310 \mathrm{~nm}$ & $162 \mu \mathrm{A}$ & $229 \mathrm{~s} \& 547 \mathrm{~s}$ & - & & \\
\hline $\mathrm{ZnS} / \mathrm{ZnO}$ biaxial nanobelt ${ }^{144}$ & $5 \mathrm{~V}$ & $320 \mathrm{~nm}$ & $3.97 \mu \mathrm{A}$ & $0.3 \mathrm{~s} \& 1.7 \mathrm{~s}$ & 6.9 & & \\
\hline ZnS-ZnO bilayer film ${ }^{145}$ & $5 \mathrm{~V}$ & $370 \mathrm{~nm}$ & $\sim 16 \mu \mathrm{A}$ & $50 \mathrm{~s} \& 50 \mathrm{~s}$ & 1066 & & \\
\hline${\mathrm{ZnO}-\mathrm{SnO}_{2}}_{2}$ nanofibers film ${ }^{151}$ & $10 \mathrm{~V}$ & $300 \mathrm{~nm}$ & $\sim 7.9 \mathrm{nA}$ & $32.2 \mathrm{~s} \& 7.8 \mathrm{~s}$ & 4600 & - & - \\
\hline Electrospun ZnO NWs/PbS QDs ${ }^{174}$ & $10 \mathrm{~V}$ & $350 \mathrm{~nm}$ & - & - & - & $51 \mathrm{~mA} \mathrm{~W}^{-1}$ & $3.4 \times 10^{8}$ \\
\hline $\mathrm{Ag} @ Z n O \mathrm{NWs}^{120}$ & $5 \mathrm{~V}$ & $365 \mathrm{~nm}$ & $\sim 25000 \mu \mathrm{A}$ & $1.02 \mathrm{~s} \& 15.5 \mathrm{~s}$ & $\sim 11.2$ & - & - \\
\hline ZnO film with Ag NPs ${ }^{121}$ & $5 \mathrm{~V}$ & $380 \mathrm{~nm}$ & - & $\sim 15 \mathrm{~s} \& \sim 330 \mathrm{~s}$ & - & $2.86 \mathrm{~A} \mathrm{~W}^{-1}$ & - \\
\hline La-doped ZnO NWs ${ }^{181}$ & $10 \mathrm{~V}$ & $365 \mathrm{~nm}$ & $481 \mathrm{nA}$ & - & 2.6 & - & - \\
\hline Al-doped ZnO NWs ${ }^{182}$ & $1 \mathrm{~V}$ & $365 \mathrm{~nm}$ & $62 \mu \mathrm{A}$ & $0.1 \mathrm{~s} \& 20 \mathrm{~s}$ & $6.2 \times 10^{5}$ & $3.8 \mathrm{~A} \mathrm{~W}^{-1}$ & - \\
\hline Cu-doped ZnO NRs ${ }^{183}$ & - & UV lamp & $23 \mu \mathrm{A}$ & $2.7 \mathrm{~s} \& 118 \mathrm{~s}$ & $5.6 \times 10^{4}$ & - & - \\
\hline Ga-doped ZnO nanopagodas ${ }^{184}$ & $1 \mathrm{~V}$ & $254 \mathrm{~nm}$ & $28.3 \mu \mathrm{A}$ & $0.53 \mathrm{~s} \& 14 \mathrm{~s}$ & 1.3 & - & - \\
\hline Mg-doped ZnO NRs ${ }^{185}$ & $1 \mathrm{~V}$ & $365 \mathrm{~nm}$ & $8 \mu \mathrm{A}$ & $24.5 \mathrm{~s} \& 18.4 \mathrm{~s}$ & 5.2 & - & - \\
\hline In-doped $\mathrm{ZnO} \mathrm{NRs}^{186}$ & $1 \mathrm{~V}$ & UV lamp & $49.3 \mu \mathrm{A}$ & - & 71.4 & $2.5 \mathrm{~A} \mathrm{~W}^{-1}$ & $1.44 \times 10^{11}$ Jones \\
\hline
\end{tabular}

and excitons of the ZnO NRs. An Au NP-decorated ZnO NW UV PD was fabricated by Liu et al. ${ }^{119}$ where $\sim 10^{3}$ times enhancement in the sensitivity in Au NP-decorated ZnO NW PD was reported compared to that in the pristine ZnO NW PD due to the plasmonic enhancement in the light absorption efficiency of the Au NPs. In addition, an improvement in recovery time from $\sim 300$ to $\sim 10 \mathrm{~s}$ was reported in the Au NP PD.

3.1.2 Schottky junction-based UV photodetectors. Generally, conventional MSM-based devices with non-rectifying electrodes show a higher dark current, slow photodetection speed in terms of response time and recovery time, and higher recombination rate of photogenerated charge carriers under UV illumination. However, Schottky junction-based UV PDs, i.e. Schottky barrier photodiodes, display a relatively low dark current, fast switching behavior and controllable photoresponse performance under an external driving force. ${ }^{109,110}$ Various Schottky barrier-based ZnO UV PDs have been reported by researchers. Among them, graphene and ZnO Schottky barrier-based UV PDs have been drawn significant research interest due to the intrinsic properties of graphene, as discussed earlier. The difference in the work function of graphene and $\mathrm{ZnO}$ creates a rectification barrier, which can be directly applied for both efficient charge transportation and Schottky barrier formation for carrier separation. Nie and coauthors fabricated a PMMA-supported monolayer graphene (MLG) film/ ZnO NR array-based UV PD. ${ }^{124}$ The step-by-step fabrication of the device is illustrated in Fig. 6a (inset shows the PMMAsupported MLG on ZnO NR array), where the respective 

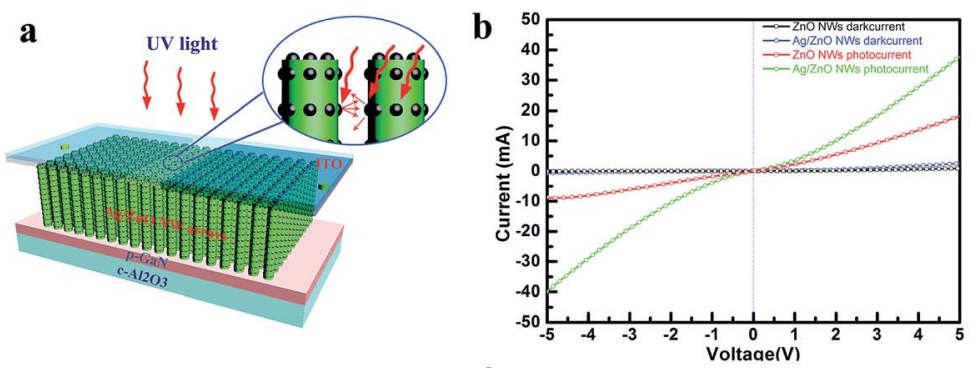

e
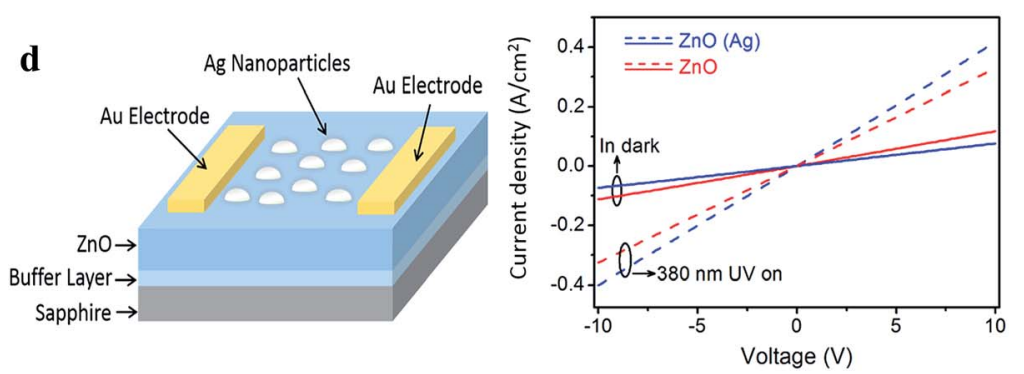
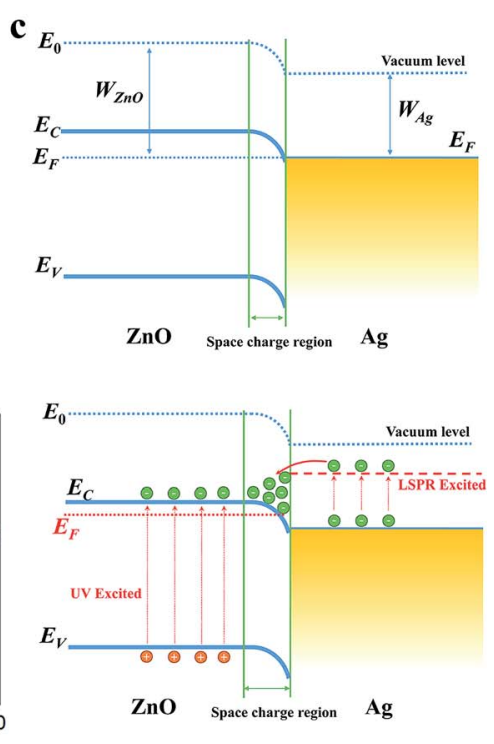

Fig. 5 (a and b) Schematic representation of Ag NPs/ZnO NW-based plasmonic PD and the respective I-V profiles with and without UV illumination ( $365 \mathrm{~nm}, 0.24 \mathrm{~mW} \mathrm{~cm}^{-2}$ ), respectively. (c) Energy band diagrams of the Ag/ZnO heterojunction (top schematic) and LPSR excited electrons transfer from $\mathrm{Ag}$ to $\mathrm{ZnO}$ upon exposure to UV illumination (bottom schematic). Reproduced with permission from ref. $120 \mathrm{Copyright}$ 2014 Optical Society of America. (d) Schematic diagram of Ag NPs decorated ZnO-based PD. (e) J-V characteristics of pristine ZnO and Ag NPs decorated ZnO based PDs in both the presence and absence of UV light. Reproduced with permission from ref. 121 Copyright 2017 American Chemical Society.

current-voltage $(I-V)$ characteristics of the device at different temperatures ( 80 to $300 \mathrm{~K}$ ) confirm the formation of rectifying behavior with a turn-on voltage of $1.0 \mathrm{~V}$ (Fig. $6 \mathrm{~b}$ ). Due to the work function difference in between graphene $(4.6 \mathrm{eV})$ and $\mathrm{ZnO}$ $(4.4 \mathrm{eV})$, the Schottky junction is formed by energy band bending in the upward direction, and hence, efficient electron and hole separation occurs due to the built-in electric field under exposure to UV light. As a result, outstanding photoconduction, nearly three orders of magnitude higher under

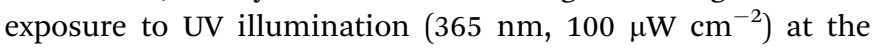
reversed bias voltage was observed (Fig. 6c, typical $I-V$ responses taken with and without UV illumination), which is much higher than that of conventional ZnO nanomaterial-based PDs. The authors also reported the higher responsivity of $113 \mathrm{~A} \mathrm{~W}^{-1}$ at $-1 \mathrm{~V}$ together with a faster photodetection speed of $0.7 \mathrm{~ms}$ response time and $3.6 \mathrm{~ms}$ recovery time (Fig. $6 \mathrm{~d}$ ). The attributed higher photodetection performance of the PD was mainly due to the rapid transportation of photogenerated charges through monolayer graphene under exposure to UV light and built-in electric field.

Likewise, Zhang et al. reported a graphene-ZnO Schottky junction-based PD, as shown in Fig. 6e, for high-performance photoconduction, where Fig. $6 \mathrm{f}$ depicts a schematic illustration of the respective energy band diagram of the grapheneZnO Schottky junction under exposure to UV illumination. ${ }^{125}$ Under a reverse bias condition, the strength of the Schottky barrier height was enhanced to reduce the dark current. Upon exposure to UV light, the photogenerated electrons were transported from $\mathrm{ZnO}$ to graphene by crossing the barrier to generate a photocurrent. Fig. $6 \mathrm{~g}$ shows the $I-V$ characteristics both in the absence and presence of UV illumination at different intensities, where with an increase in UV illumination intensity, the current in the reverse bias direction increased due to the increase in the electron and hole generation efficiency. The asymmetric $I-V$ profiles demonstrated Schottky junction formation between graphene and $\mathrm{ZnO}$. The fabricated PD displayed a response time and recovery time of $<1 \mathrm{~s}$ and $22 \mathrm{~s}$ (Fig. 6h), respectively. The authors noted that because of the existence of defect states such as $\mathrm{O}$ and $\mathrm{Zn}$ vacancies or excess $\mathrm{Zn}$ and $\mathrm{O}$ atoms in $\mathrm{ZnO}$, the PD exhibited a relatively slow response under exposure to UV light. Moreover, the authors reported a high responsivity of $3 \times 10^{4} \mathrm{~A} \mathrm{~W}^{-1}$ and specific detectivity of $4.33 \times 10^{14}$ Jones in the reverse bias condition.

3.1.3 Homojunction/heterojunction-based UV photodetectors. In recent years, homojunctions and heterojunctions of ZnO nanomaterial-based UV PDs have been reported, where the generated built-in electric field at the semiconductor/ semiconductor interface boosts the overall photoconductivity through the separation of photogenerated charges. In $\mathrm{ZnO}$ homojunctions PDs, n-type ZnO nanostructures with p-type $\mathrm{ZnO}$ nanostructures are mostly conjugated to form $\mathrm{p}-\mathrm{n}$ type homojunctions. Under exposure to UV illumination, the photogenerated electrons are driven to the n-type region, while holes move toward the p-type region due to the internal built-in electric field. Leung and coauthors fabricated a $\mathrm{p}-\mathrm{n}$ homojunction visible-blind UV PD based on n-type ZnO NWs covered with a p-type $\mathrm{Al}, \mathrm{N}$ co-doped $\mathrm{ZnO}$ film. ${ }^{126}$ Fig. 7a illustrates the device schematic of the as-fabricated $\mathrm{p}-\mathrm{n} \mathrm{ZnO} \mathrm{PD}$, which was fabricated via a combination of hydrothermal synthesis and sol-gel synthesis methods (Fig. 7b cross-sectional image). The typical $I-V$ profiles (Fig. $7 \mathrm{c}$ and inset shows the ohmic 
$\mathbf{a}$
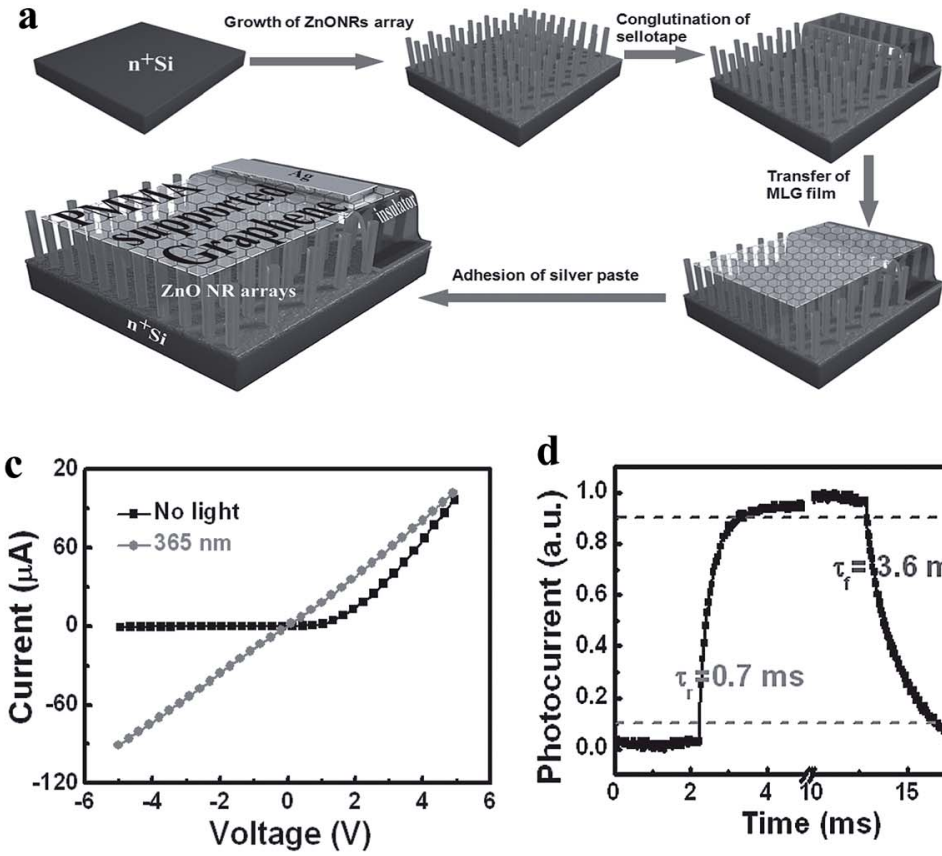

f

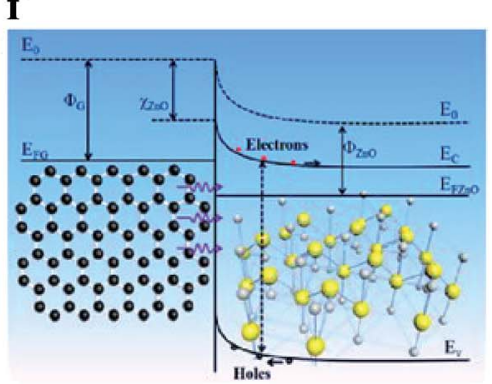

d
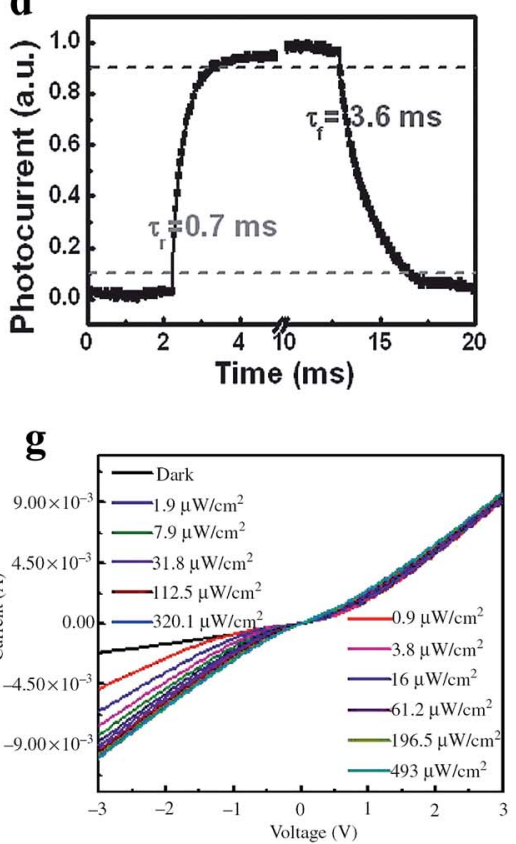
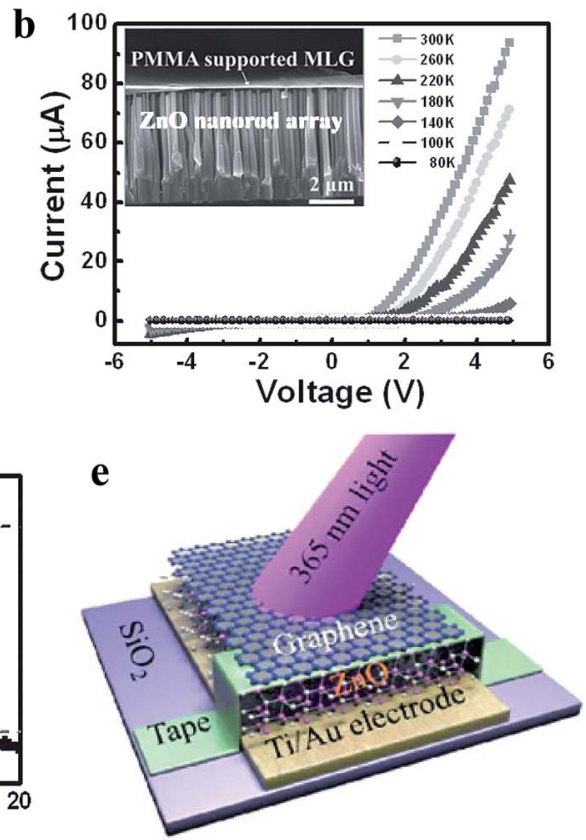

$\mathbf{h}$

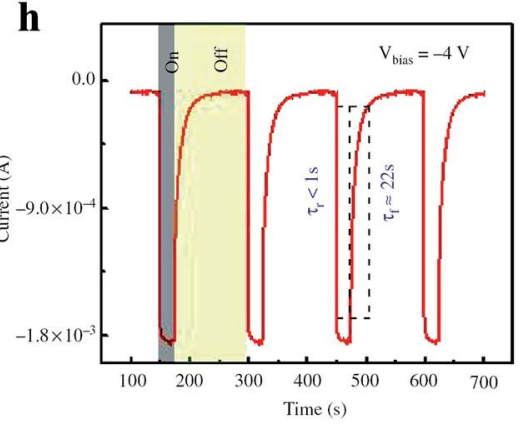

Fig. 6 (a) Schematic illustration of the processes involved in the fabrication of MLG film/ZnO NR PD. (b) I-V characteristics at different operational temperatures $(80$ to $300 \mathrm{~K}$ ) of the PD, inset depicts the typical cross-sectional SEM image of the PMMA-supported MLG film/ZnO NR junction. (c and d) $I-V$ responses recorded with and without $365 \mathrm{~nm}$ UV illumination and estimation of response time/recovery time of the PD, respectively. Reproduced with permission from ref. 124 Copyright 2013 Wiley-VCH. (e and f) Schematic diagram of the graphene-ZnO Schottky junction-based PD and the respective energy band diagram of the PD under exposure to UV light illumination, respectively. (g and h) $I-V$ responses at different UV illumination $(365 \mathrm{~nm}$ ) intensities and estimation of response time/recovery time of the PD, respectively. Reproduced with permission from ref. 125 Copyright 2016 De Gruyter.

characteristics of the electrodes (ITO and $\mathrm{Au}$ ) with $\mathrm{ZnO}$ ) of the $\mathrm{PD}$ confirm a $\mathrm{p}-\mathrm{n}$ junction device characteristic, and its current characteristic is nonlinear with respect to the reverse bias. The measured reverse leakage current and turn-on voltage for the homojunction were $\sim 5 \mu \mathrm{A}$ and $\sim 1.5 \mathrm{~V}$, respectively. The current in the reverse bias direction increased upon exposure to $\mathrm{UV}$ illumination $(380 \mathrm{~nm}$, incident power $\sim 55 \mu \mathrm{W})$ and at the reverse bias voltage of $-3 \mathrm{~V}$, the observed response current was $150 \mu \mathrm{A}$. As illustrated in Fig. 7d, the photoresponse spectra PD at different bias voltages confirm its UV sensitive behavior. However, the PD also showed a weak response to orange/red light due to the deep-level defects in $\mathrm{ZnO}$, which was confirmed from the photoluminescence spectrum (inset figure). The authors measured the responsivity of $4 \mathrm{~A} \mathrm{~W}^{-1}$ at a reverse bias voltage of $-3 \mathrm{~V}$ and no other photodetection parameters were measured. Wang et al. fabricated Sb-doped p-type ZnO NW and n-type ZnO film homojunction UV PDs, as depicted in Fig. 7e (schematic diagram), ${ }^{127}$ where the typical $I-V$ characteristics (Fig. 7f) with and without exposure to UV illumination confirmed their UV sensitive response. Similarly, a small photocurrent peak at around $570 \mathrm{~nm}$ at all the applied bias voltages was observed due to the defects in $\mathrm{ZnO}$ (Fig. 7g). Likewise, different $\mathrm{ZnO}$ homojunction-based UV PDs have been reported, for instance, $\mathrm{p}^{-}$ $n$ ZnO NW homojunction, ${ }^{128} \mathrm{ZnO}$ :(Ag,N)/ZnO NRs p-n homojunction, ${ }^{129} \mathrm{Cu}$-doped $\mathrm{ZnO} / \mathrm{n}$-type $\mathrm{ZnO}$ NRs homojunction, ${ }^{130}$ $\mathrm{Mg}_{0.4} \mathrm{Zn}_{0.6} \mathrm{O} / \mathrm{ZnO}$ homojunction, ${ }^{131} \mathrm{CdMoO}_{4}-\mathrm{ZnO}$ composite film, ${ }^{132}$ BiOCl/ZnO hybrid film, ${ }^{133} \mathrm{p}-\mathrm{Mg}_{0.2} \mathrm{Zn}_{0.8} \mathrm{O} / \mathrm{n}-\mathrm{ZnO}$ homojunction, ${ }^{134}$ vertically stacked $\mathrm{ZnO}$ sheet-like nanorod $\mathrm{p}-\mathrm{n}$ homojunction, ${ }^{135} \mathrm{ZnO}$ microwire $\mathrm{p}-\mathrm{n}$ homojunction, ${ }^{136}$ and $\mathrm{ZnO}$ NW p-n homojunction. ${ }^{137}$

Heterojunctions of ZnO nanomaterials with other semiconductors have been introduced to form $\mathrm{p}-\mathrm{n}$ junctions or $\mathrm{n}-\mathrm{n}$ junctions depending on the photoactive materials for UV PDs, for example, $\mathrm{ZnO} / \mathrm{Si}$ heterojunction, ${ }^{138} \mathrm{ZnO} \mathrm{NWs} / \mathrm{p}-\mathrm{GaN}$ 

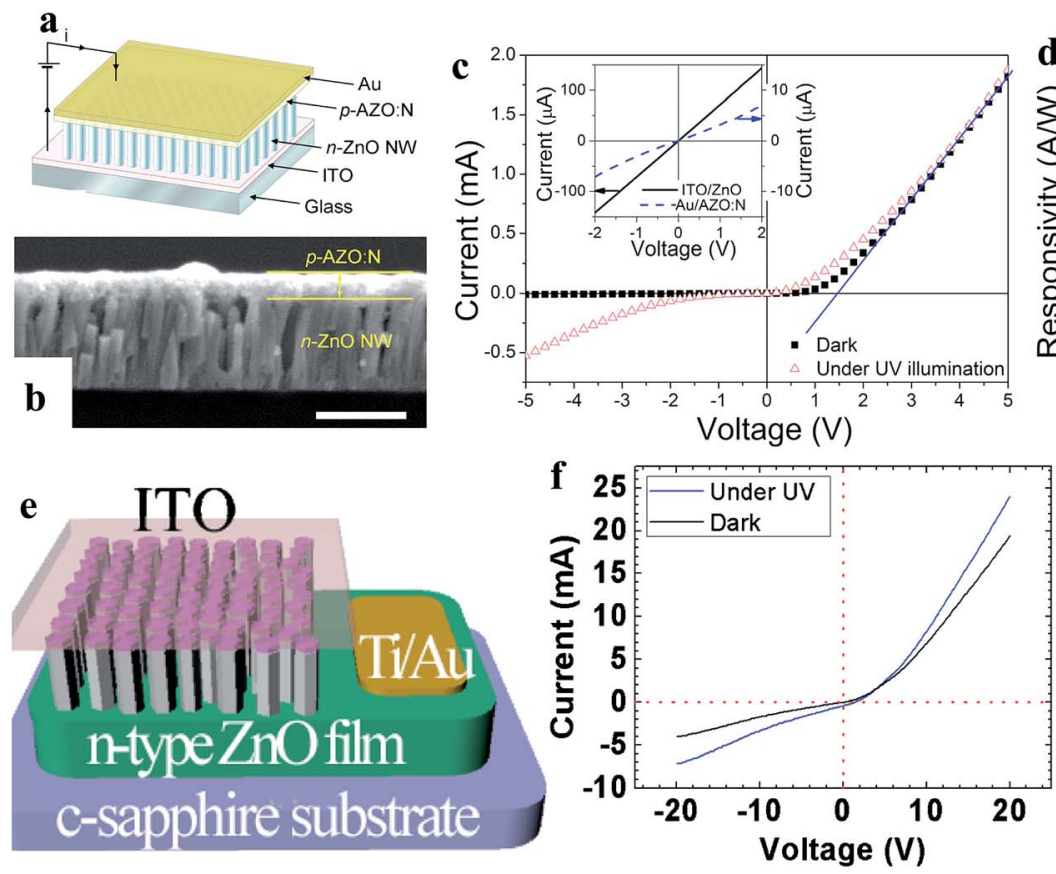
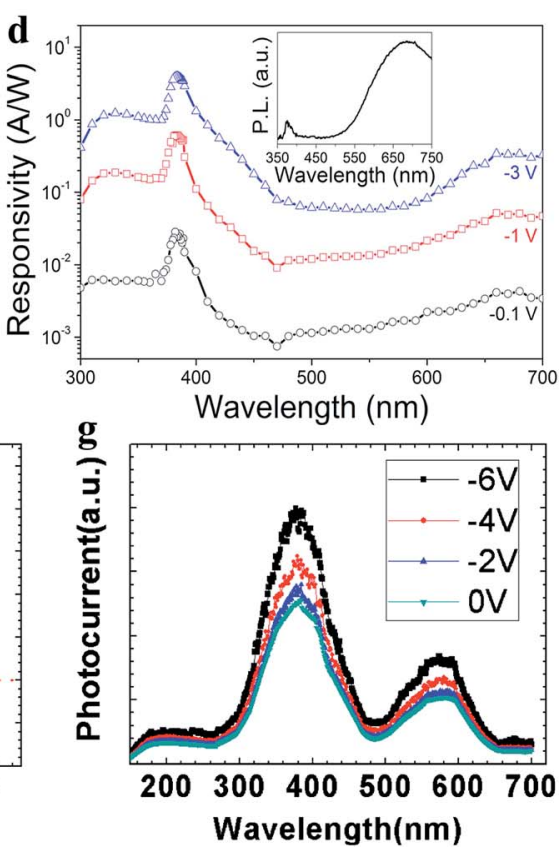

Fig. $7 \mathrm{Al}$, N-codoped p-type ZnO film and n-type ZnO NW-based homojunction: (a and b) schematic diagram and cross-sectional SEM image (scale bar is $500 \mathrm{~nm}$ ) of the $\mathrm{p}-\mathrm{n}$ homojunction PD, respectively. (c and d) I-V characteristics recorded with and without UV light and spectral photoresponses of the PD, respectively. Reproduced with permission from ref. 126 Copyright 2010 American Institute of Physics. Sb-doped ptype ZnO NWs and n-type ZnO film based homojunction: (e and f) schematic diagram of the homojunction PD and the respective I-V characteristics before and after exposure to UV, respectively. (g) Photocurrent spectra of the PD at different reversed bias voltages. Reproduced with permission from ref. 127 Copyright 2011 American Institute of Physics.

heterojunction, ${ }^{\mathbf{1 3 9}} \mathrm{n}$-Ga:ZnO NRs/p-GaN heterojunction, ${ }^{\mathbf{1 4 0}} \mathrm{NiO} /$ $\mathrm{ZnO}$ heterojunction, ${ }^{\mathbf{1 4 1}} \mathrm{ZnO} / \mathrm{GaN}$ heterojunction, ${ }^{\mathbf{1 4 2}} \mathrm{ZnS}-\mathrm{ZnO}$ heterojunction, ${ }^{\mathbf{1 4 3 - 1 4 6}} \mathrm{p}-\mathrm{GaN} / \mathrm{n}-\mathrm{ZnO}$ NRs heterojunction, ${ }^{\mathbf{1 4 7}} \mathrm{ZnO}$ $\mathrm{NR} /$ graphene heterostructure, ${ }^{\mathbf{1 4 8}}$ and ZnO NP-graphene coreshell heterostructure. ${ }^{149}$ Unlike homojunctions, photogenerated electrons and holes are separated by internally generated and externally applied electric fields under UV illumination. Hence, the selection of the semiconductor material to form heterojunctions with $\mathrm{ZnO}$ is important, which defines the strength of the internal electric field. As shown in Fig. 8a (device schematic), Tsai and co-authors reported p-type NiO with n-type ZnO for a $\mathrm{p}-\mathrm{NiO} / \mathrm{n}-\mathrm{ZnO}$ heterojunction UV PD. ${ }^{150}$ The energy band diagram of the respective $\mathrm{p}-\mathrm{NiO} / \mathrm{n}-\mathrm{ZnO}$ heterojunction is illustrated in Fig. 8b, confirming the generation of a built-in electric field due to the Fermi level alignment. Diode-like characteristics (Fig. 8c, $I-V$ ) with a leakage current of $6.64 \times 10^{-8} \mathrm{~A} \mathrm{~cm}^{-2}$ were obtained in the PD. Upon UV illumination on the PD, the current increased in both the forward and reversed bias directions and the current sensitivity of 11.56 was measured at a reverse bias voltage of $-1 \mathrm{~V}$. No additional photodetection parameters for the heterojunction $\mathrm{PD}$ were reported by the authors. Tian and co-authors fabricated a $\mathrm{ZnO}$ and $\mathrm{SnO}_{2}(\mathrm{n}-\mathrm{n})$ heterojunction $\left(\mathrm{ZnO} / \mathrm{SnO}_{2}\right) \mathrm{UV} \mathrm{PD}$, as illustrated Fig. 8d (energy band diagram). ${ }^{151}$ It can be seen from the schematic (Fig. $8 \mathrm{~d}$ ) that the photogenerated holes move from $\mathrm{SnO}_{2}$ to $\mathrm{ZnO}$ and electrons from $\mathrm{ZnO}$ to $\mathrm{SnO}_{2}$ due to the internal built-in electric field, which facilitates the overall photoconduction process upon exposure to UV illumination. As shown in Fig. 8e, the typical $I-V$ profiles recorded with and without light illumination ( 250 to $400 \mathrm{~nm}$ ) showed photoconduction behavior. Under UV light illumination of $300 \mathrm{~nm}\left(0.45 \mathrm{~mW} \mathrm{~cm}^{-2}\right.$ intensity) on the $\mathrm{PD}$, the current increased from $1.7 \mathrm{pA}$ to $7.9 \mathrm{nA}(\sim 4600$ times enhancement) at a bias voltage of $10 \mathrm{~V}$. Likewise, effective increments in the current were reported when the PD was exposed to light sources of $250 \mathrm{~nm}, 280 \mathrm{~nm}, 320 \mathrm{~nm}$ and $350 \mathrm{~nm}$. The highest sensitivity of $\sim 5 \times 10^{3}$ was measured upon exposure to $300 \mathrm{~nm}$ wavelength on the $\mathrm{PD}$ due to the highest light power intensity. Moreover, the PD showed a sensitive response upon exposure to $400 \mathrm{~nm}$ light having energy below than the band gaps of $\mathrm{ZnO}$ and $\mathrm{SnO}_{2}$, which was mainly due to the possible transition of carriers from the defect states to the CB. As shown in Fig. 8f, the spectroscopic photoresponse and inset (absorption spectrum) of the PD confirmed its UV sensitive photoresponse with an exhibited threshold excitation energy of $3.6 \mathrm{eV}$, which is close to the bandgap energy of the $\mathrm{ZnO} / \mathrm{SnO}_{2}$ heterojunction. The measured photodetection speed for the $\mathrm{ZnO} / \mathrm{SnO}_{2}$ heterojunction $\mathrm{PD}$ was $32.2 \mathrm{~s}$ (response time) and $7.8 \mathrm{~s}$ (recovery time). Likewise, Fang's group fabricated a $\mathrm{ZnS} / \mathrm{ZnO}$ biaxial NB based high-performance UV PD, ${ }^{152}$ where efficient photodetection performances were measured in the $\mathrm{ZnS} / \mathrm{ZnO}$ heterostructure compared to the pure $\mathrm{ZnS}$ or $\mathrm{ZnO}$ nanostructures due to the internal built-in electric field. The authors reported the a wide-range UV-A light photoresponse in the wavelength range from around 200 to $380 \mathrm{~nm}$, ultra-high responsivity of $5.0 \times 10^{5} \mathrm{~A} \mathrm{~W}^{-1}$ at a bias voltage of $5 \mathrm{~V}$, and response time of $<0.3 \mathrm{~s}$ and recovery time of $1.5 \mathrm{~s}$. Therefore, it 

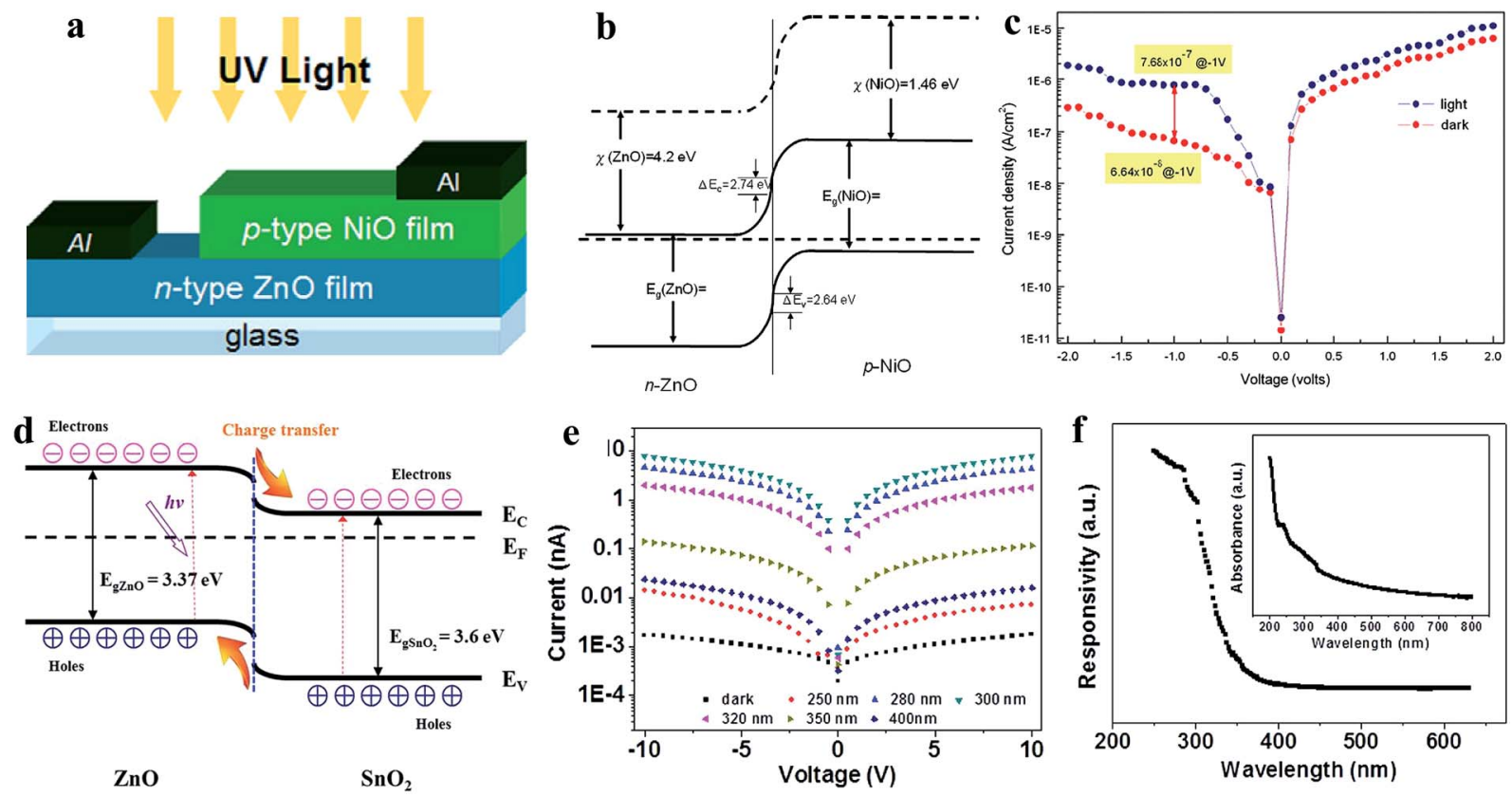

Fig. 8 Transparent $\mathrm{p}-\mathrm{NiO} / \mathrm{n}-\mathrm{ZnO}$ heterojunction PD: (a and b) schematic illustration of $\mathrm{p}-\mathrm{NiO} / \mathrm{n}-\mathrm{ZnO}$ heterojunction PD and the respective energy band diagram, respectively. (c) $\mathrm{J}-\mathrm{V}$ characteristics of the $\mathrm{p}-\mathrm{NiO} / \mathrm{n}-\mathrm{ZnO}$ heterojunction PD recorded before and after exposure to UV illumination. Reproduced with permission from ref. 150 Copyright 2011 Elsevier. $\mathrm{ZnO}-\mathrm{SnO}_{2}$ heterojunction PD: (d and e) energy band diagram and $I-V$ profiles of the $\mathrm{ZnO}-\mathrm{SnO}_{2}$ heterojunction $\mathrm{PD}$ in both the absence and presence of light illumination of different wavelengths (250 to 400 $\mathrm{nm}$ ), respectively. (f) Spectroscopic photoresponse profile at a bias voltage of $5 \mathrm{~V}$ and inset depicts the absorption spectrum. Reproduced with permission from ref. 151 Copyright 2013 WILEY-VCH.

can be concluded that junction-based UV PDs show a higher photodetection performance compared to their pristine counterparts due to synergistic effects and generated internal electric fields.

As mentioned earlier, ZnO displays a piezoelectric effect due to its noncentral-symmetric crystal structure, where $1 \mathrm{D} \mathrm{ZnO}$ nanomaterials show a higher piezoelectric response due to their $c$-axis orientation. Under external force/strain, piezoelectric potentials are generated across $1 \mathrm{D}$ nanomaterials, which can be considered to control photogenerated charge carrier separation, transportation, generation and recombination. ${ }^{153-155}$ Therefore, currently, the piezoelectric effect is considered an additional advantage of $\mathrm{ZnO}$, which helps in tuning the photoconductivity of PDs. Wang's group developed a $\mathrm{ZnO} / \mathrm{ZnS}$ heterojunction core/ shell NW PD, where the piezo-phototronic effect was introduced for photoresponse enhancement. ${ }^{156}$ As illustrated in Fig. 9a, $\mathrm{ZnO} / \mathrm{ZnS}$ core/shell NWs were directly grown on an ITO-coated glass substrate, then an $\mathrm{Ag} /$ polyester zigzag electrode was connected on top of the NWs and external compressive loads were applied from the Ag/polyester zigzag electrode, where UV illuminated the ITO substrate. The as-fabricated PD displayed a highly sensitive response to UV $(385 \mathrm{~nm})$, blue and green illumination, as depicted in Fig. 9b ( $I-V$ responses). It was concluded that under light illumination, with photon energy smaller than the band gaps of $\mathrm{ZnO}$ and $\mathrm{ZnS}$, indirect type-II transitions of electrons from the $\mathrm{VB}(\mathrm{ZnO})$ to $\mathrm{CB}(\mathrm{ZnS})$ take place at the interface of the $\mathrm{ZnO}$ core and $\mathrm{ZnS}$ shell. Moreover, the authors enhanced the photoconduction performance of the PD by coupling the piezo-phototronic effect, which facilitated the lowering of the barrier height across the $\mathrm{ZnO} / \mathrm{ZnS}$ interface for easy charge carrier transportation, and hence an increase in current with an increase in external load (Fig. 9c, $I-V$ curves at different loads ranging from 0.05 to $0.4 \mathrm{~kg}$ force (kgf) under UV illumination of $1.32 \mathrm{~mW} \mathrm{~cm}^{-2}$ intensity). A large enhancement of $\sim 31$ times in the peak photocurrent at $0.4 \mathrm{kgf}$ was reported compared to that in the absence of a load under exposure to UV illumination. Similar responses of $\sim 18$ times for blue ( $465 \mathrm{~nm}$, $\left.3 \mathrm{~mW} \mathrm{~cm}{ }^{-2}\right)$ and $\sim 19$ times for green $\left(520 \mathrm{~nm}, 3.2 \mathrm{~mW} \mathrm{~cm}^{-2}\right)$ excitation were reported in the presence of an external load. The calculated responsivities at $0.4 \mathrm{kgf}$ compressive load under exposure to $385 \mathrm{~nm}\left(1.32 \mathrm{~mW} \mathrm{~cm}^{-2}\right), 465 \mathrm{~nm}\left(3 \mathrm{~mW} \mathrm{~cm}^{-2}\right)$ and $520 \mathrm{~nm}\left(3.2 \mathrm{~mW} \mathrm{~cm}^{-2}\right)$ illumination were $2.5 \mathrm{~A} \mathrm{~W}^{-1}, 0.54 \mathrm{~A} \mathrm{~W}^{-1}$ and $0.13 \mathrm{~A} \mathrm{~W}^{-1}$, respectively at a bias voltage of $1.5 \mathrm{~V}$, which are nearly an order of magnitude higher than that with no load. Fig. $9 \mathrm{~d}$ shows the comparative change in the responsivity $\left(\left(R_{\text {Load }}\right.\right.$ $\left.-R_{\mathrm{o}} / R_{\mathrm{o}}\right) \times 100 \%$, where $R_{\mathrm{Load}}$ and $R_{\mathrm{o}}$ are the responsivities with and without load, respectively) plots with respect to the applied compressive load, which increased with an increase in the external load due to the increase in the piezo-phototronic effect. The associated piezo-phototronic effect can be explained from the schematic diagrams in Fig. 9e, where (i) and (ii) are the band diagrams of the PD before and after bend alignment, respectively. The direct band to band and indirect type-II transitions of electrons under exposure to light in the absence of an external load are depicted in Fig. 9e(iii). As shown in Fig. 9e(iv), the generation of piezopotentials across the ZnO NRs led to band bending for efficient charge carrier transportation across the 

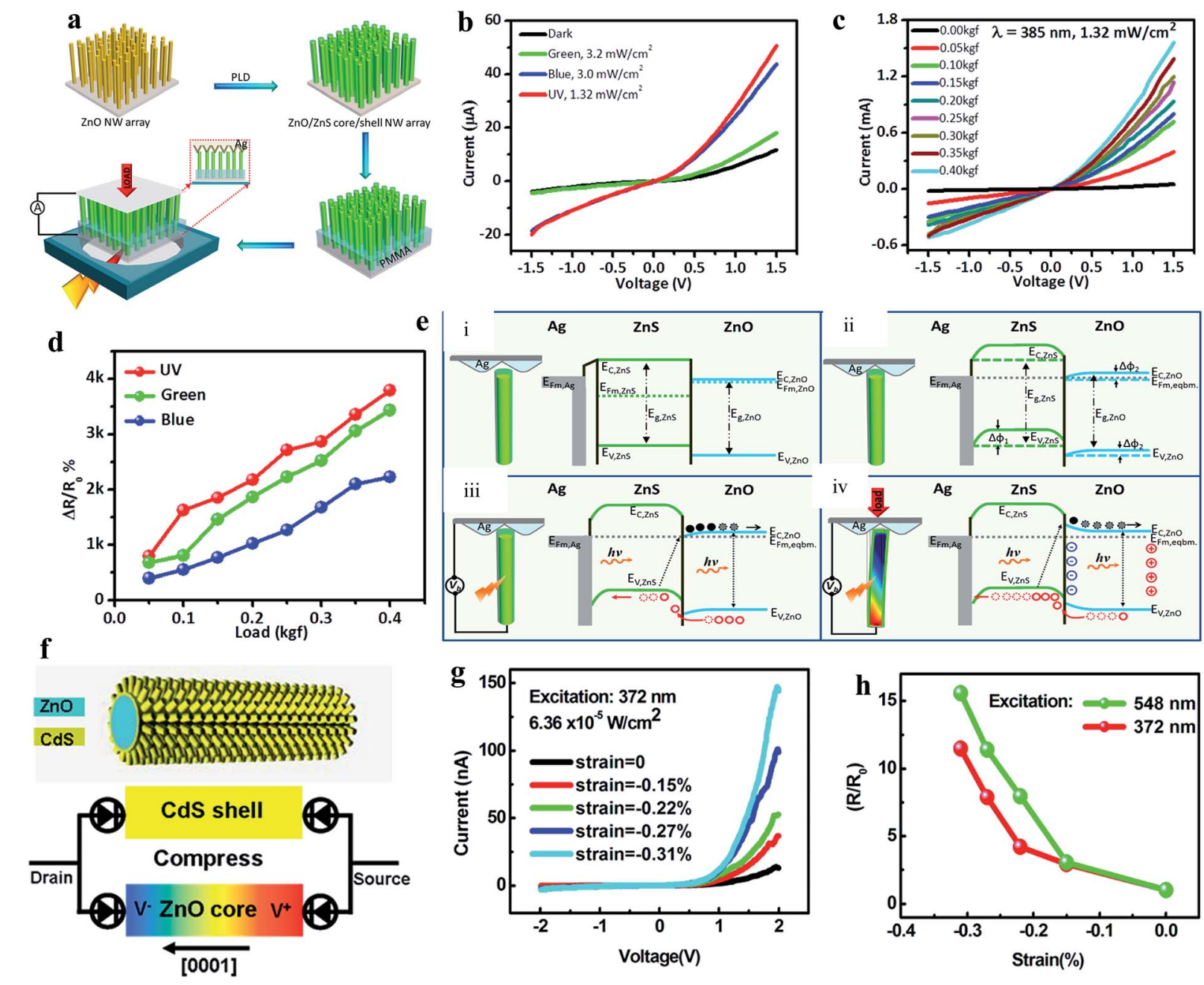

Fig. $9 \mathrm{ZnO} / \mathrm{ZnS}$ heterojunction core/shell NWs PD: (a) schematic illustration of the processes involved in fabrication of the $\mathrm{ZnO} / \mathrm{ZnS}$ core/shell NWs PD. (b) I-V responses measured before and after exposure to green, blue and UV light. (c) I-V profiles at a fixed exposure to UV light of intensity of $1.32 \mathrm{~mW} \mathrm{~cm}^{-2}$ at different compressive loads. (d) Change in responsivity with respect to compressive load under light illumination. (e) Photoconduction mechanism of the PD under compressive load: (i) and (ii) are the energy band diagrams of the Ag/ZnS/ZnO interface before and after the alignment of the Fermi levels, respectively. (iii) and (iv) are the schematics of the direct band-to-band and indirect type-II transitions of electrons from the VB to CB under light illumination in the absence and presence of compressive strain, respectively. In the presence of compressive strain together with light illumination, piezopotential-induced band bending occurs across the $\mathrm{ZnO} / \mathrm{ZnS}$ interface. Reproduced with permission from ref. 156 Copyright 2015 American Chemical Society. ZnO/CdS core-shell micro/NWs: (f) 3D structure representation of a $\mathrm{ZnO} / \mathrm{CdS}$ core-shell wire (top schematic) and the respective proposed sandwich model of the PD composed of two back-to-back Schottky diodes integrated into a $\mathrm{ZnO}$ core and $\mathrm{CdS}$ shell structure under compressive strain (bottom schematic). (g) I-V responses of the PD at different compressive strains in the presence of UV. (h) Change in responsivity with respect to compressive strain under exposure to green light (548 nm) and UV light ( $372 \mathrm{~nm}$ ), where $R$ and $R_{0}$ are the responsivities with and without compressive strain, respectively. Reproduced with permission from ref. 157 Copyright 2012 American Chemical Society.

$\mathrm{ZnO} / \mathrm{ZnO}$ interface under illumination in the presence of external compressive strain.

Zhang and co-authors fabricated piezo-phototronically modulated a $\mathrm{ZnO} / \mathrm{CdS}$ core-shell micro/NW-based PD, as illustrated in Fig. 9f (top schematic), and the bottom schematic shows the proposed model of the PD integrated with back-toback Schottky diodes under compressive strain. ${ }^{\mathbf{1 5 7}}$ Remarkably, the photoconduction of the PD increased with an increase in compressive strain under steady state UV illumination $(372 \mathrm{~nm}$, $6.36 \times 10^{-5} \mathrm{~W} \mathrm{~cm}^{-2}$ ) (Fig. 9g). It was found that the photocurrent of the $\mathrm{PD}$ increased from 12.9 to $144 \mathrm{nA}$ when the strain increased to $-0.31 \%$ at a positive bias voltage of $2.0 \mathrm{~V}$. A similar response was also noticed when the $\mathrm{PD}$ was illuminated by green light ( $548 \mathrm{~nm}, 1.43 \times 10^{-3} \mathrm{~W} \mathrm{~cm}^{-2}$ ). As depicted in Fig. 9h, with the change in responsivity with compressive strain under both green and UV light illumination, nearly more than 10 times enhancement in the responsivity of the PD was measured under $-0.31 \%$ strain compared to that in the unstrained condition. Moreover, Luo and coauthors fabricated a p-NiO/n-ZnO type piezo-phototronic-based UV PD, and the recovery time of the $\mathrm{PD}$ was notably improved through modulation of its piezopotentials. ${ }^{158} \mathrm{An} \mathrm{Au}-\mathrm{MgO}-\mathrm{ZnO}$ NW piezo-phototronic-based UV PD was reported by Zhang's group. ${ }^{159}$ They effectively enhanced the sensitivity of the PD by controlling the piezo-phototronic effect. 
Likewise, a number of piezo-phototronic-based UV PDs have been reported, for instance, $\mathrm{ZnO}-\mathrm{Ga}_{2} \mathrm{O}_{3}$ core-shell heterojunction microwire, ${ }^{\mathbf{1 6 0}} \mathrm{CuI} / \mathrm{ZnO}$ double-shell nanostructure, ${ }^{\mathbf{1 6 1}}$ $\mathrm{ZnO} / \mathrm{NiO}$ core/shell $\mathrm{NRs},{ }^{162} \mathrm{ZnO}$ microwire, ${ }^{163}$ and $\mathrm{ZnO} / \mathrm{Cu}_{2} \mathrm{O}$ heterojunction ${ }^{\mathbf{1 6 4}}$ to enhance the overall photoconductivities.

It needs to be noted that in the last few years, incredible research progress has been made in conventional $\mathrm{ZnO}$ nanostructure UV PDs, and Table 2 summarizes some of the highperformance conventional UV PDs.

\subsection{Self-powered UV photodetectors}

In a conventional UV PD, an external driving force needs to be applied for the separation and transportation of photogenerated electrons and holes for photoconduction. Hence, conventional UV PDs sometimes consume a large amount of energy and reduced lifetime due to the generation of internal heat in the presence of an external bias voltage. It has been realized that junction-based PDs generate internal built-in electric fields, which effectively participate in $\mathrm{e}^{-}-\mathrm{h}^{+}$pair separation and transportation without any external driving force (self-powered). ${ }^{9}$ Thus, significant research has been devoted towards the fabrication of self-powered UV PDs in the modern scientific community. Self-powered UV PDs have additional advantages such as extremely low power consumption, resolve unnecessary energy-related issues and reduce the overall size of PDs over conventional PDs. Moreover, self-powered PDs display a faster photoconduction performance due to the quick separation and transportation of photogenerated electrons and holes by their internal built-in electric field under UV illumination.

3.2.1 Schottky junction-based self-powered UV photodetectors. ZnO Schottky junctions have been introduced for selfpowered UV PDs, where the generated internal built-in electric field across the junctions allow charge separation and conduction in the absence of a bias voltage. Zhang's group fabricated a single Sb-doped $\mathrm{ZnO}$ nanobelt bridging an ohmic contact (Ag) and a Schottky contact (Au) PD for self-powering. ${ }^{46}$ The as-reported PD showed a self-powered photodetection performance, and upon exposure to UV illumination, the current increased from 1 to $23 \mathrm{nA}$ in the absence of a bias voltage. $\mathrm{Sb}$ doping in $\mathrm{ZnO}$ introduces a high donor impurity density, which increases the electric field strength, resulting in an enhancement in self-powering performance. This PD displayed a much faster photodetection speed of less than $100 \mathrm{~ms}$. Duan and co-authors reported a graphene and ZnO:Al NR array-film (AZNF) (graphene/AZNF) Schottky junction for application in self-powered UV PDs. ${ }^{187}$ As shown in Fig. 10a (device schematic), an $\mathrm{ZnO}$ :Al seed layer was first sputtered on an $\mathrm{Al}$ substrate for the growth of vertically aligned pristine $\mathrm{ZnO}$ NWs. Thereafter, graphene was transferred on top of the NRs and the PD fabricated by depositing an Au electrode on the edge of graphene. For an efficient self-powering performance, the as-synthesized AZNF was surface treated (T-AZNF) and pristine graphene (PG) was doped (DG) with $\mathrm{Au}^{3+}$ to control the Schottky junction height. Fig. $10 \mathrm{~b}$ and c show the $I-V$ profiles of the PDs in the dark and UV (365 nm) states, and it was found that as-fabricated DG/T-AZNF PD displayed good rectifying behavior, having a lower leakage current of $6.2 \times 10^{-3} \mathrm{~mA}$ at $-1 \mathrm{~V}$ compared to $1.3 \times 10^{-1} \mathrm{~mA}$ for the DG/AZNF device, while the PG/T-AZNF device displayed linear non-rectifying behavior. However, upon exposure to UV illumination, the DG/AZNF device displayed an unstable Schottky barrier, while the DG/T-AZNF device maintained good rectifying behavior (Fig. 10c), which resulted in stable self-powered photodetection (Fig. 10d, cyclic photoresponses at different UV illumination intensities at zero bias voltage). The measured responsivity and photodetection speed of the DG/T-AZNF PD were $0.04 \mathrm{~A} \mathrm{~W}^{-1}, 37 \mu$ s (response time) and $330 \mu$ s (recovery time), respectively. Fig. 10e shows the formation of a Schottky junction having barrier height of $1.03 \mathrm{eV}$ in between DG and the AZNF interface.

Likewise, asymmetric Schottky junction-based self-powered UV PDs were reported by Chen and co-authors, where $\mathrm{Au}$ asymmetric electrodes were introduced to control the charge carrier transportation. ${ }^{188}$ Fig. 10 f shows schematic diagrams of the fabricated devices having different asymmetric Au electrode width ratios (width of wide fingers : width of narrow fingers), including $20: 1$ (S1), $10: 1$ (S2), $4: 1$ (S3), $2: 1$ (S4) and $1: 1$ (S5). Fig. $10 \mathrm{~g}$ shows the photoconduction measurement configuration (left schematic) and optical image of the respective PDs (right image). The $I-V$ characteristics of the PDs with and without UV illumination are depicted in Fig. 10h and i, confirming their rectifying behaviors. It can be observed from the results that with an increase in asymmetric ratio from S5 to $\mathrm{S} 1$, the $I-V$ asymmetricity between the positive and negative voltage increased due to the increase in the asymmetric Schottky barrier width in both the absence and presence of UV illumination. The authors reported efficient self-powered photoconduction responses in the S1 PD, which were $\sim 20 \mathrm{~mA} \mathrm{~W}^{-1}$ responsivity, $\sim 710 \mathrm{~ns}$ response time and $\sim 4 \mathrm{~ms}$ recovery time, where the S3-S5 PDs showed relatively negligible self-powered responses due to their nearly back-to-back symmetric Schottky barrier width. The self-powered working mechanism of S1 can be explained by the energy band diagrams before and after UV illumination (Fig. 10j and k, respectively). Upon exposure to UV illumination, electrons and holes are photogenerated (Fig. 10k, top schematic) and due to the asymmetrical width of the Au electrodes, an asymmetric electric potential distribution occurs, where the generated carriers become separated and transported by the potentials at zero bias voltage (Fig. 10k, bottom schematic).

Similar to that in piezo-phototronic-based conventional UV PDs, the piezo-phototronic effect of $\mathrm{ZnO}$ was coupled to enhance the performance of self-powered PDs. The generated piezopotentials across $\mathrm{ZnO}$ allow the separation and transportation of photogenerated electrons and holes, which boost the selfpowered photoconduction of PDs. A ZnO/Au Schottky junctionbased self-powered UV PD was explored by Zhang's group, ${ }^{189}$ where its self-powered photodetection performance was improved by applying an external strain. Fig. 11a depicts the optical image (top) and schematic representation of the fabricated $\mathrm{ZnO} / \mathrm{Au} \mathrm{PD}$ on a flexible polystyrene substrate. As shown in Fig. 11b, the typical $I-V$ characteristics (in linear and log scales) 

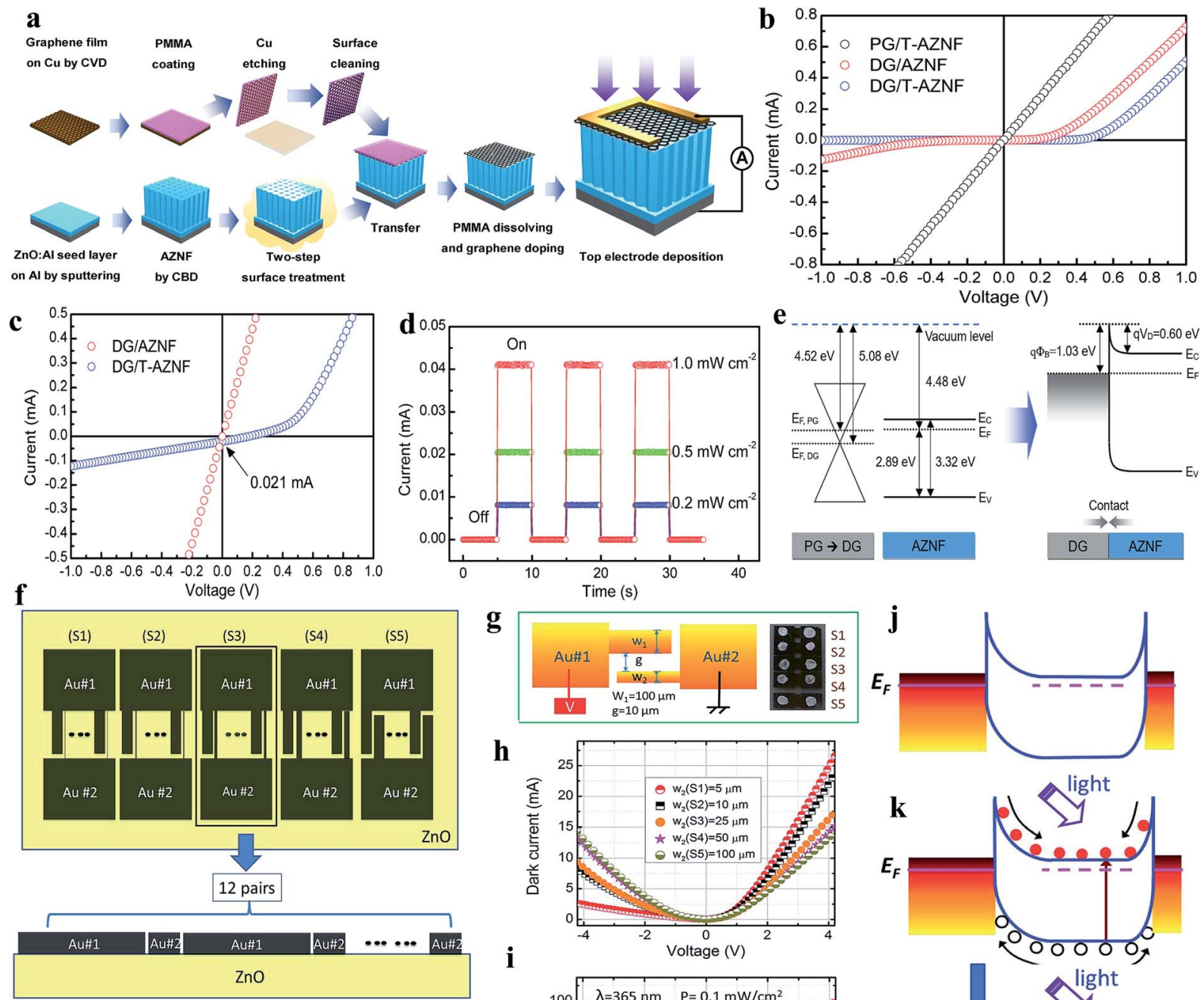

g
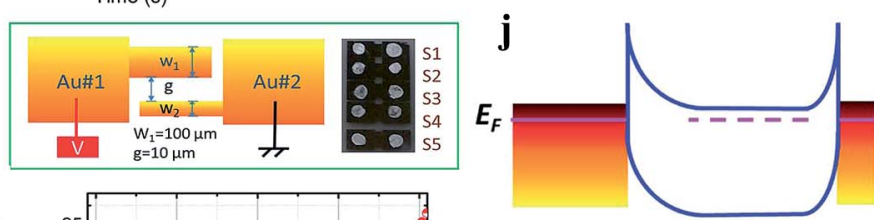

h
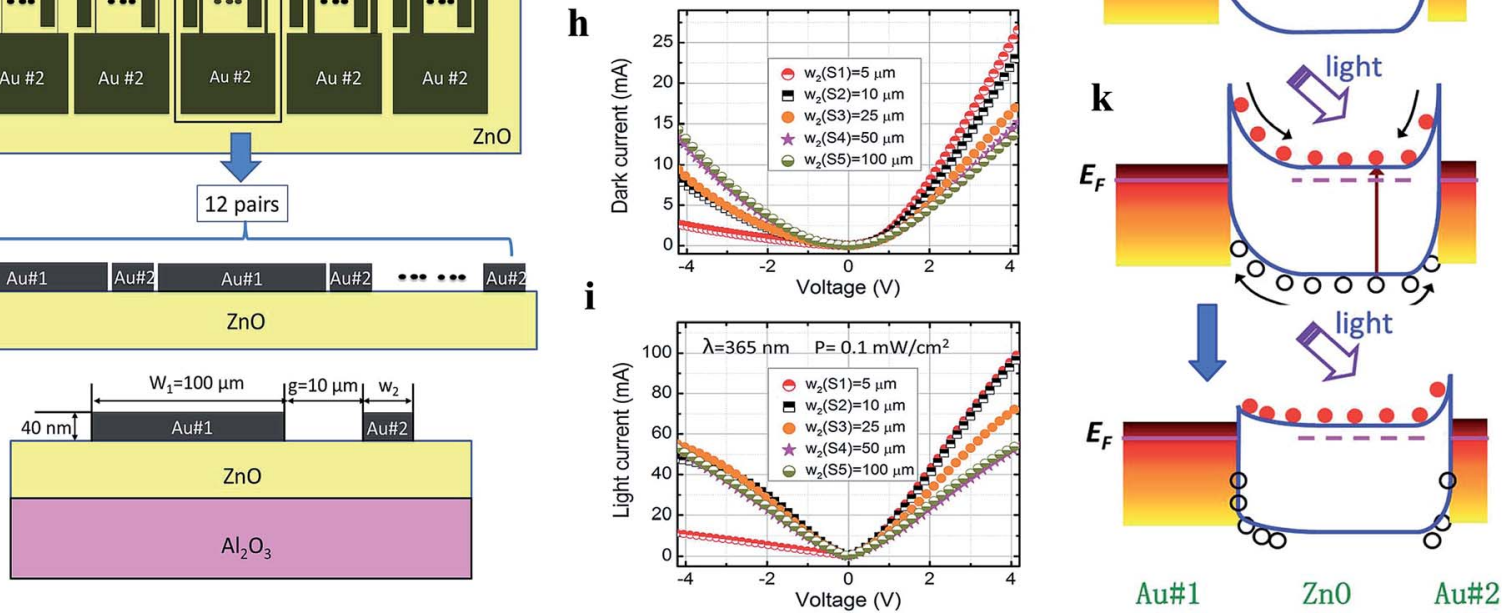

Fig. 10 (a) Schematic representation of the processes involved in the fabrication of graphene/AZNF PD. (b and c) $I-V$ characteristics of graphene/AZNF PDs in dark and UV conditions. (d) Cyclic photoresponses of the DG/T-AZNF PD at zero bias voltage under different UV illumination intensities $\left(0.2\right.$ to $1 \mathrm{~mW} \mathrm{~cm}{ }^{-2}$ ). (e) Schematic illustration of the energy band diagram of the DG/AZNF Schottky junction. Reproduced with permission from ref. 187 Copyright 2017 American Chemical Society. Asymmetric Schottky junctions: (f) schematic diagram of ZnO self-powered PDs having asymmetric electrodes. (g) Schematic demonstration of the photoresponse measurement configuration (left schematic) and the optical image of the PDs with different electrode dimensions (right image). (h and i) I-V characteristics in both the absence and presence of UV illumination (365 nm). ( $\mathrm{j}$ and $\mathrm{k}$ ) Energy band diagrams of the PD in dark and UV illumination conditions at zero bias voltage. Reproduced with permission from ref. 188 Copyright 2014 Royal Society of Chemistry.

confirmed the rectifying barrier between $\mathrm{ZnO}$ and $\mathrm{Au}$, having an ideality factor of about 3.04. It was reported that with an increase in strain from 0 to $0.580 \%$, the self-powered photoconduction of the PD increased due to the increase in piezopotential, as depicted in Fig. 11c (cyclic photoresponses at different tensile strains), where Fig. 11d illustrates the photocurrent versus strain plot. At an applied tensile strain of $0.580 \%$, nearly $440 \%$ enhancement in the photocurrent and five times improvement in sensitivity were measured compared to that with zero strain (Fig. 11e). The enhanced photoconduction of the PD under external tensile strain can be explained from the schematic shown in Fig. 11f (device schematic and bend diagram under tensile strain). Under an external tensile strain, enhancement and expansion of the built-in field occur at the $\mathrm{ZnO} / \mathrm{Au}$ interface, which directly participates in the photoexcited separation and extraction to increase the self-powered photoconduction. 

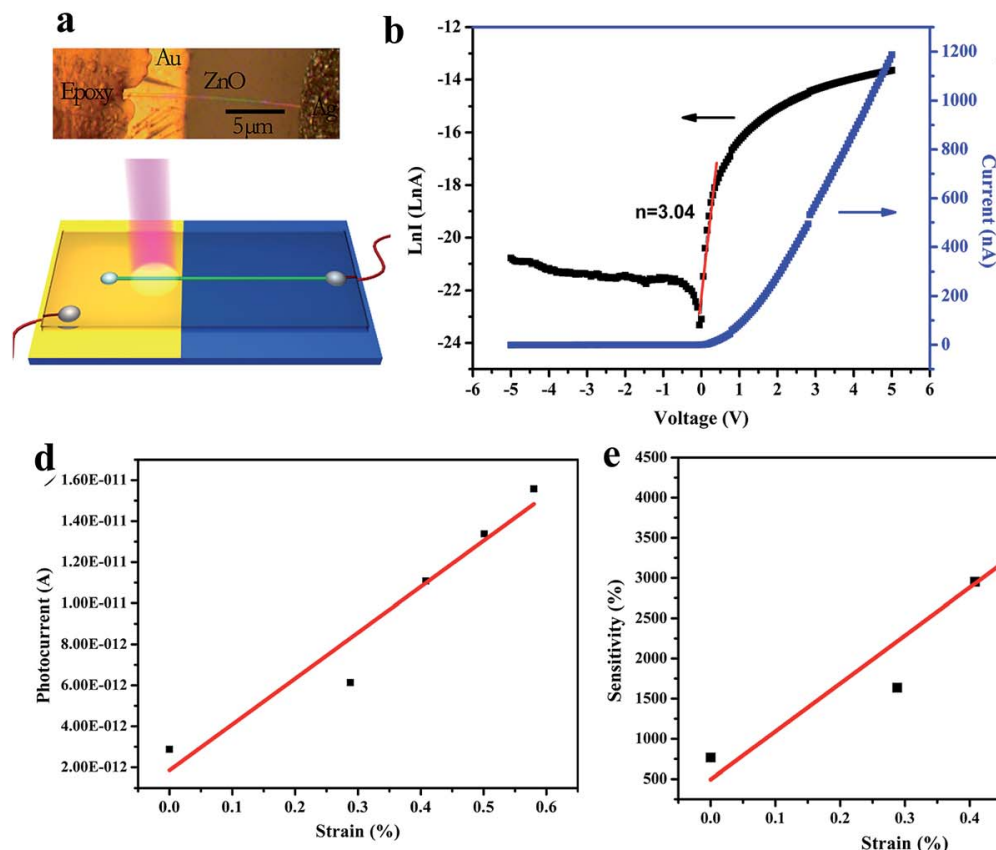

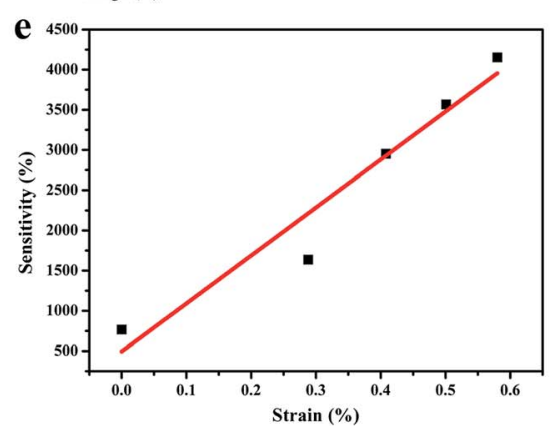

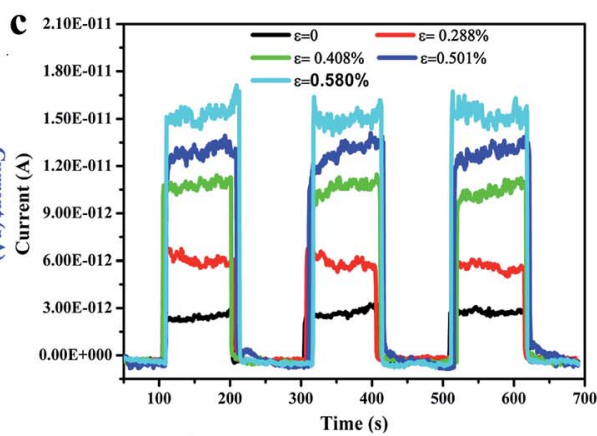

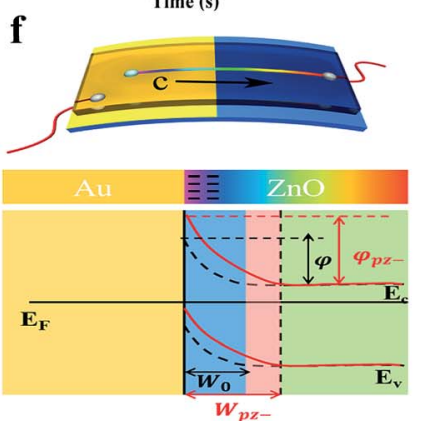

Fig. 11 ZnO/Au Schottky junction: (a) optical image (top) and respective schematic of the ZnO/Au PD. (b and c) I-V characteristics (linear and log scales) and cyclic photoresponses at different tensile strains applied on the PD, respectively. ( $d$ and e) Photocurrent and sensitivity plots with respect to applied tensile strain, respectively. (f) Device schematic (top schematic) and the respective energy band diagram (bottom schematic) under tensile strain. Solid red and dotted black curves represent the energy band diagrams with and without tensile strain. $W$ and $\varphi$ represent the depletion region width and Schottky barrier height, respectively. Reproduced with permission from ref. 189 Copyright 2014 American Chemical Society.

\subsection{2 p-n junction-based self-powered UV photodetectors}

3.2.2.1 Inorganic homojunction/heterojunction-based selfpowered UV photodetectors. In a $\mathrm{p}-\mathrm{n}$ junction self-powered UV PDs, the generation of a built-in electric field occurs due to spontaneous electron and hole diffusion. The generated internal built-in electric field at the $\mathrm{p}-\mathrm{n}$ junction interface is beneficial for the separation and transportation of photogenerated electrons and holes under UV illumination in the absence of an external driving force. Hence, the overall selfpowered photoconduction is determined by the generated internal built-in electric field. Fig. 12a shows the SEM image of the $\mathrm{n}-\mathrm{ZnO} \mathrm{NW} / \mathrm{p}-\mathrm{GaN}$ junction self-powered UV PD reported by Bie and coauthors. ${ }^{190}$ The typical $I-V$ profiles (Fig. 12b) of the PD in the dark and UV (325 nm) states confirm its rectifying behavior, having a threshold voltage of $\sim 3 \mathrm{~V}$, open-circuit voltage of $\sim 2.7 \mathrm{~V}$ and short-circuit current of $\sim 2 \mu \mathrm{A}$. Upon exposure to UV illumination, the current of the PD increased from $\sim 1$ pA to $2 \mu \mathrm{A}$ at zero bias voltage due to the photovoltaic effect. Fig. 12c depicts the cyclic photoresponses of the PD measured with UV illumination turned on and off periodically at zero bias voltage, where an outstanding sensitivity $\sim 10^{6}$ together with a much faster photodetection speed of $\sim 20 \mu \mathrm{s}$ response time and $\sim 219 \mu$ s recovery time were reported by the authors. Zhang's group fabricated a p-NiO/n-ZnO NRs selfpowered UV PD (Fig. 12d, device schematic). ${ }^{191}$ A significant enhancement in the current was observed upon exposure to UV illumination (355 $\mathrm{nm}$ ) at zero bias voltage (Fig. 12e, $I-V$ characteristics in both the dark and UV states) and Fig. $12 \mathrm{f}$ shows its photoresponses at different UV illumination intensities in the absence of a bias voltage. The authors measured a reasonable photodetection speed with a response time of $0.23 \mathrm{~s}$ and recovery time of $0.21 \mathrm{~s}$, together with a maximum responsivity of $0.44 \mathrm{~mA} \mathrm{~W}^{-1}$ at the UV illumination intensity of $0.4 \mathrm{~mW} \mathrm{~cm}^{-2}$ in the absence of an external bias voltage. Likewise, different $\mathrm{ZnO}$ $\mathrm{p}-\mathrm{n}$ junctions such as p-CuSCN/n-ZnO NWs, ${ }^{192} \mathrm{p}-\mathrm{ZnO}:(\mathrm{Li}, \mathrm{N}) / \mathrm{n}-$ ZnO homojunction, ${ }^{193} \mathrm{p}-\mathrm{Se} / \mathrm{n}$-ZnO hybrid structure, ${ }^{194} \mathrm{Te} / \mathrm{TiO}_{2}$ and $\mathrm{Te} / \mathrm{ZnO}$ heterojunctions ${ }^{\mathbf{1 9 5}}$ devices have been explored for self-powered UV PD application.

Recently, the development of transparent and self-powered UV PDs has been given significant attention in the scientific community, where Fang group's has been focusing on the fabrication of transparent and self-powered UV PDs. For instance, a homojunction of n-type $\mathrm{ZnO}$ and Ag-doped p-type $\mathrm{ZnO}$ nanofibers was reported for application in transparent and self-powered UV PDs. ${ }^{196}$ Fig. 13a shows the simulated electric field distribution around the three electrode collectors applied for the alignment of the as-prepared nanofibers (left image) and the electrospinning system for nanofiber synthesis (right image). The optical images of the aligned nanofibers and asfabricated transparent and self-powered UV PDs are depicted in Fig. 13b and c, respectively. The authors observed that the doping of $\mathrm{Ag}$ on $\mathrm{ZnO}$ not only reduced the photoresponse time but also transformed the n-type $\mathrm{ZnO}$ to $\mathrm{p}$-type conductivity for the direct fabrication of homojunction-based self-powered PDs, where Fig. 13d shows the $\mathrm{p}-\mathrm{n}$ junction type $I-V$ characteristics in both the absence and presence of UV illumination $(360 \mathrm{~nm}$, $2.5 \mathrm{~mW} \mathrm{~cm}^{-2}$ ). It can be observed from the $I-V$ characteristics that the fabricated PD exhibited a clear rectification nature and 

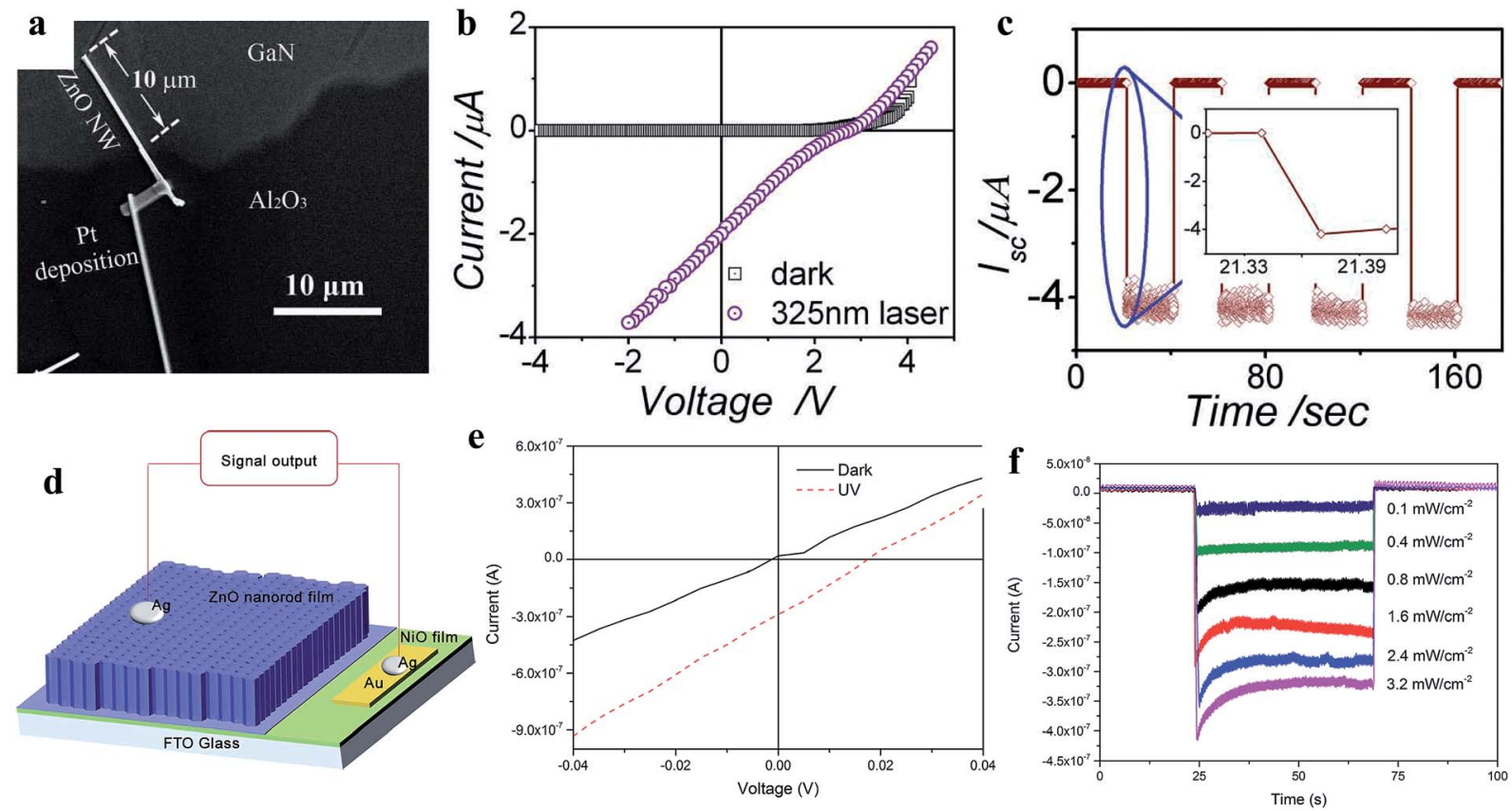

Fig. $12 \mathrm{ZnO} / \mathrm{GaN}$ junction self-powered PD: (a and b) SEM image of $\mathrm{n}-\mathrm{ZnO} \mathrm{NW} / \mathrm{p}$-GaN junction and the respective $/-V$ profiles under dark and UV illumination conditions, respectively. (c) Cyclic short circuit current-time response of the PD in the absence of a bias voltage with a $325 \mathrm{~nm}$ laser turned on and off repeatedly. Reproduced with permission from ref. 190 Copyright 2011 WILEY-VCH. p-NiO/n-ZnO NRs junction: (d and e) device schematic and I-V profiles before and after exposure to UV light. (f) Variation in current with respect to UV illumination intensity at zero bias condition. Reproduced with permission from ref. 191 Copyright 2015 Royal Society of Chemistry.

photovoltaic effect with an open circuit voltage of $0.55 \mathrm{~V}$, short circuit current of $5.0 \times 10^{-10} \mathrm{~A}$, and sensitivity of nearly $2.5 \times$ $10^{4}$ at zero bias voltage condition, which imply that the fabricated PD can be operated in the absence of an external bias voltage (Fig. 13e depicts the cyclic photoresponse at zero bias). Moreover, the authors reported a response time and recovery time of $3.90 \mathrm{~s}$ and $4.71 \mathrm{~s}$, respectively, and responsivity of nearly $1 \mathrm{~mA} \mathrm{~W}^{-1}$ in the absence of an external bias voltage.

Likewise, the same group extended their study to the fabrication of transparent and self-powered UV PDs based on $\mathrm{ZnO} /$ NiO heterojunction nanofiber arrays. ${ }^{197}$ As shown in Fig. 13f, the $I-V$ profiles of the $\mathrm{ZnO} / \mathrm{NiO}$ heterojunction $\mathrm{PD}$ (inset image) in the dark and UV states imply rectification $\mathrm{p}-\mathrm{n}$ junction behavior with a photovoltaic effect, where the respective energy band diagram is depicted in Fig. 13g. Under exposure to UV illumination ( $350 \mathrm{~nm}, 0.753 \mathrm{~mW} \mathrm{~cm}{ }^{-2}$ ), the photogenerated electrons are driven towards $\mathrm{ZnO}$; whereas, the holes move to $\mathrm{NiO}$ due to the internal built-in electric field at the interface to generate a photocurrent of $50 \mathrm{pA}$ in the absence of an external bias. Fig. 13h shows the estimation of response time and recovery time of the transparent and self-powered UV PDs, which are around $7.5 \mathrm{~s}$ and $4.8 \mathrm{~s}$, respectively. In addition, the PD showed a maximum responsivity of $0.415 \mathrm{~mA} \mathrm{~W}^{-1}$ at $0 \mathrm{~V}$ bias voltage condition. However, negligible photoresponses of pristine $\mathrm{ZnO}$ and $\mathrm{NiO}$ were observed when the photoresponses were measured in absence of an external bias voltage (Fig. 13i), which implies that the internal built-in electric field needs to drive the photogenerated electrons and holes internally for self-powered photoconduction.
3.2.2.2 Inorganic-organic heterostructure-based self-powered UV photodetectors. Similar to inorganic homojunctions/ heterojunction $\mathrm{p}-\mathrm{n}$ type self-powered PDs, the organic-inorganic heterojunctions that form $\mathrm{p}-\mathrm{n}$ junctions can also be operated without an external bias, where the generated internal electric field due to Fermi energy level alignments separate and drive the photogeneration of charges. This type of PD mainly comprises organic and inorganic semiconductors, where the inorganic semiconductor acts as the light sensitive material, while the organic semiconductor provides the direct charge conduction channel. Therefore, organic semiconductors can be used for either electron or hole transportation, depending on the type of inorganic semiconductor. Due to the n-type semiconducting behavior of $\mathrm{ZnO}$, p-type organic semiconductors such as PEDOT:PSS, Spiro-MeOTAD, and P3HT are preferable for the generation of an internal built-in electric field.

As illustrated in Fig. 14a (device schematic), we fabricated a ZnO NR and PEDOT:PSS-based self-powered UV PD, ${ }^{198}$ where properties of the $\mathrm{ZnO}$ were altered by doping chlorine $(\mathrm{Cl})$ (Cl:ZnO) for better light trapping probability and PEDOT:PSS for efficient hole transportation efficiency by introducing dimethyl sulfoxide (DMSO-PEDOT:PSS). A much better self-powered photoresponse was observed in the Cl-ZnO NRs/DMSOPEDOT:PSS PD (\#4) as compared to that of ZnO NRs/ PEDOT:PSS (\#1), Cl-ZnO NRs/PEDOT:PSS (\#2) and ZnO NRs/ DMSO-PEDOT:PSS (\#3) (Fig. 14b, cyclic photoresponses). Fig. 14c depicts the energy band diagram of Cl-ZnO NRs/ PEDOT:PSS upon exposure to UV illumination, where the photogenerated electrons migrate to the ITO electrode and holes to 

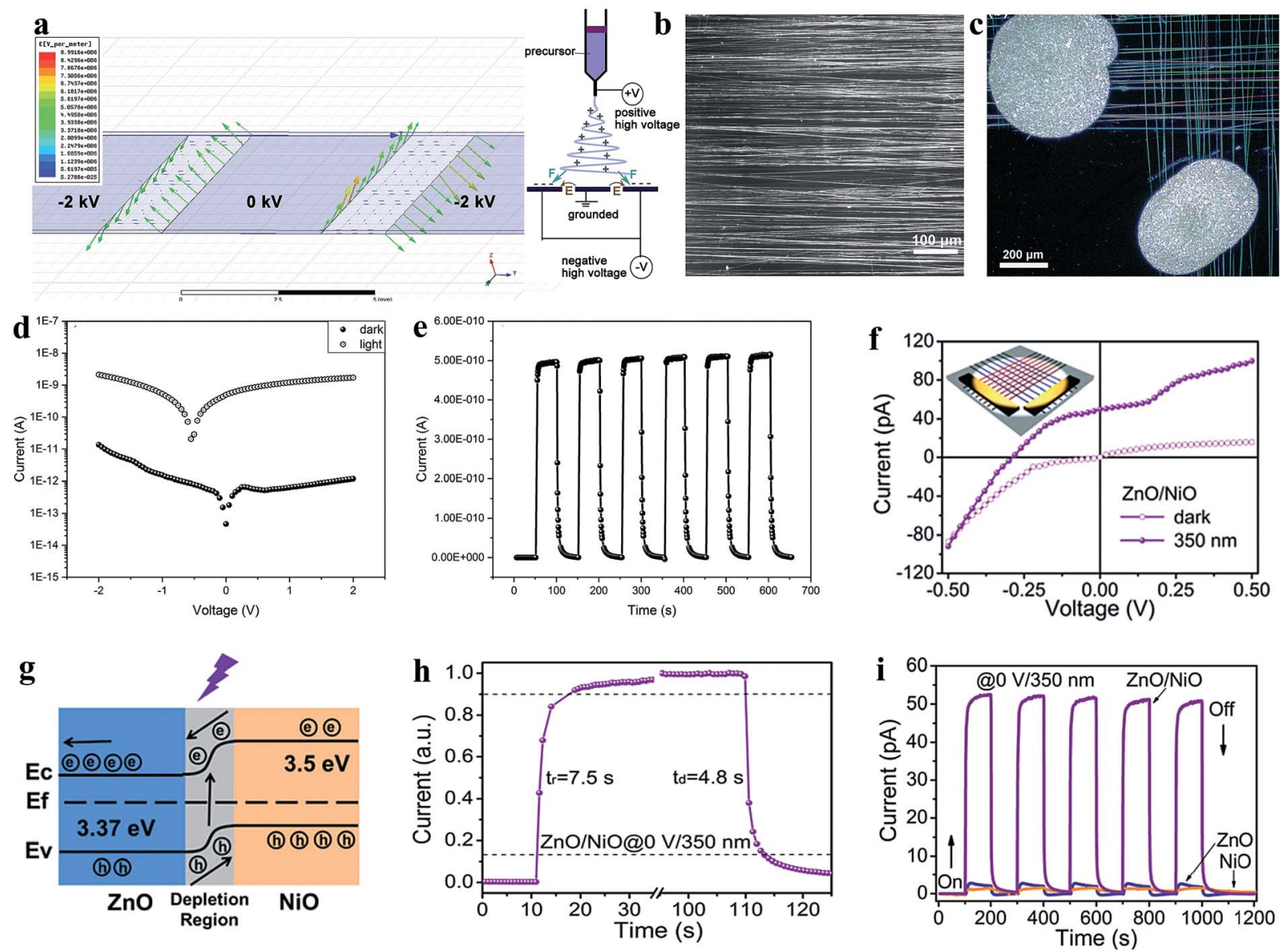

Fig. 13 Transparent and self-powered UV PDs: (a) left image shows the electric field distribution around the three electrode collector applied for nanofiber alignment and schematic diagram of electrospinning setup (right schematic). (b and c) Optical images of aligned nanofibers and the asfabricated transparent $\mathrm{p}-\mathrm{n}$ homojunction ( $\mathrm{n}$-type $\mathrm{ZnO}$ nanofibers and Ag-doped $\mathrm{p}$-type $\mathrm{ZnO}$ ) based UV PD. (d) I-V responses in both the absence and presence of UV light $\left(360 \mathrm{~nm}, 2.5 \mathrm{~mW} \mathrm{~cm}{ }^{-2}\right.$ ). (e) Cyclic photoresponses in the absence of a bias voltage. Reproduced with permission from ref. 196 Copyright 2018 WILEY-VCH. (f) I-V characteristics both in the absence and presence of UV light and inset depicts a schematic representation of the respective $\mathrm{ZnO} / \mathrm{NiO}$ heterojunction-based PD. ( $\mathrm{g}$ and $\mathrm{h}$ ) Energy band diagram of the PD with exposure to UV light and estimation of its response time and recovery time. (i) Cyclic photoresponses of the UV PDs: pristine $\mathrm{ZnO}$, pristine $\mathrm{NiO}$ and $\mathrm{ZnO} / \mathrm{NiO}$ heterojunction in the absence of a bias voltage. Reproduced with permission from ref. 197 Copyright 2019 The Royal Society of Chemistry.

PEDOT:PSS and then Ag electrode for self-powered photoconduction due to the built-in potentials. $\mathrm{Cl}$ doping in the $\mathrm{ZnO}$ NRs not only enhanced the charge carrier density, but also enhanced the surface roughness of the NRs, and hence increased the light trapping probability upon UV illumination (Fig. 14d and e shows the simulated electric field distributions on the smooth ZnO NR surface and rough Cl-ZnO NR surface, respectively). Fig. 14f shows the light harvesting efficiency (LHE $=100 \%-$ transmission $\%$ - reflection $\%$ ) plots with respect to light wavelength ( 350 to $800 \mathrm{~nm}$ ) of the $\mathrm{ZnO} \mathrm{NRs}$ and $\mathrm{Cl}-\mathrm{ZnO}$ NRs, which confirmed the capture of more photons on the rough surfaces of the Cl-ZnO NRs. At the UV illumination intensity of $3 \mathrm{~mW} \mathrm{~cm} \mathrm{c}^{-2}(365 \mathrm{~nm})$, the measured self-generated photoresponses of the Cl-ZnO NRs/DMSO-PEDOT:PSS PDs were $300 \mathrm{nA}$ (response current), $0.80 \mathrm{~mA} \mathrm{~W}^{-1}$ (responsivity), $1.12 \times$ $10^{10}$ Jones (specific detectivity), $30 \mathrm{~ms}$ (response time) and 32 ms (recovery time).

Likewise, Basak's group fabricated a ZnO@CdS core-shell NR and PEDOT:PSS-based self-powered PD, as depicted in
Fig. 14g (device schematic). ${ }^{199}$ The energy band diagram of the respective PD is shown in Fig. 14h, illustrating the migration of photogenerated electrons from ZnO to ITO and holes to CdS then PEDOT:PSS and finally to the Al electrode upon exposure to UV illumination. The authors optimized the self-powered photoresponse by controlling the CdS coating times from 0 ( $\mathrm{ZnO}$ $\mathrm{NRs}$ ) to 40 times (CdS40), and it was found that the 30-times CdS (CdS30) coated ZnO NRs showed the maximum selfpowered response due to the optimum UV absorption efficiency in the CdS@ZnO core-shell structure, and thereby increased sensitivity of $2.8 \times 10^{3}$ compared to the pristine $\mathrm{ZnO}$ NRs of sensitivity of 90 at $1 \mathrm{~mW} \mathrm{~cm} \mathrm{~cm}^{-2} \mathrm{UV}$ illumination intensity. Moreover, the as-reported PD displayed a faster photodetection speed of $\sim 20$ ms response time and $\sim 40$ ms recovery time. Furthermore, the authors extended the self-powered photoconduction measurement of the $\mathrm{ZnO@CdS/PEDOT:PSS} \mathrm{PD} \mathrm{to}$ visible light.

Moreover, we fabricated hydrogenated $\mathrm{ZnO}(\mathrm{H}: \mathrm{ZnO}) \mathrm{NFs}$ and PEDOT:PSS heterostructure for application in self-powered UV 
$\mathbf{a}$

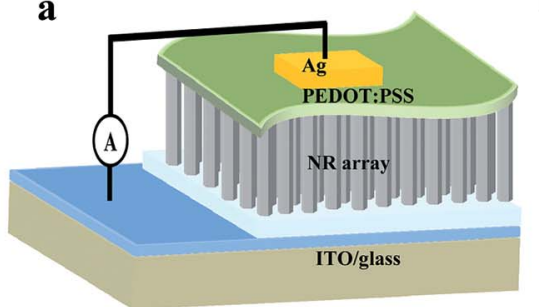

b

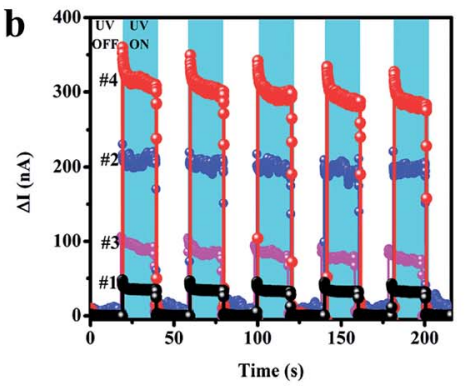

d

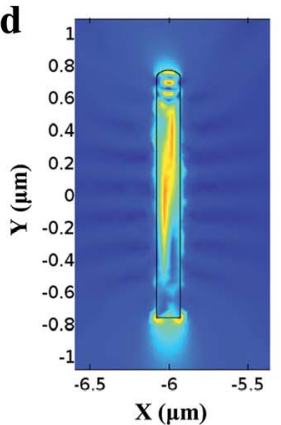

g

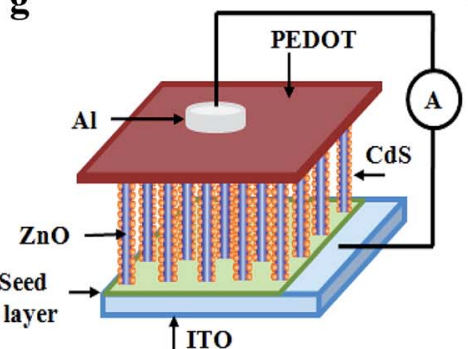

e

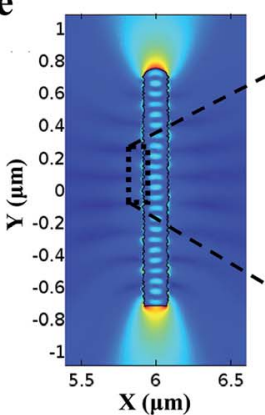

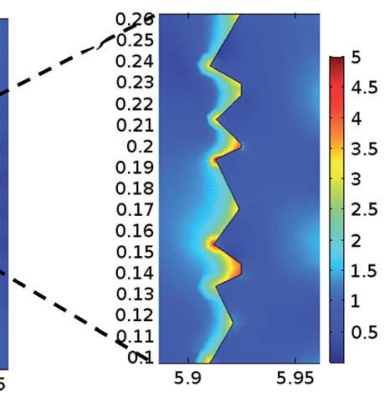

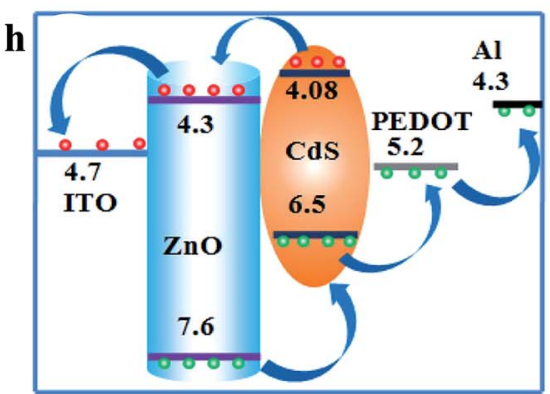

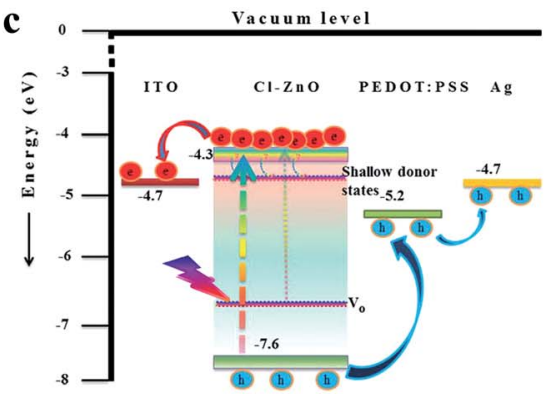

$f$
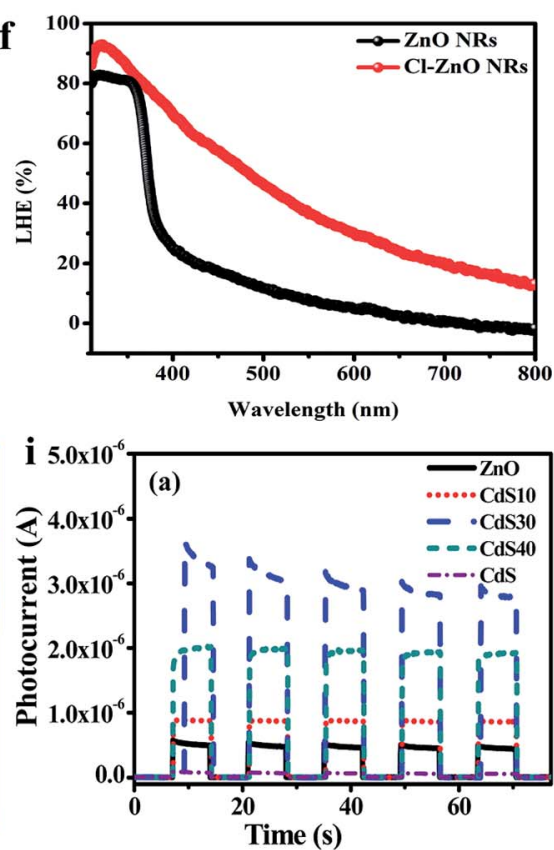

Fig. 14 ZnO NRs and PEDOT:PSS heterostructure: (a) schematic illustration of the self-powered UV PD. (b) Cyclic photoresponses of the PDs (\#1: ZnO NRs/PEDOT:PSS, \#2: Cl-ZnO NRs/PEDOT:PSS, \#3: ZnO NRs/DMSO-PEDOT:PSS and \#4: Cl-ZnO NRs/DMSO-PEDOT:PSS PDs) under UV turned off and on repeatedly at zero bias voltage. (c) Schematic illustration of energy band diagram of Cl-ZnO NRs/PEDOT:PSS PD. (d and e) 2D simulated electric field distribution in ZnO NRs and Cl-doped ZnO NR, respectively. (f) LHE of pristine ZnO NRs and Cl-ZnO NRs. Reproduced with permission from ref. 198 Copyright 2017 Royal Society of Chemistry. ZnO@CdS/PEDOT:PSS heterostructure: (g and h) device schematic and energy band diagram upon exposure to light. (i) Cyclic photoresponses under UV off and on states at zero bias voltage. Reproduced with permission from ref. 199 Copyright 2015 American Chemical Society.

PDs. ${ }^{47}$ It was found that the H:ZnO NFs PD showed much higher photoresponse (1000 nA of response current) compared to that of the hydrogenated $\mathrm{ZnO} \mathrm{NR}-$ (400 nA response current) and pristine ZnO NR- (40 nA response current) based PDs due to the abundant charge carrier density after hydrogenation and efficient light capturing in NFs. A higher LHE (98\%) in the NF structure at $300 \mathrm{~nm}$ wavelength was measured due to the higher light adsorption capacity in the cavity of the NFs compared to that in the NRs or planar seed layer, which was $84 \%$ and $30 \%$, respectively. Thereby, the fabricated H:ZnO NFs/PEDOT:PSS PD displayed efficient photodetection performances, including responsivity of $2.65 \mathrm{~mA} \mathrm{~W}^{-1}$ and $5.25 \times 10^{10}$ Jones specific detectivity at $3 \mathrm{~mW} \mathrm{~cm} \mathrm{~cm}^{-2} \mathrm{UV}(365 \mathrm{~nm})$ illumination intensity in the absence of any external driving force. In addition, a faster photodetection speed of $23 \mathrm{~ms}$ response time and $26 \mathrm{~ms}$ recovery time was measured in the self-powered $\mathrm{PD}$.

To explore the piezo-phototronic effect of $\mathrm{ZnO}$ for selfpowered photoresponse application, Zhang's group fabricated a ZnO and Spiro-MeOTAD (p-n) heterojunction-based selfpowered UV PD and enhanced its self-powered photoresponse performance by applying an external strain. ${ }^{200}$ As expected, the photoconduction of the PD increased with an increase in tensile strain due to the increase in the barrier height of $\mathrm{ZnO}$ and SpiroMeOTAD (positive piezopotential at the interface), resulting in the effective separation of photogenerated charges upon exposure to UV, thereby improving the self-generated photoconduction. Nearly a one-fold enhancement in photocurrent $\left(1.64 \times 10^{-7} \mathrm{~A}\right)$, responsivity $\left(0.8 \mathrm{~mA} \mathrm{~W}^{-1}\right)$ and specific detectivity $\left(4.2 \times 10^{9}\right.$ Jones $)$ was reported by the authors when a tensile strain of $0.753 \%$ was applied on the PD in the absence of an external bias voltage.

With the rapid development of ZnO-based self-powered UV PDs, it has been realized that under light illumination, a transient increase in temperature across the $\mathrm{ZnO}$ nanostructures occurs to generate a potential known as pyro-potential. The induced pyro-charges under UV introduce an additional 
current, which enhances the overall self-powered photodetection performance of $\mathrm{ZnO}$ PDs. The pyro-phototronic effect is a very fast and rapid phenomenon, which can be utilized for ultrafast photon detection applications. ${ }^{\mathbf{2 0 1 , 2 0 2}}$ Recently, several reports on pyro-phototronic-based ZnO self-powered UV PDs have been published by various research groups. Among them, Wang's group widely applied this effect for ultrafast selfpowered photodetection applications. ${ }^{203}$ Fig. 15a and b show a schematic representation of the ZnO NWs/PEDOT:PSS selfpowered $\mathrm{PD}$ and its respective cyclic photoresponse upon exposure to UV illumination $\left(325 \mathrm{~nm}, 2.30 \mathrm{~mW} \mathrm{~cm}^{-2}\right)$ in the on and off states repeatedly at zero bias voltage. The current-time profile of the PD was completely different from the conventional UV PDs, where four stages (I, II, III and IV) of photocurrent dynamic behavior were measured, as shown in the magnified graph of Fig. 15b. In stage I: under UV illumination, the photogenerated electrons and holes migrated to the respective electrodes (ITO and Ag) for photocurrent generation ( $\left.I_{\text {photo }}\right)$, and simultaneously, a rapid increase in temperature in the $\mathrm{ZnO}$ NWs occurred to generate pyroelectric polarization potentials, i.e. pyro-potentials across the $\mathrm{ZnO}$ NWs. The positive pyropotentials appeared at the PEDOT:PSS side; whereas, negative at the ITO electrode side according to the $c$-axis alignment of ZnO NWs, which resulted in the generation of an additional spike current known as pyro-current $\left(I_{\text {pyro }}\right)$. Therefore, the overall current of the PD in stage I can be expressed as $I=I_{\text {photo }}$ $+I_{\text {pyro }}$ (Fig. 15c(i), schematic illustration of photoconduction at stage I). While the PD is under constant UV illumination, the temperature generation of the $\mathrm{ZnO}$ NWs remained almost unchanged and the pyroelectric effect disappeared in stage II (Fig. $\left.15 \mathrm{c}(\mathrm{ii}), I=I_{\text {photo }}\right)$. When UV light is switched off, the photocurrent of the PD goes to zero $\left(I_{\text {photo }}=0\right)$, but a rapid decrease in temperature takes place across $\mathrm{ZnO}$ NWs, which generates opposite distribution of pyro-potentials across the
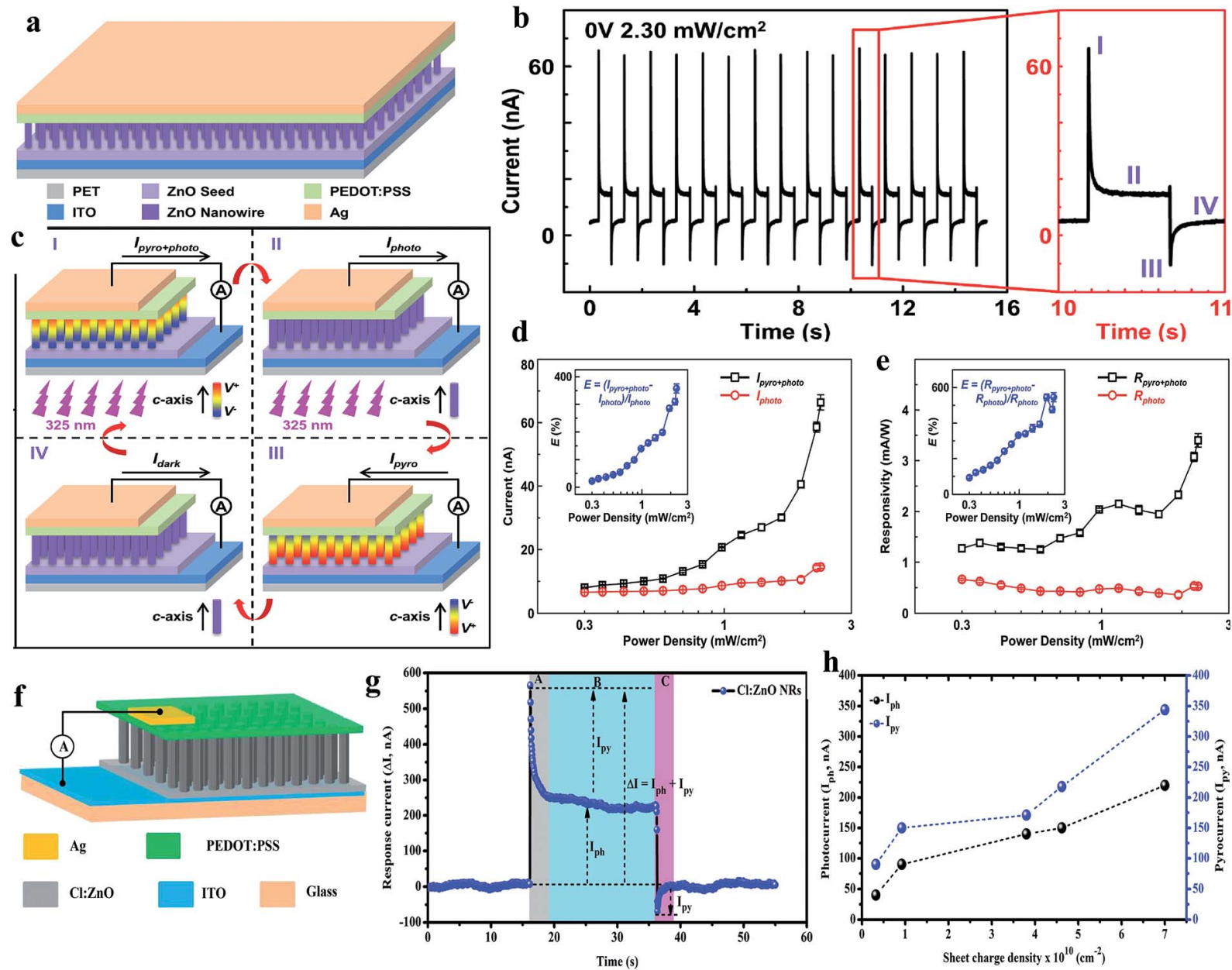

Fig. 15 (a) Schematic diagram of PEDOT:PSS/ZnO heterojunction PD. (b) Cyclic responses of the PD upon exposure to UV light (325 nm, 2.30 $\mathrm{mW} \mathrm{cm} \mathrm{cm}^{-2}$ ) at zero bias voltage and magnified plot shows four-stage (I, II, III and IV) current response profile. (c) Schematic illustration of photoconduction of the PD at the stages of I, II, III and IV. (d and e) Pyro-phototronic effect-induced current, $I_{\text {pyrotphoto, }}$ and photocurrent, $I_{\text {photo, }}$ plots and corresponding responsivity $\left(R_{\text {pyro+photo }}\right.$ and $\left.R_{\text {photo }}\right)$ plots with respect to UV illumination ( $325 \mathrm{~nm}$ ) intensity. Inset plots depict calculated corresponding enhancements at different UV illumination intensities. Reproduced with permission from ref. 203 Copyright 2017 WILEY-VCH. $\mathrm{Cl}: Z n O$ NRs/PEDOT:PSS PD: ( $\mathrm{and} \mathrm{g}$ ) device schematic and current response of the $\mathrm{Cl}: Z \mathrm{nO}$ NRs PD under UV illumination ( $365 \mathrm{~nm}, 3 \mathrm{~mW} \mathrm{~cm}^{-2}$ ) at zero bias voltage. (h) Photocurrent $\left(I_{\mathrm{ph}}\right)$ and pyrocurrent $\left(I_{\mathrm{py}}\right)$ profiles with respect to the charge carrier density of ZnO NRs. Reproduced with permission from ref. 204 Copyright 2018 Royal Society of Chemistry. 
ZnO NWs for a reverse spike pyro-current $\left(I=-I_{\text {pyro }}\right)$ in stage III (Fig. 15c(iii)). While the PD is under maintained in dark condition, the generated temperature under UV keeps constant and finally, pyro-current of the PD transforms to its original condition $\left(I=I_{\text {dark }}\right)$ as depicted in Fig. $15 \mathrm{c}$ (iv). This pyrophototronic effect in $\mathrm{ZnO}$ increased with an increase in the UV radiation temperature (illumination intensity). Fig. 15d shows the variation in $I_{\text {pyro+photo }}$ and $I_{\text {photo }}$ with UV illumination intensity, where nearly $350 \%$ enhancement $\left(E=\left(I_{\text {pyro+photo }}-\right.\right.$ $\left.\left.I_{\text {photo }}\right) / I_{\text {photo }}\right)$ in the photoresponse at $2.30 \mathrm{~mW} \mathrm{~cm}^{-2}$ was reported due to the photo-phototronic effect (inset in Fig. 15d). Likewise, Fig. 15e shows the corresponding responsivities of the $R_{\text {pyro+photo }}$ and $R_{\text {photo }}$ of the PD, where $500 \%$ enhancement in these parameters was reported after considering the pyrophototronic effect (inset in Fig. 15e).

Moreover, we tuned the pyro-phototronic effect of ZnO NRs by tuning the charge carrier density by doping halogen elements, ${ }^{204}$ and Fig. $15 f$ and $g$ depict the device schematic and photoresponse profile of the Cl:ZnO NRs/PEDOT:PSS-based self-powered PD, respectively. Interestingly, it was found that the pyro-phototronic response of the $\mathrm{ZnO}$ NRs increased with the charge carrier density, where an efficient photoresponse was observed in the Cl-doped $\mathrm{ZnO}(\mathrm{Cl}: \mathrm{ZnO})$ NRs due to the highest charge carrier density, and Fig. 15h shows the similar transient current profile of the PD upon exposure to UV illumination in the absence of a bias voltage, where four stages in the current profile were observed due to the pyro-phototronic effect. The photocurrent $\left(I_{\mathrm{ph}}\right)$ and pyrocurrent $\left(I_{\mathrm{py}}\right)$ plots with respect to the charge carrier density of the ZnO NRs confirm the enhancement in the photoresponse behavior. At the carrier density of $3.23 \times$ $10^{9} \mathrm{~cm}^{-2}$ (pristine ZnO NRs) the observed photocurrent and pyrocurrent were $\sim 40 \mathrm{nA}$ and $\sim 90 \mathrm{nA}$, which increased to 220 $\mathrm{nA}$ and $344 \mathrm{nA}$ when the charge carriers density was $7 \times 10^{10}$ $\mathrm{cm}^{-2}$ for the Cl:ZnO NRs, respectively. Likewise, various pyrophototronic-based self-powered UV PDs have been reported by many groups, for instance, $\mathrm{ZnO} /$ perovskite heterostructures, ${ }^{205,206} \mathrm{ZnO} / \mathrm{Ag}$ Schottky junction, ${ }^{207}$ and $\mathrm{ZnO} \mathrm{NWs} / \mathrm{SnS}$ PD. ${ }^{208}$

3.2.3 Photoelectrochemical cell-based self-powered UV photodetectors. Photoelectrochemical cell (PECC)-type selfpowered UV PDs comprise three main components, primarily a ZnO nanostructures/heterostructure-based photoanode, electrolyte for trapping photogenerated holes and counter electrode for receiving photogenerated electrons. The photogenerated holes (under UV illumination) migrate to the $\mathrm{ZnO} /$ electrolyte interface to trap electron donors from the electrolyte through leaving oxidized redox species. Meanwhile, the photogenerated electrons transport from the $\mathrm{ZnO}$ electrode to the counter electrode through the external circuit. The oxidized redox species diffuse through the electrolyte and finally become neutralized by the photogenerated electrons at the counter electrode. Therefore, the electrolyte of PECC-type self-powered PDs plays an important role in the photoconduction process. $\mathrm{Li}$ and coauthors used water $\left(\mathrm{H}_{2} \mathrm{O}\right)$ as the electrolyte for a PECC, where $\mathrm{ZnO}$ nanoneedle (NN) arrays were directly grown on an FTO substrate as the photoanode and Pt coated on FTO as the
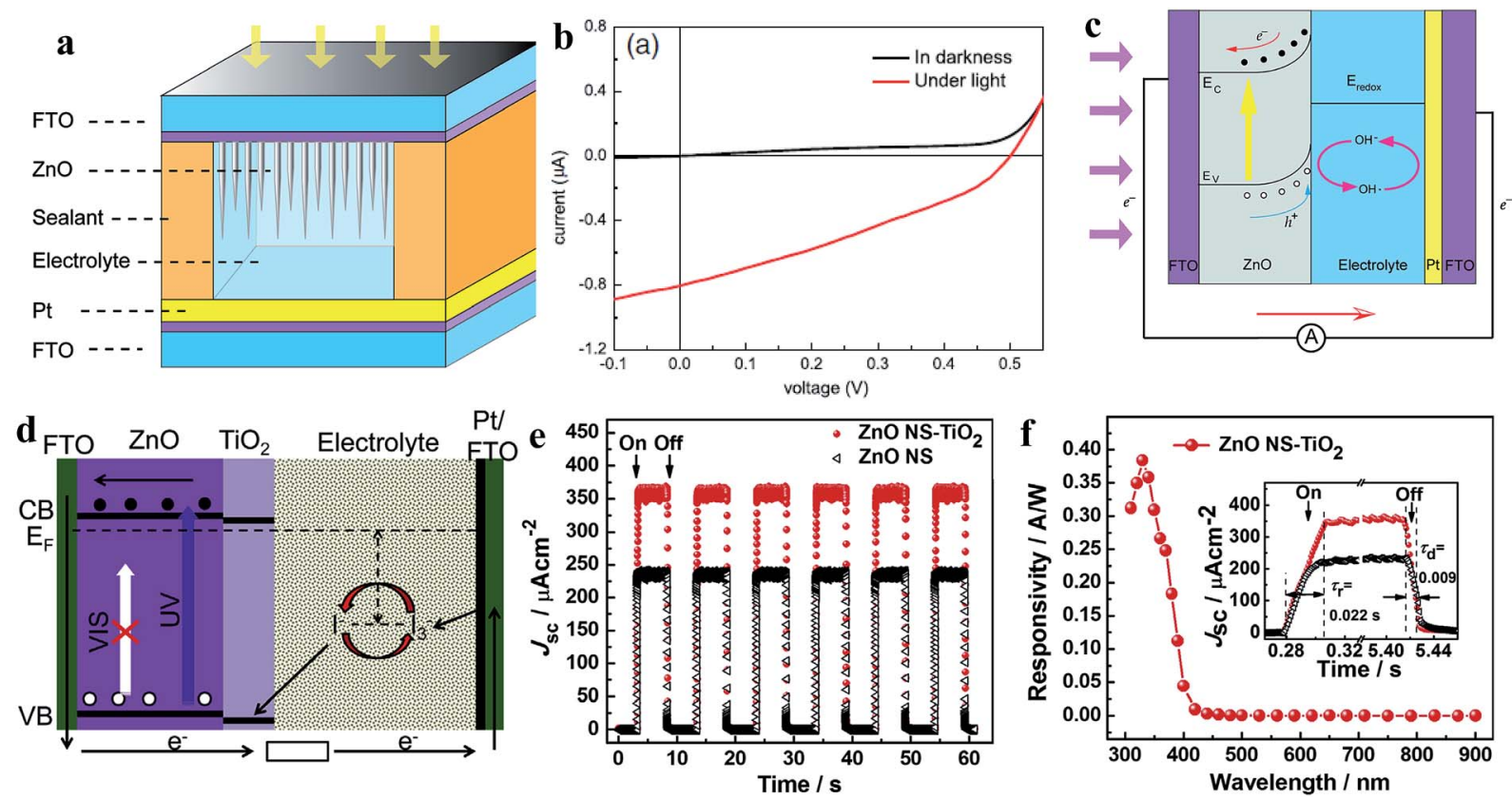

Fig. 16 ZnO NN photoanode: (a) device schematic of ZnO NN photoanode-based PECC-type PD. (b and c) I-V profiles in dark and UV (365 nm, $1.25 \mathrm{~mW} \mathrm{~cm}^{-2}$ ) conditions and self-powered working mechanism under exposure to UV, respectively. Reproduced with permission from ref. 209 Copyright 2013 Springer. $\mathrm{ZnO} N S s-\mathrm{TiO}_{2}$ core-shell photoanodes: (d) energy band diagram and working principle of the PD under exposure to UV irradiation. (e) Cyclic photoresponses of $\mathrm{ZnO} N S s-\mathrm{TiO}_{2}$ core-shell photoanode- and $\mathrm{ZnO}$ NSs photoanode-based PDs upon exposure to UV light (365 nm, $20 \mathrm{~mW} \mathrm{~cm}^{-2}$ ) in the off and on states. (f) Spectral photoresponse and inset response/recovery time calculation of the PECC PD. Reproduced with permission from ref. 210 Copyright 2013 Elsevier. 
counter electrode (Fig. 16a depicts the device schematic). ${ }^{209}$ The self-powered photoconduction performance of the PECC can be confirmed from the typical $I-V$ characteristics (Fig. 16b), where a larger short circuit current response of $0.8 \mu \mathrm{A}$ and an opencircuit voltage of $0.5 \mathrm{~V}$ were measured upon exposure to UV

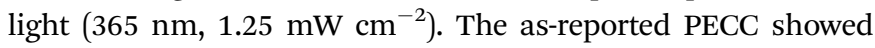
a maximum responsivity of $\sim 0.022 \mathrm{~A} \mathrm{~W}^{-1}$ together with a reasonable photodetection speed with the same response time and recovery time of $\sim 0.1 \mathrm{~s}$. As illustrated in Fig. 16c, the selfpowered photoconduction mechanism of the PECC PD can be explained from the energy band diagram, where upon UV illumination, the photogenerated holes in the $\mathrm{ZnO} \mathrm{NN}$ arrays are driven to the $\mathrm{ZnO}$ and electrolyte interface due to the built-in potential and captured by redox molecules according to the relation, $\mathrm{h}^{+}+\mathrm{OH}^{-} \rightarrow \mathrm{OH}^{*}$. Simultaneously, the photogenerated electrons are collected by the FTO electrode and transported to the counter electrode (Pt/FTO) through the external circuit. Finally, the photogenerated electrons become neutralized by the redox molecules at the counter electrode and reduced back to the reduced form of $\mathrm{OH}^{-}$through the process, $\mathrm{e}^{-}+\mathrm{OH}^{\cdot} \rightarrow \mathrm{OH}^{-}$. This process occurs incessantly to generate a photocurrent under UV illumination in the absence of an external driving force.

Table 3 Summary of the photoresponses of $\mathrm{ZnO}$ junction-based self-powered UV PDs. All the photoresponses are listed in the absence of a bias voltage $(V=0 \mathrm{~V})$

\begin{tabular}{|c|c|c|c|c|c|c|}
\hline PD & UV light & $\begin{array}{l}\text { Response } \\
\text { current }\end{array}$ & $\begin{array}{l}\text { Response time \& } \\
\text { recovery time }\end{array}$ & Sensitivity & Responsivity & Specific detectivity \\
\hline H:VZnO NFs/PEDOT:PSS ${ }^{47}$ & $365 \mathrm{~nm}$ & $100 \mathrm{nA}$ & $23 \mathrm{~ms} \& 26 \mathrm{~ms}$ & - & $2.65 \mathrm{~mA} \mathrm{~W}^{-1}$ & $5.25 \times 10^{10}$ Jones \\
\hline Cl-ZnO NRs/DMSO-PEDOT:PSS ${ }^{198}$ & $365 \mathrm{~nm}$ & $300 \mathrm{nA}$ & $30 \mathrm{~ms} \& 32 \mathrm{~ms}$ & - & $0.80 \mathrm{~mA} \mathrm{~W}^{-1}$ & $1.12 \times 10^{10}$ Jones \\
\hline rGO-ZnO nanostructure 213 & $334 \mathrm{~nm}$ & $20 \mathrm{nA}$ & $0.2 \mathrm{~s} \& 0.2 \mathrm{~s}$ & & & \\
\hline PEDOT:PSS/ZnO micro/NW ${ }^{214}$ & $325 \mathrm{~nm}$ & $1.2 \mathrm{nA}$ & $1 \mathrm{~s} \& 1 \mathrm{~s}$ & - & - & - \\
\hline p-NiO/ZnO-NRs ${ }^{191}$ & $355 \mathrm{~nm}$ & $300 \mathrm{nA}$ & $0.23 \mathrm{~s} \& 0.21 \mathrm{~s}$ & $\sim 10^{5}$ & $0.44 \mathrm{~mA} \mathrm{~W}^{-1}$ & - \\
\hline $\mathrm{Ag}-\mathrm{ZnO} \mathrm{NWs}^{215}$ & $365 \mathrm{~nm}$ & $71 \times 10^{3} \mathrm{nA}$ & $0.14 \mathrm{~s} \& 0.52 \mathrm{~s}$ & & & \\
\hline Cl:ZnO NRs/PEDOT:PSS ${ }^{204}$ & $365 \mathrm{~nm}$ & $564 \mathrm{nA}$ & $28 \mathrm{~ms} \& 23 \mathrm{~ms}$ & - & $2.33 \mathrm{~mA} \mathrm{~W}^{-1}$ & $1.54 \times 10^{10}$ Jones \\
\hline $\mathrm{n}-\mathrm{Ga}: \mathrm{ZnO} / \mathrm{p}-\mathrm{GaN}^{140}$ & - & - & - & $3.2 \times 10^{5}$ & $230 \mathrm{~mA} \mathrm{~W}^{-1}$ & $2.32 \times 10^{12}$ Jones \\
\hline $\mathrm{n}-\mathrm{ZnO} / \mathrm{i}-\mathrm{MgO} / \mathrm{p}-\mathrm{GaN}^{216}$ & $365 \mathrm{~nm}$ & - & $3.2 \mathrm{~s} \& 3.84 \mathrm{~s}$ & - & $320 \mathrm{~mA} \mathrm{~W}^{-1}$ & $8.0 \times 10^{12}$ Jones \\
\hline $\mathrm{ZnO} / \mathrm{GaN}^{190}$ & & & $0.02 \mathrm{~ms} \& 0.22 \mathrm{~ms}$ & & $\sim 132 \mathrm{~mA} \mathrm{~W}^{-1}$ & - \\
\hline $\mathrm{n}-\mathrm{ZnO} / \mathrm{p}-\mathrm{CuSCN}{ }^{217}$ & $325 \mathrm{~nm}$ & - & $0.5 \mu \mathrm{s} \& 6.7 \mu \mathrm{s}$ & - & $7.5 \mathrm{~mA} \mathrm{~W}^{-1}$ & - \\
\hline $\mathrm{n}-\mathrm{ZnO} / \mathrm{p}-\mathrm{NiO}^{191}$ & $355 \mathrm{~nm}$ & - & $0.23 \mathrm{~s} \& 0.21 \mathrm{~s}$ & - & $0.44 \mathrm{~mA} \mathrm{~W}^{-1}$ & - \\
\hline Au\#1-ZnO-Au\#2 (ref. 218) & $365 \mathrm{~nm}$ & - & $710 \mathrm{~ns} \& 4 \mu \mathrm{s}$ & - & $20 \mathrm{~mA} \mathrm{~W}^{-1}$ & - \\
\hline $\mathrm{p}-\mathrm{ZnO}(\mathrm{Li}, \mathrm{N}) / \mathrm{n}-\mathrm{ZnO}^{193}$ & - & - & - & - & $0.018 \mathrm{~mA} \mathrm{~W}^{-1}$ & - \\
\hline $\mathrm{p}-\mathrm{GaN} / \mathrm{n}-\mathrm{ZnO}^{219}$ & $374 \mathrm{~nm}$ & - & - & - & $0.001 \mathrm{~mA} \mathrm{~W}^{-1}$ & $1.41 \times 10^{8}$ Jones \\
\hline $\mathrm{Au} / \mathrm{MgZnO}^{220}$ & - & - & - & - & $0.059 \mathrm{~mA} \mathrm{~W}^{-1}$ & - \\
\hline $\mathrm{Au}-\mathrm{ZnO}(\mathrm{I}) / \mathrm{ZnO}(\mathrm{n}) / \mathrm{In}^{221}$ & - & - & - & - & $0.03 \mathrm{~mA} \mathrm{~W}^{-1}$ & - \\
\hline $\mathrm{Au} / \mathrm{MgO} / \mathrm{MgZnO}^{222}$ & $366 \mathrm{~nm}$ & - & - & - & $11 \mathrm{~mA} \mathrm{~W}^{-1}$ & - \\
\hline $\mathrm{Pt} / \mathrm{ZnO} \mathrm{NWs} / \mathrm{Al}^{223}$ & $355 \mathrm{~nm}$ & - & $81 \mathrm{~ms} \& 95 \mathrm{~ms}$ & $3.1 \times 10^{4}$ & - & - \\
\hline ZnO NWs/CuSCN ${ }^{192}$ & $370 \mathrm{~nm}$ & - & - & - & $0.02 \mathrm{~A} \mathrm{~W}^{-1}$ & - \\
\hline $\mathrm{n}-\mathrm{ZnO} / \mathrm{p}-\mathrm{GaN}^{190}$ & $325 \mathrm{~nm}$ & $\sim 2 \mu \mathrm{A}$ & $20 \mu \mathrm{s} \& 219 \mu \mathrm{s}$ & - & - & - \\
\hline Sb-doped $\mathrm{ZnO}$ nanobelt/Au ${ }^{46}$ & $325 \mathrm{~nm}$ & $22 \mathrm{nA}$ & $100 \mathrm{~ms} \& 100 \mathrm{~ms}$ & 23 & - & - \\
\hline $\mathrm{ZnO} /$ Spiro-MeOTAD ${ }^{200}$ & $365 \mathrm{~nm}$ & $\sim 0.2 \mu \mathrm{A}$ & $0.16 \mathrm{~s} \& 0.20 \mathrm{~s}$ & - & $0.8 \mathrm{~mA} \mathrm{~W}^{-1}$ & $4.2 \times 10^{9}$ Jones \\
\hline $\mathrm{n}-\mathrm{ZnO} / \mathrm{CdS} / \mathrm{p}-\mathrm{GaN}^{224}$ & $365 \mathrm{~nm}$ & - & $0.35 \mathrm{~s} \& 0.35 \mathrm{~s}$ & - & $176 \mathrm{~mA} \mathrm{~W}^{-1}$ & $2.5 \times 10^{12}$ Jones \\
\hline Graphene/ZnO:Al NRs ${ }^{187}$ & $365 \mathrm{~nm}$ & - & $37 \mu \mathrm{s} \& 330 \mu \mathrm{s}$ & 100 & $39 \mathrm{~mA} \mathrm{~W}^{-1}$ & - \\
\hline p-CuSCN/n-ZnO NRs ${ }^{175}$ & $365 \mathrm{~nm}$ & - & $3.20 \mathrm{~s} \& 3.84 \mathrm{~s}$ & - & $22.5 \mathrm{~mA} \mathrm{~W}^{-1}$ & - \\
\hline $\mathrm{ZnO} / \mathrm{Ga}_{2} \mathrm{O}_{3}$ (ref. 225) & $251 \mathrm{~nm}$ & $\sim 6 \mathrm{nA}$ & $100 \mu \mathrm{s} \& 900 \mu \mathrm{s}$ & - & $9.7 \mathrm{~mA} \mathrm{~W}^{-1}$ & $6.29 \times 10^{12}$ Jones \\
\hline $\mathrm{CuSCN} / \mathrm{ZnO}^{217}$ & $350 \mathrm{~nm}$ & - & $500 \mathrm{~ns} \& 6.7 \mu \mathrm{s}$ & - & $7.5 \mathrm{~mA} \mathrm{~W}^{-1}$ & - \\
\hline Polyaniline/MgZnO ${ }^{226}$ & $250 \mathrm{~nm}$ & - & $0.3 \mathrm{~s} \& 0.3 \mathrm{~s}$ & $\sim 10^{4}$ & $0.16 \mathrm{~mA} \mathrm{~W}^{-1}$ & $1.5 \times 10^{11}$ Jones \\
\hline $\mathrm{ZnO}(\mathrm{N})-$ Spiro-MeOTAD ${ }^{227}$ & $390 \mathrm{~nm}$ & - & $200 \mu \mathrm{s} \& 950 \mu \mathrm{s}$ & 300 & $17 \mathrm{~mA} \mathrm{~W}^{-1}$ & - \\
\hline ZnO \& PEDOT/ITO PECC ${ }^{211}$ & $365 \mathrm{~nm}$ & - & $0.2 \mathrm{~s} \& 0.2 \mathrm{~s}$ & - & - & - \\
\hline $\mathrm{ZnO} \& \mathrm{Pt} / \mathrm{FTO} \mathrm{PECC}^{228}$ & $365 \mathrm{~nm}$ & $\sim 30 \mathrm{nA}$ & $0.06 \mathrm{~s} \& 0.06 \mathrm{~s}$ & - & - & - \\
\hline $\mathrm{ZnO} \& \mathrm{Pt} / \mathrm{FTO} \mathrm{PECC}^{229}$ & - & - & $0.07 \mathrm{~s} \& 0.07 \mathrm{~s}$ & $10^{2}$ & - & - \\
\hline $\mathrm{ZnO} \& \mathrm{Pt} / \mathrm{FTO} \mathrm{PECC}^{215}$ & $365 \mathrm{~nm}$ & $21.61 \mu \mathrm{A} \mathrm{cm}^{-2}$ & $0.15 \mathrm{~s} \& 0.5 \mathrm{~s}$ & 32.32 & $370 \mathrm{~mA} \mathrm{~W}^{-1}$ & - \\
\hline ZnO NRs \& Pt/FTO PECC ${ }^{212}$ & $365 \mathrm{~nm}$ & $\sim 140 \mu \mathrm{A}$ & $0.09 \mathrm{~s} \& 0.31 \mathrm{~s}$ & $\sim 534$ & $2.33 \mathrm{~A} \mathrm{~W}^{-1}$ & - \\
\hline $\mathrm{ZnO} \mathrm{NSe}-\mathrm{TiO}_{2} \& \mathrm{Pt} / \mathrm{FTO} \mathrm{PECC}^{210}$ & $365 \mathrm{~nm}$ & - & $0.022 \mathrm{~s} \& 0.009 \mathrm{~s}$ & 37900 & $\sim 0.38 \mathrm{~A} \mathrm{~W}^{-1}$ & - \\
\hline ZnO NNs \& Pt/FTO PECC Peg $^{209}$ & $365 \mathrm{~nm}$ & - & $0.1 \mathrm{~s} \& 0.1 \mathrm{~s}$ & - & $0.022 \mathrm{~A} \mathrm{~W}^{-1}$ & - \\
\hline $\mathrm{ZnO} / \mathrm{Au}^{189}$ & $325 \mathrm{~nm}$ & - & $0.1 \mathrm{~s} \& 0.1 \mathrm{~s}$ & $\sim 4000$ & - & - \\
\hline $\mathrm{ZnO} / \mathrm{Ag}^{207}$ & $325 \mathrm{~nm}$ & - & $4.5 \mathrm{~ms} \& 3.5 \mathrm{~ms}$ & - & - & $2.7 \times 10^{9}$ Jones \\
\hline $\mathrm{ZnO} /$ perovskite-heterostructure ${ }^{206}$ & $325 \mathrm{~nm}$ & - & $53 \mu \mathrm{s} \& 63 \mu \mathrm{s}$ & - & $26.7 \mathrm{~mA} \mathrm{~W}^{-1}$ & $4.0 \times 10^{10}$ Jones \\
\hline $\mathrm{ZnO} /$ perovskite ${ }^{205}$ & $325 \mathrm{~nm}$ & $\sim 1 \mu \mathrm{A}$ & - & - & - & - \\
\hline p-ZnO:(As) $/ \mathrm{n}-\mathrm{ZnO}^{137}$ & $370 \mathrm{~nm}$ & - & $30 \mathrm{~ms} \& 50 \mathrm{~ms}$ & $10^{6}$ & - & - \\
\hline $\mathrm{p}-\mathrm{CuSCN} / \mathrm{n}-\mathrm{ZnO}^{192}$ & $370 \mathrm{~nm}$ & - & - & & $20 \mathrm{~mA} \mathrm{~W}^{-1}$ & - \\
\hline $\mathrm{p}-\mathrm{GaN} / \mathrm{n}-\mathrm{ZnO}^{230}$ & $358 \mathrm{~nm}$ & - & - & - & $0.68 \mathrm{~mA} \mathrm{~W}^{-1}$ & - \\
\hline $\mathrm{n}-\mathrm{ZnO} / \mathrm{p}-\mathrm{PANI} / \mathrm{n}-\mathrm{ZnO}{ }^{231}$ & $365 \mathrm{~nm}$ & $0.5 \mu \mathrm{A}$ & - & $1.68 \times 10^{5}$ & - & - \\
\hline Graphene/ZnO ${ }^{187}$ & $380 \mathrm{~nm}$ & - & $37 \mu \mathrm{s} \& 330 \mu \mathrm{s}$ & 100 & $\sim 40 \mathrm{~mA} \mathrm{~W}^{-1}$ & - \\
\hline
\end{tabular}


Xie's group fabricated $\mathrm{TiO}_{2}$-coated $\mathrm{ZnO}$ nanostrawberry (NS) $\left(\mathrm{ZnO}\right.$ NS-TiO $\left.{ }_{2}\right)$ core-shell photoanodes for application in PECCtype self-powered UV PDs, as depicted in Fig. 16d (schematic of the energy band diagram under self-powered photoconduction). ${ }^{210}$ The photogenerated holes under UV illumination migrated to the $\mathrm{TiO}_{2} /$ electrolyte interface for the reaction of $\mathrm{h}^{+}+\mathrm{I}^{-} \rightarrow \mathrm{I}_{3}{ }^{-}$due to the internal built-in electric field, while the photogenerated electrons were transported to the counter electrode through $\mathrm{ZnO}$ and the external circuit. Finally, the oxidized redox species were reduced at the counter electrode by electrons $\left(\mathrm{I}_{3}{ }^{-}+\mathrm{e}^{-} \rightarrow \mathrm{I}^{-}\right)$. The authors reported higher selfbiased photoresponse behavior in the $\mathrm{ZnO} \mathrm{NS}-\mathrm{TiO}_{2}$ core-shell photoanode ( $357 \mathrm{~mA} \mathrm{~cm}^{-2}$ ) compared to the pristine $\mathrm{ZnO}$ NS photoanode $\left(234 \mathrm{~mA} \mathrm{~cm}^{-2}\right.$ ) due to the obvious generated builtin electric field at the $\mathrm{ZnO}$ and $\mathrm{TiO}_{2}$ interface (Fig. 16e, cyclic photoresponses at $365 \mathrm{~nm}$ and $20 \mathrm{~mW} \mathrm{~cm}^{-2}$ intensity). The $\mathrm{ZnO}$ $\mathrm{NS}^{-\mathrm{TiO}_{2}}$ core-shell photoanode-based PECC PD showed a sensitivity of $\sim 37900$, maximum responsivity of $\sim 0.38 \mathrm{~A} \mathrm{~W}^{-1}$ at $\sim 330 \mathrm{~nm}$ together with a faster photodetection speed of $\sim 22$ ms (response time) and $\sim 9 \mathrm{~ms}$ (recovery time) (Fig. 16f). Likewise, a ZnO NR photoanode, $\left[\mathrm{Co}(\mathrm{bpy})_{3}\right]^{3+/ 2+}$ electrolyte, PEDOT/ ITO counter electrode-based PECC, ${ }^{\mathbf{2 1 1}} \mathrm{ZnO}$ NR photoanode, iodine-free quasi solid-state electrolyte and Pt/FTO counterbased PECC ${ }^{212}$ were reported for self-powered photodetection. However, due to the involvement of liquid electrolytes, PECC PDs may have restricted applications.

With the constant efforts and research dedication by researchers, various $\mathrm{ZnO}$ nanostructure-based self-powered UV PDs have been reported, and Table 3 summarizes the photoresponse performances of the various reported $\mathrm{ZnO}$ nanostructures/heterostructure-based self-powered PDs.

\section{Conclusions and perspectives}

This article reviewed the recent development in $\mathrm{ZnO}$ nanostructure/heterostructure-based UV PDs from the conventional to self-powered device designs. The intrinsic $\mathrm{ZnO}$ photoresponse mechanism and various potential nanostructures ranging from $0 \mathrm{D}$ to $3 \mathrm{D}$ were briefly introduced. Both the conventional and self-powered ZnO-based UV PDs were precisely categorized based on device structure and working mechanism, where recently introduced novel phenomena such as piezo-electric, pyro-electric and plasmonic effects for efficient photoconduction were discussed carefully. Moreover, there are still a couple of that issues need to be investigated in the development of next-generation conventional and self-powered UV PDs as follows:

\subsection{Improvement of photodetection speed of UV photodetectors}

It can be observed from the literature (Table 2) that the photodetection speed (response time and recovery time) of conventional ZnO-based UV PDs varies from a few hundred seconds to milliseconds. It is important to note that the existence of native defects such as $\mathrm{O}$ and $\mathrm{Zn}$ vacancies and the excess of $\mathrm{Zn}$ and $\mathrm{O}$ atoms in $\mathrm{ZnO}$ behave like trapping centers for charge careers to extend the recombination and charge carrier generation time under exposure to UV illumination. Therefore, it is very important to reduce the native defects in $\mathrm{ZnO}$ nanostructures for efficient photoconduction.

\subsection{Reduction of lattice mismatch of heterostructures}

It is well known that homojunction/heterojunction-based $\mathrm{ZnO}$ PDs show a higher-photoresponse performance than their bare counterparts due to the internal built-in electric at their interface. Sometimes, heterojunction-based ZnO PDs show a slower response time and recovery time during photoconduction, which is mainly due to the defect states present at the junction interface originating mainly due to lattice mismatch at the interface of heterostructures. Therefore, to achieve a desirable photoresponse in homojunction- or heterojunction-based UV PDs, the lattice mismatch at the interface needs to be reduced.

\subsection{Improvement of responsivities of self-powered photodetectors}

It is necessary to highlight that even though there has been significant research effort in the development of $\mathrm{ZnO}$ selfpowered PDs with rapid photodetection speed and superior sensitivity, the responsivities of the reported self-powered $\mathrm{ZnO}$ PDs are still limited, which are relatively lower than that of conventional ZnO UV PDs (Tables 2 and 3). As discussed earlier, the built-in electric fields at the junctions/interfaces of selfpowered UV PDs define their photoresponse performance in terms of both response current and responsivity. Thus, to enhance the responsivity of self-powered PDs, the strength of the built-in electric field and the photoconductivity of photoactive materials for faster conduction need to increase for the realization of their direct practical applications.

\subsection{Optimization of surface roughness of nanomaterials}

$\mathrm{ZnO}$ nanostructure morphologies play a crucial role in the light trapping effect, which determines the electron and hole pair generation efficiency. Therefore, the optimum surface roughness on $\mathrm{ZnO}$ nanostructures needs to be considered to increase the surface-induced photocharge effects. In addition, the carrier concentration of $\mathrm{ZnO}$ nanomaterials needs to be improved for optimum charge conduction.

\subsection{Development of on-chip and planar wearable UV photodetectors}

Nowadays, the rapid increase in the demands of portable modern electronic devices have made it necessary for on-chip, small size, lightweight with high-performance miniaturized UV PDs. Therefore, to fulfill these requirements, wearable highperformance UV $\operatorname{PDs}^{232}$ and silicon-compatible-based conventional/self-powered UV PDs for on-chip and planar technology ${ }^{233,234}$ need to be focused on in upcoming research.

\section{Conflicts of interest}

There are no conflicts to declare. 


\section{Acknowledgements}

BDB would like to acknowledge the support from the Royal Society, grant number of NIF\R1\181656.

\section{References}

1 F. Teng, K. Hu, W. Ouyang and X. Fang, Adv. Mater., 2018, 30, 1706262.

2 S. Bhandari, D. Mondal, S. K. Nataraj and R. G. Balakrishna, Nanoscale Adv., 2019, 1, 913.

3 W. Ouyang, F. Teng, J. -H. He and X. Fang, Adv. Funct. Mater., 2019, 29, 1807672.

4 H. Chen, L. Su, M. Jiang and X. Fang, Adv. Funct. Mater., 2017, 27, 1704181.

5 J. Zhou, L. Chen, Y. Wang, Y. He, X. Pan and E. Xie, Nanoscale, 2016, 8, 50.

6 Y. Zhang, W. Xu, X. Xu, J. Cai, W. Yang and X. Fang, J. Phys. Chem. Lett., 2019, 10, 836.

7 T. Tong, S. Wang, J. Zhao, B. Cheng, Y. Xiao and S. Lei, Nanoscale Horiz., 2019, 4, 138.

8 L. Peng, L. Hu and X. Fang, Adv. Mater., 2013, 25, 5321.

9 L. Su, W. Yang, J. Cai, H. Chen and X. Fang, Small, 2017, 13, 1701687.

10 H. Chen, K. Liu, L. Hu, A. A. Al-Ghamdi and X. Fang, Mater. Today, 2015, 18, 493.

11 T. Zhai, X. Fang, M. Liao, X. Xu, H. Zeng, B. Yoshio and D. Golberg, Sensors, 2009, 9, 6504.

12 http://en.wikipedia.org/wiki/Sunlight\#.

13 E. Monroy, F. Omnès and F. Calle, Semicond. Sci. Technol., 2003, 18, R33.

14 X. Li, M. Rui, J. Song, Z. Shen and H. Zeng, Adv. Funct. Mater., 2015, 25, 4929.

15 K. Thorkelsson, P. Bai and T. Xu, Nano Today, 2015, 10, 48. 16 Y. Guo, K. Xu, C. Wu, J. Zhao and Y. Xie, Chem. Soc. Rev., 2015, 44, 637.

17 J. Lahnemann, M. D. Hertog, P. Hille, M. d. l. Mata, T. Fournier, J. Schörmann, J. Arbiol, M. Eickhoff and E. Monroy, Nano Lett., 2016, 16, 3260.

18 X. Fang, Y. Bando, M. Liao, U. K. Gautam, C. Zhi, B. Dierre, B. Liu, T. Zhai, T. Sekiguchi, Y. Koide and D. Golberg, Adv. Mater., 2009, 21, 2034.

19 C. Zhang, Y. Xie, H. Deng, T. Tumlin, C. Zhang, J. -W. Su, P. Yu and J. Lin, Small, 2017, 13, 1604197.

20 A. Aldalbahi, E. Li, M. Rivera, R. Velazquez, T. Altalhi, X. Peng and P. X. Feng, Sci. Rep., 2016, 6, 23457.

21 E. Oksenberg, R. Popovitz-Biro, K. Rechav and E. Joselevich, Adv. Mater., 2015, 27, 3999.

22 M. Shaygan, K. Davami, B. Jin, T. Gemming, J.-S. Lee and M. Meyyappan, J. Mater. Chem. C, 2016, 4, 2040.

23 J. Yao, Z. Deng, Z. Zheng and G. Yang, ACS Appl. Mater. Interfaces, 2016, 8, 20872.

24 P. Zhou, C. Chen, X. Wang, B. Hu and H. San, Sens. Actuators, A, 2018, 271, 389.

25 X. Fang, L. Hu, K. Huo, B. Gao, L. Zhao, M. Liao, P. K. Chu, Y. Bando and D. Golberg, Adv. Funct. Mater., 2011, 21, 3907.
26 R. A. Rani, A. S. Zoolfakar, N. S. Khairir, M. H. Mamat, S. Alrokayan, H. A. Khan and M. R. Mahmood, J. Mater. Sci.: Mater. Electron., 2018, 29, 16765.

27 W. -Y. Kong, G. -A. Wu, K. -Y. Wang, T. -F. Zhang, Y. -F. Zou, D. -D. Wang and L. -B. Luo, Adv. Mater., 2016, 28, 10725.

28 X. Zhou, Q. Zhang, L. Gan, X. Li, H. Li, Y. Zhang, D. Golberg and T. Zhai, Adv. Funct. Mater., 2016, 26, 704.

29 L. Li, L. Gu, Z. Lou, Z. Fan and G. Shen, ACS Nano, 2017, 11, 4067.

30 Z. Wang, H. Wang, B. Liu, W. Qiu, J. Zhang, S. Ran, H. Huang, J. Xu, H. Han, D. Chen and G. Shen, ACS Nano, 2011, 5, 8412.

31 K. Liu, M. Sakurai and M. Aono, Sensors, 2010, 10, 8604.

32 L. Zheng, F. Teng, Z. Zhang, B. Zhao and X. Fang, J. Mater. Chem. C, 2016, 4, 10032.

33 L. Hu, J. Yan, M. Liao, L. Wu and X. Fang, Small, 2011, 7, 1012.

34 H. Liu, Z. Zhang, L. Hu, N. Gao, L. Sang, M. Liao, R. Ma, F. Xu and X. Fang, Adv. Opt. Mater., 2014, 771.

35 Ü. Özgür, Y. I. Alivov, C. Liu, A. Teke, M. A. Reshchikov, S. Doğan, V. C. S. J. Avrutin, S.-J. Cho and H. Morkoç, J. Appl. Phys., 2005, 98, 11.

36 Z. L. Wang, Mater. Sci. Eng., R, 2009, 64, 33.

37 Z. L. Wang, J. Phys.: Condens. Matter, 2004, 16, R829.

38 Z. L. Wang, Adv. Mater., 2012, 24, 4632.

39 Z. Gao, J. Zhou, Y. Gu, P. Fei, Y. Hao, G. Bao and Z. L. Wang, J. Appl. Phys., 2009, 105, 113707.

40 Y. Yang, W. Guo, K. C. Pradel, G. Zhu, Y. Zhou, Y. Zhang, Y. Hu, L. Lin and Z. L. Wang, Nano Lett., 2012, 12, 2833.

41 H. Kind, H. Yan, B. Messer, M. Law and P. Yang, Adv. Mater., 2002, 14, 158.

42 C. Soci, A. Zhang, B. Xiang, S. A. Dayeh, D. P. R. Aplin, J. Park, X. Y. Bao, Y.-H. Lo and D. Wang, Nano Lett., 2007, 7, 1003.

43 X. Liu, L. Gu, Q. Zhang, J. Wu, Y. Long and Z. Fan, Nat. Commun., 2014, 5, 4007.

44 G. Chai, O. Lupan, L. Chow and H. Heinrich, Sens. Actuators, A, 2009, 150, 184.

45 N. Chantarat, Y.-W. Chen, S.-Y. Chen and C.-C. Lin, Nanotechnology, 2009, 20, 395201.

46 Y. Yang, W. Guo, J. Qi, J. Zhao and Y. Zhang, Appl. Phys. Lett., 2010, 97, 223113.

47 B. D. Boruah and A. Misra, ACS Appl. Mater. Interfaces, 2016, 8, 18182.

48 Y. Jin, J. Wang, B. Sun, J. C. Blakesley and N. C. Greenham, Nano Lett., 2008, 8, 1649.

49 H. Y. Yang, D. I. Son, T. W. Kim, J. M. Lee and W. I. Park, Org. Electron., 2010, 11, 1313.

50 C. He, T. Sasaki, Y. Shimizu and N. Koshizaki, Appl. Surf. Sci., 2008, 254, 2196.

51 X. H. Zhang, Y. C. Liu, X. H. Wang, S. J. Chen, G. R. Wang, J. Y. Zhang, Y. M. Lu, D. Z. Shen and X. W. Fan, J. Phys.: Condens. Matter, 2005, 17, 3035.

52 M. H. Huang, Y. Wu, H. Feick, N. Tran, E. Weber and P. Yang, Adv. Mater., 2001, 13, 113.

53 L. Li, S. Pan, X. Dou, Y. Zhu, X. Huang, Y. Yang, G. Li and L. Zhang, J. Phys. Chem. C, 2007, 111, 7288. 
54 J. L. Yang, S. J. An, W. I. Park, G. -C. Yi and W. Choi, Adv. Mater., 2004, 16, 1661.

55 L. Wang, X. Zhang, S. Zhao, G. Zhou, Y. Zhou and J. Qi, Appl. Phys. Lett., 2005, 86, 024108.

56 J. -J. Wu and S. -C. Liu, Adv. Mater., 2002, 14, 215.

57 K.-F. Lin, H.-M. Cheng, H.-C. Hsu, L.-J. Lin and W.-F. Hsieh, Chem. Phys. Lett., 2005, 409, 208.

58 B. Liu and H. C. Zeng, J. Am. Chem. Soc., 2003, 125, 4430.

59 F. Lu, W. Cai and Y. Zhang, Adv. Funct. Mater., 2008, 18, 1047.

60 K. Raagulan, M. M. M. G. P. G. Mantilaka, G. T. D. Chandrakumara, U. G. M. Ekanayake, W. P. S. L. Wijesinghe, S. Ehanathan, R. M. G. Rajapakse, R. Braveenth and K. Y. Chai, Nanoscale Adv., 2019, 1, 481.

61 M. K. Choudhary, J. Kataria, V. K. Bhardwaj and S. Sharma, Nanoscale Adv., 2019, 1, 1035.

62 Y. Sun, N. G. Ndifor-Angwafor, D. J. Riley and M. N. R. Ashfold, Chem. Phys. Lett., 2006, 431, 352.

63 H. Lu, S. Wang, L. Zhao, J. Li, B. Dong and Z. Xu, J. Mater. Chem., 2011, 21, 4228.

64 J. Liang, J. Liu, Q. Xie, S. Bai, W. Yu and Y. Qian, J. Phys. Chem. B, 2005, 109, 9463.

65 J. Joo, B. Y. Chow, M. Prakash, E. S. Boyden and J. M. Jacobson, Nat. Mater., 2011, 10, 596.

66 A. Manekkathodi, M. -Y. Lu, C. W. Wang and L. -J. Chen, Adv. Mater., 2010, 22, 4059.

67 S. Zhang, Y. Shen, H. Fang, S. Xu, J. Song and Z. L. Wang, J. Mater. Chem., 2010, 20, 10606.

68 Y. Liang, N. Guo, L. Li, R. Li, G. Ji and S. Gan, RSC Adv., 2015, 5, 59887.

69 T. Zhang, W. Dong, M. Keeter-Brewer, S. Konar, R. N. Njabon and Z. R. Tian, J. Am. Chem. Soc., 2006, 128, 10960.

70 X. Wang, W. Liu, J. Liu, F. Wang, J. Kong, S. Qiu, C. He and L. Luan, ACS Appl. Mater. Interfaces, 2012, 4, 817.

71 Y. Shi, C. Zhu, L. Wang, C. Zhao, W. Li, K. K. Fung, T. Ma, A. Hagfeldt and N. Wang, Chem. Mater., 2013, 25, 1000.

72 M. K. Gupta, J.-H. Lee, K. Y. Lee and S.-W. Kim, ACS Nano, 2013, 7, 8932.

73 H. V. Ngoc and D. J. Kang, Nanoscale, 2016, 8, 5059.

74 M. R. Alenezi, S. J. Henley, N. G. Emerson and S. R. P. Silva, Nanoscale, 2014, 6, 235.

75 T. Shinagawa, M. Watanabe, J.-I. Tani and M. Chigane, Cryst. Growth Des., 2017, 17, 3826.

76 N. Jalali, J. Briscoe, P. Woolliams, M. Stewart, P. M. Weaver, M. Cain and S. Dunn, J. Phys.: Conf. Ser., 2013, 476, 012131.

77 L. Zhang, Y. Ruan, Y. Liu and Y. Zhai, Cryst. Res. Technol., 2013, 48, 11.

78 Q. Yu, C. Yu, J. Wang, F. Guo, S. Gao, S. Jiao, H. Li, X. Zhang, X. Wang, H. Gao, H. Yang and L. Zhao, RSC Adv., 2013, 3, 16619.

79 C. Lu, L. Qi, J. Yang, L. Tang, D. Zhang and J. Ma, Chem. Commun., 2006, 33, 3551.

80 B. D. Boruah and A. Misra, RSC Adv., 2015, 5, 90838.

81 W. Wu, X. Xiao, T. Peng and C. Jiang, Chem.-Asian J., 2010, 5,315 .
82 S. M. Majhi, P. Rai and Y.-T. Yu, ACS Appl. Mater. Interfaces, 2015, 7, 9462.

83 M. Chen, L. Hu, J. Xu, M. Liao, L. Wu and X. Fang, Small, 2011, 7, 2449.

84 B. D. Boruah, D. B. Ferry, A. Mukherjee and A. Misra, Nanotechnology, 2015, 26, 235703.

85 M. R. Alenezi, S. J. Henley and S. R. P. Silva, Sci. Rep., 2015, $5,8516$.

86 X. H. Huang, Z. Y. Zhan, K. P. Pramoda, C. Zhang, L. X. Zheng and S. J. Chua, CrystEngComm, 2012, 14, 5163.

87 L. W. Chang, Y. C. Sung, J. W. Yeh and H. C. Shih, J. Appl. Phys., 2011, 109, 074318.

88 L. J. Luo, W. Tao, X. Y. Hu, T. Xiao, B. J. Heng, W. Huang, H. Wang, H. W. Han, Q. Jiang, J. B. Wang and Y. W. Tang, J. Power Sources, 2011, 196, 10518.

89 J. B. Cui, Y. C. Soo, T. P. Chen and U. J. Gibson, J. Phys. Chem. C, 2008, 112, 4475.

90 J. H. Lee, C. Y. Chou, Z. X. Bi, C. F. Tsai and H. Y. Wang, Nanotechnology, 2009, 20, 395704.

91 A. Escobedo-Morales and U. Pal, Appl. Phys. Lett., 2008, 93, 193120.

92 K. Mahmood, S. B. Park and H. J. Sung, J. Mater. Chem. C, 2013, 1, 3138.

93 D. D. Wang, G. Z. Xing, M. Gao, L. L. Yang, J. H. Yang and T. Wu, J. Phys. Chem. C, 2011, 115, 22729.

94 N. Kouklin, Adv. Mater., 2008, 20, 2190.

95 H. M. Chiu and J. M. Wu, J. Mater. Chem. A, 2013, 1, 5524.

96 C. L. Hsu, H. H. Li and T. J. Hsueh, ACS Appl. Mater. Interfaces, 2013, 5, 11142.

97 T.-H. Kao, J.-Y. Chen, C.-H. Chiu, C.-W. Huang and W.-W. Wu, Appl. Phys. Lett., 2014, 104, 111909.

98 C.-L. Hsu and S.-J. Chang, Small, 2014, 10, 4562.

99 X. Y. Yang, A. Wolcott, G. M. Wang, A. Sobo, R. C. Fitzmorris, F. Qian, J. Z. Zhang and Y. Li, Nano Lett., 2009, 9, 2331.

100 M. P. Lu, J. Song, M. Y. Lu, M. T. Chen, Y. Gao, L. J. Chen and Z. L. Wang, Nano Lett., 2009, 9, 1223.

101 J. Y. Zhang, P. J. Li, H. Sun, X. Shen, T. S. Deng, K. T. Zhu, Q. F. Zhang and J. L. Wu, Appl. Phys. Lett., 2008, 93, 021116.

102 M. Ahmad, C. F. Pan and J. Zhu, J. Mater. Chem., 2010, 20, 7169.

103 W. T. Wan, J. Huang, L. P. Zhu, L. Hu, Z. Wen, L. W. Sun and Z. Z. Ye, CrystEngComm, 2013, 15, 7887.

104 Y. W. Song, K. Kim, J. P. Ahn, G. E. Jang and S. Y. Lee, Nanotechnology, 2009, 20, 275606.

105 N. Hongsith, C. Viriyaworasakul, P. Mangkomtong, N. Mangkorntong and S. Choopun, Ceram. Int., 2008, 34, 823.

106 O. D. Jayakumar, I. K. Gopalakrishnan and S. K. Kulshreshtha, Adv. Mater., 2006, 18, 1857.

107 H. N. Zhang, Z. Y. Li, W. Wang, C. Wang and L. Liu, J. Am. Ceram. Soc., 2010, 93, 142.

108 S. Ghosh, G. G. Khan, B. Das and K. Mandal, J. Appl. Phys., 2011, 109, 123927.

109 S. Liang, H. Sheng, Y. Liu, Z. Huo, Y. Lu and H. Shen, J. Cryst. Growth, 2001, 225, 110. 
110 D. Y. Guo, Z. P. Wu, Y. H. An, X. C. Guo, X. L. Chu, C. L. Sun, L. H. Li, P. G. Li and W. H. Tang, Appl. Phys. Lett., 2014, 105, 023507.

111 R. Tang, S. Han, F. Teng, K. Hu, Z. Zhang, M. Hu and X. Fang, Adv. Sci., 2018, 5, 1700334.

112 F. Teng, L. Zheng, K. Hu, H. Chen, Y. Li, Z. Zhang and X. Fang, J. Mater. Chem. C, 2016, 4, 8416.

113 V. Q. Dang, T. Q. Trung, D. -I. Kim, L. T. Duy, B. -U. Hwang, D. -W. Lee, B. -Y. Kim, L. D. Toan and N. -E. Lee, Small, 2015, 11, 3054.

114 B. D. Boruah, A. Mukherjee, S. Sridhar and A. Misra, ACS Appl. Mater. Interfaces, 2015, 7, 10606.

115 B. D. Boruah, A. Mukherjee and A. Misra, Nanotechnology, 2016, 27, 095205.

116 J. G. Ok, J. Y. Lee, H. W. Baac, S. H. Tawfick, L. J. Guo and A. J. Hart, ACS Appl. Mater. Interfaces, 2014, 6, 874.

117 B. D. Boruah and A. Misra, Nanotechnology, 2016, 27, 355204 .

118 N. Gogurla, A. K. Sinha, S. Santra, S. Manna and S. K. Ray, Sci. Rep., 2014, 4, 6483.

119 K. Liu, M. Sakurai, M. Liao and M. Aono, J. Phys. Chem. C, 2010, 114, 19835.

120 Y. Liu, X. Zhang, J. Su, H. Li, Q. Zhang and Y. Gao, Opt. Express, 2014, 22, 30148.

121 X. Wang, K. Liu, X. Chen, B. Li, M. Jiang, Z. Zhang, H. Zhao and D. Shen, ACS Appl. Mater. Interfaces, 2017, 9, 5574.

122 J. Lu, C. Xu, J. Dai, J. Li, Y. Wang, Y. Lin and P. Li, Nanoscale, 2015, 7, 3396.

123 C. Tian, D. Jiang, B. Li, J. Lin, Y. Zhao, W. Yuan, J. Zhao, Q. Liang, S. Gao, J. Hou and J. Qin, ACS Appl. Mater. Interfaces, 2014, 6, 2162.

124 B. Nie, J. -G. Hu, L. -B. Luo, C. Xie, L. -H. Zeng, P. Lv, F. -Z. Li, J. S. Jie, M. Feng, C. Y. Wu and Y. Q. Yu, Small, 2013, 9, 2872.

125 T.-F. Zhang, G.-A. Wu, J.-Z. Wang, Y.-Q. Yu, D.-Y. Zhang, D.-D. Wang, J.-B. Jiang, J.-M. Wang and L.-B. Luo, Nanophotonics, 2017, 6, 1073.

126 Y. H. Leung, Z. B. He, L. B. Luo, C. H. A. Tsang, N. B. Wong, W. J. Zhang and S. T. Lee, Appl. Phys. Lett., 2010, 96, 053102.

127 G. Wang, S. Chu, N. Zhan, Y. Lin, L. Chernyak and J. Liu, Appl. Phys. Lett., 2011, 98, 041107.

128 P.-J. Li, Z.-M. Liao, X.-Z. Zhang, X.-J. Zhang, H.-C. Zhu, J.-Y. Gao, K. Laurent, Y. Leprince-Wang, N. Wang and D.-P. Yu, Nano Lett., 2009, 9, 2513.

129 L. Duan, P. Wang, W. Zhang, X. Yu, J. Fan and F. Wei, Chem. Phys. Lett., 2015, 618, 123.

130 C.-L. Hsu, Y.-D. Gao, Y.-S. Chen and T.-J. Hsueh, ACS Appl. Mater. Interfaces, 2014, 6, 4277.

131 Y. Zhu, H. Zhou, G. Fang and M. Li, Semicond. Sci. Technol., 2012, 27, 065003.

132 W. Ouyang, F. Teng, M. Jiang and X. Fang, Small, 2017, 13, 1702177.

133 F. Teng, W. Ouyang, Y. Li, L. Zheng and X. Fang, Small, 2017, 13, 1700156.

134 Y. F. Li, B. Yao, R. Deng, B. H. Li, J. Y. Zhang, Y. M. Zhao, D. Y. Jiang, Z. Z. Zhang, C. X. Shan, D. Z. Shen and X. W. Fan, J. Phys. D: Appl. Phys., 2009, 42, 105102.
135 W. B. Ko, S. H. Lee, N. S. Myoung and J. P. Hong, J. Mater. Chem. C, 2016, 4, 142.

136 L. Shi, F. Wang, B. Li, X. Chen, B. Yao, D. Zhao and D. Shen, J. Mater. Chem. C, 2014, 2, 5005.

137 H. D. Cho, A. S. Zakirov, S. U. Yuldashev, C. W. Ahn, Y. K. Yeo and T. W. Kang, Nanotechnology, 2012, 23, 115401.

138 S. K. Singh, P. Hazra, S. Tripathi and P. Chakrabart, Superlattices Microstruct., 2016, 91, 62.

139 C.-H. Chen, S.-J. Chang, S.-P. Chang, M.-J. Li, I. C. Chen, T.-J. Hsueh and C.-L. Hsu, Chem. Phys. Lett., 2009, 476, 69.

140 L. Yang, H. Zhou, M. Xue, Z. Song and H. Wang, Sens. Actuators, A, 2017, 267, 76.

141 N. Park, K. Sun, Z. Sun, Y. Jing and D. Wang, J. Mater. Chem. C, 2013, 1, 7333 .

142 H. Zhu, C. X. Shan, B. Yao, B. H. Li, J. Y. Zhang, D. X. Zhao, D. Z. Shen and X. W. Fan, J. Phys. Chem. C, 2008, 112, 20546.

143 W. Tian, C. Zhang, T. Zhai, S. -L. Li, X. Wang, J. Liu, X. Jie, D. Liu, M. Liao, Y. Koide and D. Golberg, Adv. Mater., 2014, 26, 3088.

144 L. Hu, J. Yan, M. Liao, H. Xiang, X. Gong, L. Zhang and X. Fang, Adv. Mater., 2012, 24, 2305.

145 L. Hu, M. Chen, W. Shan, T. Zhan, M. Liao, X. Fang, X. Hu and L. Wu, Adv. Mater., 2012, 24, 5872.

146 A. Bera and D. Basak, ACS Appl. Mater. Interfaces, 2010, 2, 408.

147 L. S. Vikas, K. A. Vanaja, P. P. Subha and M. K. Jayaraj, Sens. Actuators, A, 2016, 242, 116.

148 H. Chang, Z. Sun, K. Y.-F. Ho, X. Tao, F. Yan, W.-M. Kwok and Z. Zheng, Nanoscale, 2011, 3, 258.

149 D. Shao, M. Yu, H. Sun, T. Hu and S. Sawyer, Nanoscale, 2013, 5, 3664.

150 S. Y. Tsai, M. H. Hon and Y. M. Lu, Solid-State Electron., 2011, 63, 37.

151 W. Tian, T. Zhai, C. Zhang, S. L. Li, X. Wang, F. Liu, D. Liu, X. Cai, K. Tsukagoshi, D. Golberg and Y. Bando, Adv. Mater., 2013, 25, 4625.

152 L. Hu, J. Yan, M. Liao, H. Xiang, X. Gong, L. Zhang and X. Fang, Adv. Mater., 2012, 24, 2305.

153 Z. Wang, R. Yu, C. Pan, Y. Liu, Y. Ding and Z. L. Wang, Adv. Mater., 2015, 27, 1553.

154 R. Yu, W. Wu, C. Pan, Z. Wang, Y. Ding and Z. L. Wang, Adv. Mater., 2015, 27, 940.

155 Z. Wang, R. Yu, X. Wen, Y. Liu, C. Pan, W. Wu and Z. L. Wang, ACS Nano, 2014, 8, 12866.

156 S. C. Rai, K. Wang, Y. Ding, J. K. Marmon, M. Bhatt, Y. Zhang, W. Zhou and Z. L. Wang, ACS Nano, 2015, 9, 6419.

157 F. Zhang, Y. Ding, Y. Zhang, X. Zhang and Z. L. Wang, ACS Nano, 2012, 6, 9229.

158 Y. Luo, B. Yin, H. Zhang, Y. Qiu, J. Lei, Y. Chang, Y. Zhao, J. Ji and L. Hu, Appl. Surf. Sci., 2016, 361, 157.

159 Q. Liao, M. Liang, Z. Zhang, G. Zhang and Y. Zhang, Nano Res., 2015, 8, 3772.

160 M. Chen, B. Zhao, G. Hu, X. Fang, H. Wang, L. Wang, J. Luo, X. Han, X. Wang, C. Pan and Z. L. Wang, Adv. Funct. Mater., 2018, 28, 1706379.

161 J. Liu, Y. Zhang, C. Liu, M. Peng, A. Yu, J. Kou, W. Liu, J. Zhai and J. Liu, Nanoscale Res. Lett., 2016, 11, 281. 
162 B. Yin, Y. Qiu, H. Zhang, Y. Chang, D. Yang and L. Hu, RSC Adv., 2016, 6, 48319.

163 H. Li, X. Zhang, N. Liu, L. Ding, J. Tao, S. Wang, J. Su, L. Li and Y. Gao, Opt. Express, 2015, 23, 21204.

164 D. Xiong, W. Deng, G. Tian, Y. Gao, X. Chu, C. Yan, L. Jin, Y. Su, W. Yan and W. Yang, Nanoscale, 2019, 11, 3021.

165 W. Y. Weng, S. J. Chang, C. L. Hsu, T. J. Hsueh and S. P. Chang, J. Electrochem. Soc., 2010, 157, K30.

166 J. P. Kar, S. N. Das, J. H. Choi, Y. A. Lee, T. Y. Lee and J. M. Myoung, J. Cryst. Growth, 2009, 311, 3305.

167 S. E. Ahn, J. S. Lee, H. Kim, S. Kim, B. H. Kang, K. H. Kim and G. T. Kim, Appl. Phys. Lett., 2004, 84, 5022.

168 B. D. Boruah and A. Misra, ACS Appl. Mater. Interfaces, 2016, $8,4771$.

169 X.-W. Fu, Z.-M. Liao, Y.-B. Zhou, H.-C. Wu, Y.-Q. Bie, J. Xu and D.-P. Yu, Appl. Phys. Lett., 2012, 100, 223114.

170 L. Yingying, C. Chuanwei, D. Xiang, G. Junshan and Z. Haiqian, J. Semicond., 2009, 30, 063004.

171 J. B. Law and J. T. Thong, Appl. Phys. Lett., 2006, 88, 133114.

172 Y. Hao, J. Zhao, L. Qin, Q. Guo, X. Feng and P. Wang, Micro Nano Lett., 2012, 7, 200.

173 D. Gedamu, I. Paulowicz, S. Kaps, O. Lupan, S. Wille, G. Haidarschin, Y. K. Mishra and R. Adelung, Adv. Mater., 2014, 26, 1541.

174 Z. Zheng, L. Gan, J. Zhang, F. Zhuge and T. Zhai, Adv. Sci., 2017, 4, 1600316.

175 Y. Z. Zhang, J. P. Xu, S. B. Shi, Y. Y. Gao, C. Wang, X. S. Zhang, S. G. Yin and L. Li, ACS Appl. Mater. Interfaces, 2016, 8, 22647.

176 K. S. Ranjith and R. T. R. Kumar, Nanotechnology, 2016, 27, 095304.

177 D. I. Son, H. Y. Yang, T. W. Kim and W. I. Park, Appl. Phys. Lett., 2013, 102, 021105.

178 C. C. Lin, Y. W. Chen, M. C. Chiang, C. H. Lee, Y. L. Tung and S. Y. Chen, J. Electrochem. Soc., 2010, 157, H227.

179 X. B. Liu, H. J. Du and X. W. Sun, RSC Adv., 2014, 4, 5136.

180 Q. Ayun, M. Kashif and U. Hashim, J. Nanomater., 2013, 792930.

181 C. L. Hsu, H. H. Li and T. J. Hsueh, ACS Appl. Mater. Interfaces, 2013, 5, 11142.

182 R. C. Wang, H. Y. Lin, C. H. Wang and C. P. Liu, Adv. Funct. Mater., 2012, 22, 3875.

183 S. Sarkar and D. Basak, Appl. Phys. Lett., 2013, 103, 041112. 184 H. M. Chiu and J. M. Wu, J. Mater. Chem. A, 2013, 1, 5524. 185 Y. H. Liu, S. J. Young, C. H. Hsiao, L. W. Ji, T. H. Meen, W. Water and S. J. Chang, IEEE Photonics Technol. Lett., 2014, 26, 645.

186 S. J. Chang, B. G. Duan, C. H. Hsiao, S. J. Young, B. C. Wang, T. H. Kao, K. S. Tsai and S. L. Wu, IEEE Photonics Technol. Lett., 2013, 25, 2043.

187 L. Duan, F. He, Y. Tian, B. Sun, J. Fan, X. Yu, L. Ni, Y. Zhang, Y. Chen and W. Zhang, ACS Appl. Mater. Interfaces, 2017, 9, 8161.

188 H.-Y. Chen, K.-W. Liu, X. Chen, Z.-Z. Zhang, M.-M. Fan, M.-M. Jiang, X.-H. Xie, H.-F. Zhao and D.-Z. Shen, J. Mater. Chem. C, 2014, 2, 9689.
189 S. Lu, J. Qi, S. Liu, Z. Zhang, Z. Wang, P. Lin, Q. Liao, Q. Liang and Y. Zhang, ACS Appl. Mater. Interfaces, 2014, 6, 14116.

190 Y. -Q. Bie, Z. -M. Liao, H. -Z. Zhang, G. -R. Li, Y. Ye, Y. -B. Zhou, J. Xu, Z. -X. Qin, L. Dai and D. -P. Yu, Adv. Mater., 2011, 23, 649.

191 Y. Shen, X. Yan, Z. Bai, X. Zheng, Y. Sun, Y. Liu, P. Lin, X. Chen and Y. Zhang, RSC Adv., 2015, 5, 5976.

192 J. Garnier, R. Parize, E. Appert, O. Chaix-Pluchery, A. Kaminski-Cachopo and V. Consonni, ACS Appl. Mater. Interfaces, 2015, 7, 5820.

193 H. Shen, C. X. Shan, B. H. Li, B. Xuan and D. Z. Shen, Appl. Phys. Lett., 2013, 103, 232112.

194 K. Hu, F. Teng, L. Zheng, P. Yu, Z. Zhang, H. Chen and X. Fang, Laser Photonics Rev., 2017, 11, 1600257.

195 Y. Zhang, W. Xu, X. Xu, W. Yang, S. Li, J. Chen and X. Fang, Nanoscale Horiz., 2019, 4, 452.

196 Y. Ning, Z. Zhang, F. Teng and X. Fang, Small, 2018, 14, 1703754.

197 Z. Zhang, Y. Ning and X. Fang, J. Mater. Chem. C, 2019, 7, 223.

198 B. D. Boruah, S. N. Majji and A. Misra, Nanoscale, 2017, 9, 4536.

199 S. Sarkar and D. Basak, ACS Appl. Mater. Interfaces, 2015, 7, 16322.

200 Y. Shen, X. Yan, H. Si, P. Lin, Y. Liu, Y. Sun and Y. Zhang, ACS Appl. Mater. Interfaces, 2016, 8, 6137.

201 Z. Wang, R. Yu, X. Wang, W. Wu and Z. L. Wang, Adv. Mater., 2016, 28, 6880.

202 Y. Feng, Y. Zhang, Y. Wang and Z. Wang, Nano Energy, 2018, 54, 429.

203 W. Peng, X. Wang, R. Yu, Y. Dai, H. Zou, A. C. Wang, Y. He and Z. L. Wang, Adv. Mater., 2017, 29, 1606698.

204 B. D. Boruah, S. N. Majji, S. Nandi and A. Misra, Nanoscale, 2018, 10, 3451.

205 W. Peng, R. Yu, X. Wang, Z. Wang, H. Zou, Y. He and Z. L. Wang, Nano Res., 2016, 9, 3695.

206 Z. Wang, R. Yu, C. Pan, Z. Li, J. Yang, F. Yi and Z. L. Wang, Nat. Commun., 2015, 6, 8401.

207 Y. Wang, L. Zhu, Y. Feng, Z. Wang and Z. L. Wang, Adv. Funct. Mater., 2018, 1807111.

208 B. Ouyang, K. Zhang and Y. Yang, iScience, 2018, 1, 16.

209 Q. Li, L. Wei, Y. Xie, K. Zhang, L. Liu, D. Zhu, J. Jiao, Y. Chen, S. Yan, G. Liu and L. Mei, Nanoscale Res. Lett., 2013, 8, 415.

210 C. Gao, X. Li, Y. Wang, L. Chen, X. Pan, Z. Zhang and E. Xie, J. Power Sources, 2013, 239, 458.

211 J. Li, X. Wu, M. M. Shirolkar, M. Li, C. Xu and H. Wang, RSC Adv., 2017, 7, 18987.

212 X. Peng, Y. Zeng, X. Pan, W. Wang, Y. Zhou, F. Wang, Q. Lu and Z. Ye, RSC Adv., 2017, 7, 29440.

213 Z. Zhan, L. Zheng, Y. Pan, G. Sun and L. Li, J. Mater. Chem., 2012, 22, 2589.

214 P. Lin, X. Yan, Z. Zhang, Y. Shen, Y. Zhao, Z. Bai and Y. Zhang, ACS Appl. Mater. Interfaces, 2013, 5, 3671.

215 Y. Zeng, X. Pan, W. Dai, Y. Chen and Z. Ye, RSC Adv., 2015, 5,66738 . 
216 H. Zhou, P. Gui, Q. Yu, J. Mei, H. Wang and G. Fang, J. Mater. Chem. C, 2015, 3, 990.

217 S. M. Hatch, J. Briscoe and S. Dunn, Adv. Mater., 2013, 25, 867.

218 X. L. Wang, C. Y. Luan, Q. Shao, A. Pruna and C. W. Leung, Appl. Phys. Lett., 2013, 102, 102112.

219 H. Zhu, C. Shan, B. Yao, B. Li, J. Zhang, D. Zhao, D. Shen and X. Fan, J. Phys. Chem. C, 2008, 112, 20546.

220 G. Tabares, A. Hierro, J. Ulloa, A. Guzman, E. Munoz, A. Nakamura, T. Hayashi and J. Temmyo, Appl. Phys. Lett., 2010, 96, 101112.

221 P.-N. Ni, C.-X. Shan, S.-P. Wang, B.-H. Li, Z.-Z. Zhang, D.-X. Zhao, L. Liu and D.-Z. Shen, J. Phys. Chem. C, 2011, 116, 1350.

222 H. Zhu, C. Shan, L. Wang, J. Zheng, J. Zhang, B. Yao and D. Shen, J. Phys. Chem. C, 2010, 114, 7169.

223 Z. Bai, X. Chen, X. Yan, X. Zheng, Z. Kang and Y. Zhang, Phys. Chem. Chem. Phys., 2014, 16, 9525.

224 H. Zhou, P. Gui, L. Yang, C. Ye, M. Xue, J. Mei, Z. Song and H. Wang, New J. Chem., 2017, 41, 4901.
225 B. Zhao, F. Wang, H. Chen, L. Zheng, L. Su, D. Zhao and X. Fang, Adv. Funct. Mater., 2017, 27, 1700264.

226 H. Y. Chen, P. P. Yu, Z. M. Zhang, F. Teng, L. X. Zheng, K. Hu and X. S. Fang, Small, 2016, 42, 5809.

227 O. Game, U. Singh, T. Kumari, A. Banpurkar and S. Ogale, Nanoscale, 2014, 6, 503.

228 Q. Li, L. Wei, Y. Xie, K. Zhang, L. Liu, D. Zhu, J. Jiao, Y. Chen, S. Yan, G. Liu and L. Mei, Nanoscale Res. Lett., 2013, 8, 7.

229 P. Lin, X. Yan, Y. Liu, P. Li, S. Lu and Y. Zhang, Phys. Chem. Chem. Phys., 2014, 16, 26697.

230 L. Su, Q. Zhang, T. Wu, M. Chen, Y. Su, Y. Zhu, R. Xiang, X. Gui and Z. Tang, Appl. Phys. Lett., 2014, 105, 072106.

231 S. Yang, J. Gong and Y. Deng, J. Mater. Chem., 2012, 22, 13899.

232 S. Cai, X. Xu, W. Yang, J. Chen and X. Fang, Adv. Mater., 2019, 31, 1808138.

233 W. Yang, J. Chen, Y. Zhang, Y. Zhang, J. -H. He and X. Fang, Adv. Funct. Mater., 2019, 29, 1808182.

234 W. Yang, K. Hu, F. Teng, J. Weng, Y. Zhang and X. Fang, Nano Lett., 2018, 18, 4697. 